\title{
COMING TOGETHER TO CALM THE HUNGER: GROUP THERAPY PROGRAM FOR ADULTS DIAGNOSED WITH ANOREXIA NERVOSA
}

\author{
Heather Ponech, M.C. (Master of Counselling) ${ }^{1}$ \\ heather.ponech@uleth.ca \\ Dawn Lorraine McBride, Ph.D. \\ University of Lethbridge \\ dawn.mcbride@uleth.ca \\ Faculty of Education: Counsellor Education \\ 4401 University Drive \\ Lethbridge, Alberta T1K 3M4
}

March 4, 2012

\footnotetext{
${ }^{1}$ Note: This manuscript was based on a comprehensive graduate project originally submitted to the School of Graduate Studies, Faculty of Education, University of Lethbridge, Canada on June 22, 2010 in partial fulfillment of the requirements for the degree of Master of Counselling.
} 


\section{Narrative Abstract}

This project provides a comprehensive overview of the research literature on anorexia nervosa in female adults and concludes by offering 14 group therapy lesson plans for anorexia nervosa that therapists may use in their practice. There is a remarkable lack of research on the efficacy of treatment designed for individuals diagnosed with anorexia nervosa (Lamoureux \& Bottorff, 2005). The overall intent is to provide an applied project that will be useful to counsellors wanting to provide a therapeutic group to female adult clients who are struggling with disordered eating, particularly anorexia nervosa. This project proposes that group therapy is a beneficial treatment format for individuals diagnosed with anorexia nervosa. This project critically explores how group therapy may be beneficial and synthesizes the therapeutic needs of females diagnosed with anorexia nervosa. A literature review that explores the benefits of group psychotherapy, which includes the key therapeutic factors for change and the development and stages of group therapy, is included. This project also identifies what therapeutic factors within group therapy appear to be the most prominent for successful treatment of anorexia nervosa clients. A second literature review explores the characteristics of anorexia nervosa that would be addressed within a group format. The core of this project is the development of 12-session experiential group program manual with a pre-group and post-group lesson, designed as an intervention framework for the facilitation of a group with adult women diagnosed with anorexia nervosa. 
Table of Contents

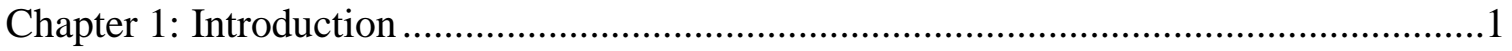

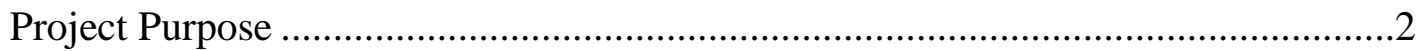

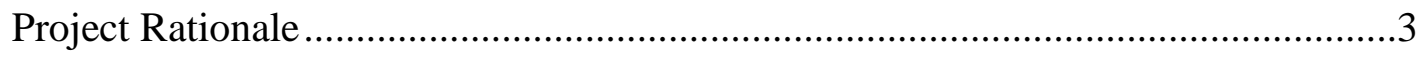

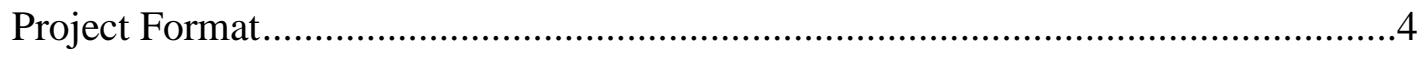

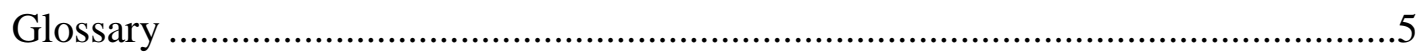

Conclusion ..................................................................................................

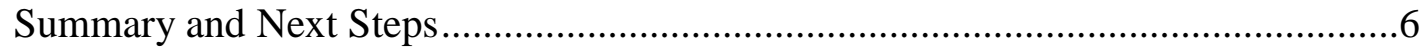

Chapter 2: Anorexia Nervosa—A Literature Review ....................................................

Genetics and Environment ...........................................................................

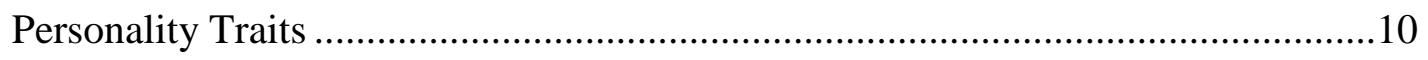

Perfectionism ................................................................................. 10

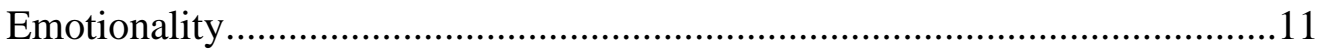

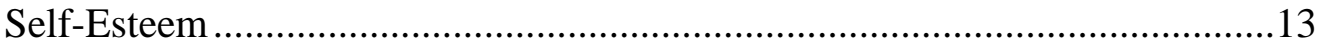

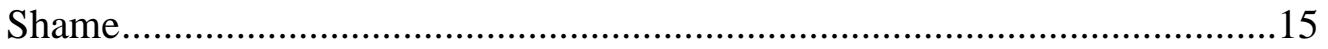

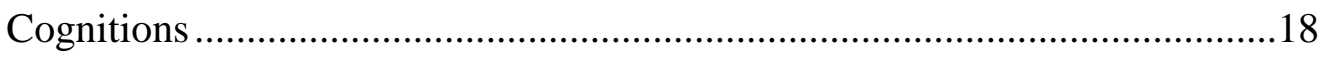

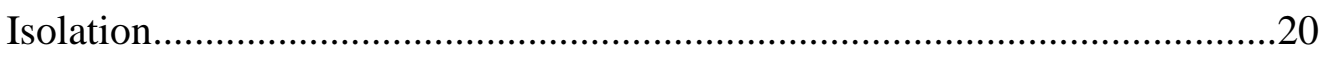

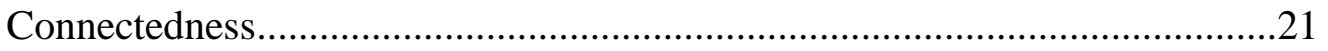

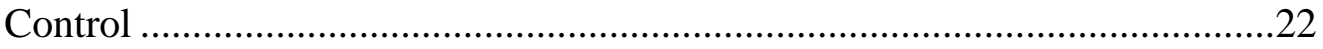

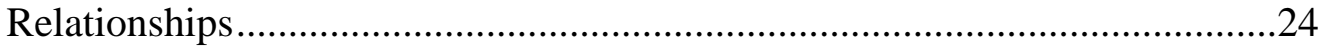

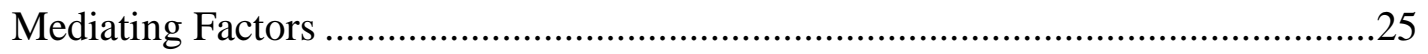

Childhood Sexual Abuse............................................................................25

Obsessive-Compulsive Disorder ........................................................27

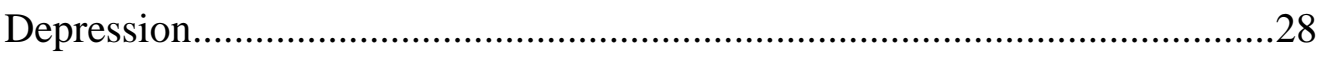


Posttraumatic Stress Disorder .......................................................................28

Borderline Personality Disorder .......................................................................29

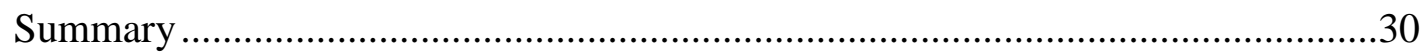

Chapter 3: Literature Review of Key Group Therapy Practices...........................................32

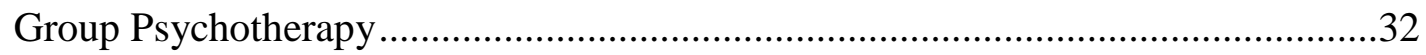

Therapist Roles and Responsibilities ........................................................................33

The Group Experience ………………………………………………………...33

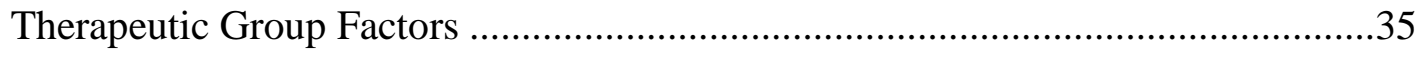

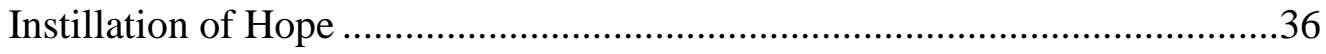

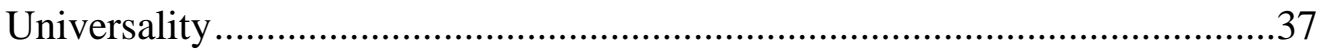

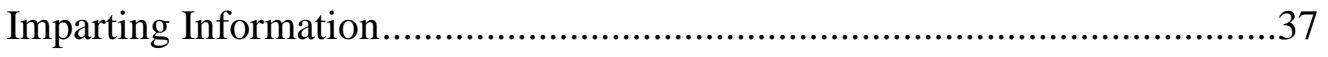

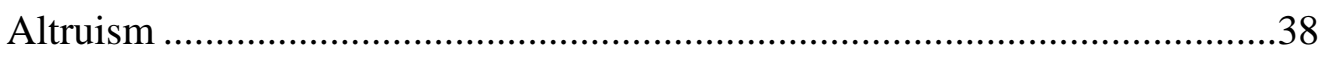

Corrective Recapitulation of Primary Family Experience..................................39

Development of Socializing Techniques ..........................................................40

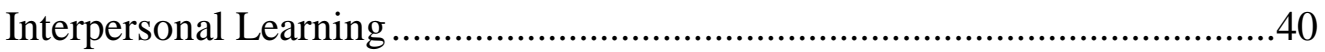

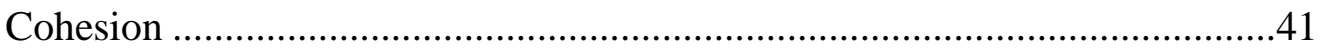

Summary of the Therapeutic Group Factors........................................................43

Group Development Issues and Stages....................................................................44

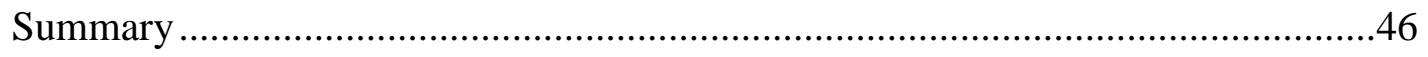

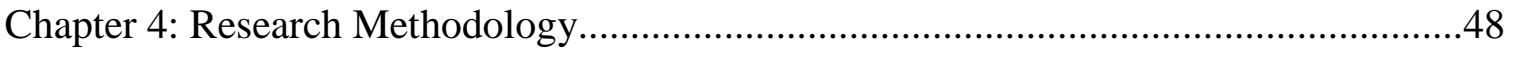

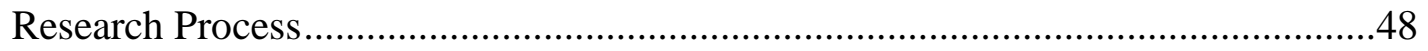

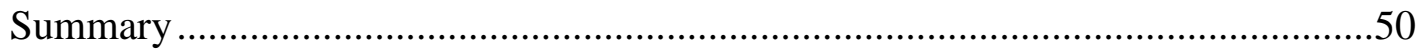

Chapter 5: Overview of the Group Manual .......................................................................51

Rationale for Experiential Group Activities .............................................................51 
Outline of the Group Manual .............................................................................52

Session Objectives .......................................................................................52

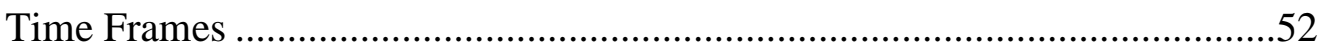

Activity Instructions and Facilitators' Notes ...................................................53

Questions for Reflection and Content Delivery ..................................................53

Handouts and Homework Exercises ..................................................................53

References and Resources for the Group Leader...............................................54

Addressing Ethical Practice in the Proposed Group Program .....................................54

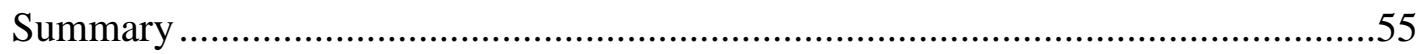

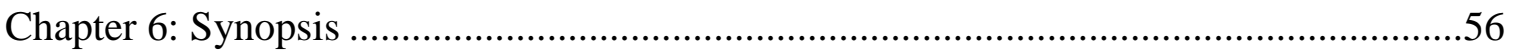

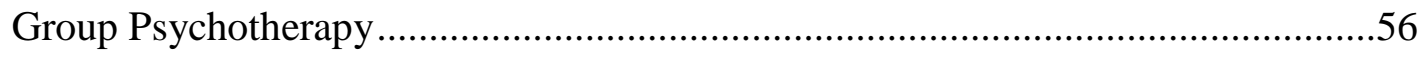

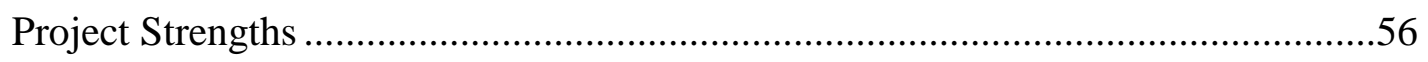

Project Limitations .............................................................................................58

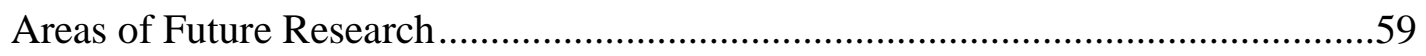

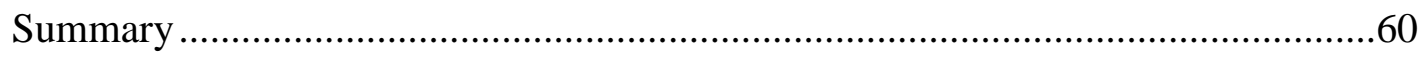

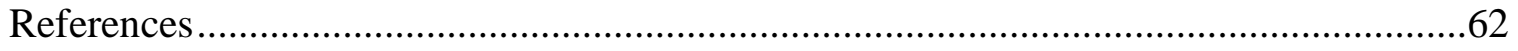

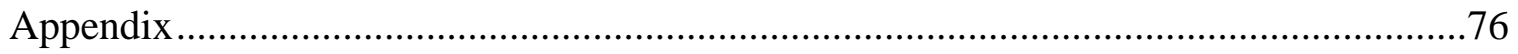




\section{Chapter 1: Introduction}

As noted by Lamoureux and Bottorff (2005), there is a remarkable lack of research on the efficacy of treatment designed for anorexia nervosa (AN). According to Geller, Brown, Zaitsoff, Goodrich, and Hastings (2003), the majority of clinical studies concerning eating disorders have focused on the use of specific therapy techniques, but the delivery of such techniques has received relatively little attention. The development of a group counselling program for AN, which this project is based on, is an important endeavour because group therapy appears to be an effective and efficient therapeutic approach for individuals suffering from AN (Lenihan \& Sanders, 1984; Wanlass, Moreno, \& Thomson, 2005; Yellowlees, 1988).

I was interested in developing a group program for the treatment of adult AN for several reasons. According to the vast amount of research on the development of this disorder, clients with eating disorders can be difficult to treat and may be perceived as undesirable clients to help (Lamoureux \& Bottorff, 2006; Lenihan \& Sanders, 1984; Wanlass et al., 2005). Throughout my Masters of Counselling studies, I have identified gaps in the literature about the AN recovery process as well as clinical neglect of empirically supported treatments. I believe that creating a group therapy manual offers an important resource to guide therapists in the treatment of individuals diagnosed with AN. I recognize that future research will be required to determine the impact and success of my proposed group program.

I was initially attracted to doing a project on AN as a result of an assignment I completed in a past Masters of Counselling course. The original assignment included three group lessons for individuals with eating disorders. Specifically, my interest in the 
efficacy of treatments for those diagnosed with AN lead to the development of this comprehensive project.

In this chapter, I outline the purpose of this applied project. I also outline the rationale for creating a group program for individuals diagnosed with AN. Finally, I provide readers with an overview of the project's format and a glossary of relevant terms.

\section{Project Purpose}

The overall intent is to provide a group program manual that will be useful to counsellors who want to provide a therapeutic group to female adult clients struggling with disordered eating, particularly AN. Specifically, this project has three purposes.

The first purpose of this project is to identify what therapeutic factors within group therapy appear to be the most prominent for successful treatment in AN clients. This purpose is addressed in chapter 2, which explores the characteristics of AN that would be addressed within a group format.

The second purpose of this project proposes that group therapy is a beneficial treatment format for individuals diagnosed with AN. I critically explore how group therapy can be beneficial in chapter 3. In this chapter, I also synthesize the key therapeutic factors for change with clients who have AN and outline the development as well as the stages of group therapy.

The last purpose of this project is to offer readers a 12-session experiential group program manual with pre-group and post-group lessons. This group program is intended to be used as an intervention framework for the facilitation of a group with adult women diagnosed with AN. I make a case that experiential learning is critical in offering a group therapy program for AN. 


\section{Project Rationale}

Eating disorders, which includes AN, are serious illnesses associated with significant psychological and medical sequelae (Kotler, Boudreau, \& Devlin, 2003) and affect as many as 5 million American adolescent and young adult women each year (Stein \& Corte, 2003). AN is a psychiatric disorder characterized by refusal of an individual to maintain a minimum normal body weight, often to the point of starvation (Arkell \& Robinson, 2008). The physical consequences of AN can be significant morbidity and mortality from starvation, suicide, or an electrolyte imbalance (Kong, 2005).

Eating disorders are characterized by clinically significant disturbances in body image and eating behaviour (Smolak \& Murnen, 2001). Smolak and Murnen asserted, "Despite extensive evidence that these disorders are associated with significant impairment in health and psychosocial adjustment, there are numerous indications that eating disorders are not taken seriously” (p. 3).

Although the exact causes of eating disorders remain elusive, investigators suspect a combination of social, interpersonal, and biochemical factors (Geller et al., 2003; Matthews, 2001). Most researchers support the belief that eating disorders do not have a single cause (Hund \& Espelage, 2006; Johnson, Cohen, Kasen, \& Brook, 2002; Swain, 2003); Jacobi, Morris, and de Zwaan (2004) highlighted that there are 30 variables considered to be risk factors. Just as the psychopathology of those with eating disorders is believed to be multidimensional, the etiology is assumed to involve multiple factors (Geller et al., 2003). 
Although there is extensive research on the development of AN, the prognosis of recovery remains low for those with this disorder. The incidences of AN continue to rise and counsellors knowledge of effective therapeutic treatments require more research and more therapeutic choices to provide individuals with AN with a more holistic approach to their healing journey.

\section{Project Format}

This project is organized into six chapters with one appendix item. Chapter 1 serves to introduce and define the project. In chapter 2, I identify the theoretical foundations for this project and review current literature on AN. Chapter 3 contains a literature review on the effectiveness of group therapy where I will specifically review the therapeutic factors that influence the success of the treatment. Chapter 4 contains a description of the research method used to gather information for chapters 2 and 3. In chapter 5, I provide an overview of the group program manual I developed: Coming Together to Calm the Hunger: Group Therapy Program for Adults Diagnosed with Anorexia Nervosa. Chapter 6 consists of a synthesis of this project and includes a summary of the literature review, the strengths and limitations of the project and its applied manual, and suggestions for future research. Finally, the appendix to this project consists of the group facilitators' manual. The manual portion of this project provides an overview of session content, the materials needed, worksheet and homework exercises, facilitator notes, and evaluation tools. In this next section, I introduce the glossary. 


\section{Glossary}

Adult refers to individuals over 18 years of age. This project is designed for adults. Anorexia nervosa is described as,

A clinical syndrome characterized by three distinct types of symptoms:

(1) disordered attitudes toward body weight including intense fear of becoming fat and undue influence of weight on self-evaluation, (2) failure to maintain body weight at least at $85 \%$ of ideal, and (3) amenorrhea for at least 3 consecutive months (American Psychiatric Association, 2000). (Stein \& Corte, 2003, p. 57)

Body image is conceptualized as a "person’s perceptions, thoughts, and feelings about his or her body" (Grogan, 2008, p. 3). This is a topic that is extensively addressed in the project's group program.

Eating disorders refers to a "series of disorders involving disturbances in eating behaviours” (Beumont \& Touyz, 2003, p. 20). This project focuses on understanding and treatment AN in a group therapy format.

Group therapy goals are to “increase members' knowledge of themselves and others, to help members clarify the changes they most want to make in their lives, to provide members the tools to make these changes, and support these changes” (Corey, Corey, \& Corey, 2010, p. 11).

Members refers to describe group participants and clients in a group therapy program. Conclusion

The Coming Together to Calm the Hunger: Group Therapy Program for Adults Diagnosed with Anorexia Nervosa group program manual is designed for therapists who want to offer group treatment for those with AN. The group program in this project 
invites personal contact with other AN sufferers and opens the doors for AN to have the experience of sharing fears and positive progress with others (Lenihan \& Sanders, 1984). With therapist preparation, a recruitment campaign, careful client selection, and appropriate group composition, group treatment for individuals with AN can be very powerful (Lenihan \& Sanders, 1984). This project is an important addition to the research and resources currently available to advise group counsellors working with women diagnosed with AN. Overall, the group program manual is a stand-alone document, incorporating flexibility in format and design, while still adhering to the American Psychological Association (2002) standards for grammar, reference and citation formats, and spelling.

\section{Summary and Next Steps}

The intention of this chapter was to provide a brief overview of the purpose of this project. I included a statement of interest, an overview of the project's format, and a glossary of relevant terms. The next chapter includes a comprehensive literature review of the current research on AN and how group therapy may be a successful treatment option for individuals diagnosed with AN. 


\section{Chapter 2: Anorexia Nervosa-A Literature Review}

The psychiatric disorder of AN is regarded as very difficult to treat. Halmi, Agras, et al. (2005) suggested that clients diagnosed with AN have a pronounced resistance to treatment and are at best ambivalent toward treatment. Further, medical complications resulting from starvation may also affect withdrawal from treatment protocols (Halmi , Agras, et al., 2005). These difficulties may serve as a strong positive function in the client's life, providing an escape from aversive developmental issues or distressing life events, often of an interpersonal nature (Halmi, Agras, et al., 2005). Halmi, Agras, et al. asserted that the disorder can become highly reinforcing and the prospect of relinquishing the anorectic behaviour pattern may be terrifying. The egosyntonic nature of the disorder may be demonstrated by the client's denial and refusal to accept the seriousness of the disorder (Halmi, Agras, et al., 2005). These difficulties may be the result that there are few empirically controlled treatment trials aiding in the development of prevention, treatment, and recovery of this disorder. One reason for the lack of research is due to AN being relatively rare, so it is difficult to generate an adequate sample size in any one centre (Halmi, Agras, et al., 2005). The following section provides an overview of this chapter in its entirety.

This chapter explores the current research on AN and how group therapy may be a successful treatment option for individuals diagnosed with AN. Genetic and environmental influences are briefly reviewed. Personality traits identified as commonly found in individuals diagnosed with AN are analyzed. Specifically, these personality traits include perfectionism, emotionality, self-esteem, and shame. Characteristics such as cognitions, isolation, relationship, and connectedness are also reviewed. Mediating 
factors, such as childhood sexual abuse, obsessive-compulsive disorder (OCD), depression, posttraumatic stress disorder, and borderline personality disorder, are explored as the literature suggested these mediating factors are common comorbid conditions with AN. To begin, the genetic aspects and the environmental factors are explored.

\section{Genetics and Environment}

The presence of eating disorders tends to be influenced by hereditary within families, with female relatives most often diagnosed (Klump, Wonderlich, Lehoux, Lilenfeld, \& Bulik, 2002). This hereditary component may suggest that there is a genetic component as well as environmental elements to the disorder onset. In terms of the latter, the environmental factors that could be causes of an eating disorder include the social pressure to be thin, high social class, high social anxiety, elevated weight or obesity, high impulsivity, individual differences in biological response to starvation, and individual differences in the reward value of starvation or eating (Striegel-Moore \& Bulik, 2007).

It is important to recognize that a genetic component may play a role in people struggling with disordered eating, particularly since the diagnosis of AN is currently based solely on signs and symptoms as opposed to objective measures. The criteria of AN remains the subject of considerable debate, in large part because it fails to result in clearly defined subgroups or to account for changing symptomatology over the course of the illness (Striegel-Moore \& Bulik, 2007). Many individuals who suffer from disordered eating do not meet the criteria for AN and bulimia nervosa, so they are placed in a residual group known as eating disorder not otherwise specified (American Psychiatric Association, 2000). Striegel-Moore and Bulik stated that risk-factor studies that include 
both the genetic and environmental factors present an untapped source of information of potential value for revising the current classification system.

Understanding the genetic components of AN is valuable for treatment. Treatment is best accomplished when the causes of a disorder are known as this aids in the search for effective interventions (Striegel-Moore \& Bulik, 2007). It is interesting to note that some individuals with a family history of AN do not develop AN, whereas others will develop disordered eating; Striegel-Moore and Bulik asserted that this is a gene plus an environmental interaction whereby varying genotypes would render individuals differentially sensitive to environmental events. The authors provided an excellent example of this where an individual with Genotype A might experiment with her first extreme diet, find the experience aversive and uncomfortable, and reject the behaviour on the basis of it not being at all reinforcing. In contrast,

An individual with Genotype B might experience that first episode of severe caloric restriction to be highly reinforcing by reducing her innate dysphoria and anxiety, providing her with a sense of control over her own body weight and resulting in her receiving positive social attention for weight-loss attempts. (Striegel-Moore \& Bulik, 2007, p. 192)

Identification of risk factors is important for determining high-risk groups for targeted interventions, designing prevention program content, and informing public policy (Striegel-Moore \& Bulik, 2007). In the next section I explore personality traits identified with AN. 


\section{Personality Traits}

Personality traits identified as commonly found in individuals with AN are analyzed in the following section. This information is important to note because recognizing the personality traits may provide a therapist with a clearer understanding of interventions and treatments that may be effective when working with individuals with AN. Specifically, this section addresses perfectionism, emotionality, self-esteem, and shame in AN clients. Characteristics commonly identified with AN clients such as cognitions, isolation, relationship, and connectedness will also be reviewed. The next section examines the characteristic of perfectionism.

\section{Perfectionism}

Perfectionism has been identified in the literature as a common characteristic of AN (Forbush, Heatherton, \& Keel, 2007; Koenig, 2008). Perfectionism is recognized as setting and striving for personal standards and striving to avoid criticism or rejection from others (Gilbert \& Procter, 2006). “The need to avoid appearing imperfect is similar to harm avoidance in the sense that perfectionists try to avoid criticism by others, and to reward dependence in the sense of relying on the approval of others” (Cassin \& von Ranson, 2005, p. 907).

Koenig (2008) asserted that clients with AN often desperately aim to be perfect as it may be their unspoken supreme and only goal, which overwhelms reality and objectivity and can drive clients into relentlessly endangering their health. Clients who are perfectionists may be afraid of failure, making mistakes, and feeling ashamed (Koenig, 2008). Furthermore, individuals diagnosed with AN often have a negative and imperfect view of self that contributes to and exacerbates perfectionist's standards as a 
means of concealing perceived imperfections (Morgan, 2008). Morgan asserted that perfectionism, in AN, may provide a new-found identity that masks problems with self and self-worth. According to Morgan (2008) and Polivy and Herman (2002), some indices of perfectionism remain high even after weight restoration, which suggested that perfectionism may be a precursor of AN.

A therapy group for those with AN have the potential to be designed to promote expressions of diverse opinions and definitions of perfection (Russell \& Arthur, 2000). Russell and Arthur suggested that the therapy group setting provides an opportunity for sharing successes and learning experiences and thereby challenges the ideal of perfection that many individuals with AN strive to reach. Thus, addressing perfectionism in group treatment is a very common treatment goal. Consequently, the group program developed for this project, Coming Together to Calm the Hunger: Group Therapy Program for Adults Diagnosed with Anorexia Nervosa addresses perfectionism within the session objectives. The following section summarizes the characteristic of emotionality.

\section{Emotionality}

Emotional intelligence relates to the ability to identify, facilitate, understand, and manage emotions (Harrison, Sullivan, Tchanturia, \& Treasure, 2009). Emotional regulation or the ability to manage emotions in the self and others is an important aspect to a holistic approach to healing (Harrison et al., 2009).

Harrison et al. (2009) asserted that people with AN have extreme personality features of emotional dysregulation and inhibition, low emotional awareness, and deficits in emotion regulation. According to Russell and Arthur (2000), women with AN often mask their emotional expression. Clients who have difficulty sitting with emotional 
discomfort or pain often use preoccupation with thinness to ward off distress (Koenig, 2008). This was supported by Krause and Robins’s (2000) research, which found that conflict over expressing emotions is an important construct for healing in individuals with AN. Wanlass et al.’s (2005) study also recognized that AN participants had difficulty recognizing and verbalizing their emotions.

As a way to manage emotions, AN may engage in restricting eating to block emotions or to regulate and mange the painful emotional states they experience (Harrison et al., 2009). The client's nonacceptance of emotions relates to a tendency towards having negative secondary responses to one's own negative emotions or not accepting emotional reactions to distress (Harrison et al., 2009). Therefore, interpreting emotions as bad or wrong, and the subsequent secondary emotional responses, such as shame or sadness, might motivate attempts to control emotions through dietary restriction (Harrison et al., 2009).

The consequence of "attempting to be completely autonomous and not rely on people emotionally is that it is highly stressful, causing more of a need to depend and exacerbate a vicious cycle” (Koenig, 2008, p. 93). The more strongly counter-dependent clients, such as AN clients, feel a need for other people, the greater their denial or suppression of this unwanted yearning, and this may lead to food restriction to push away these uncomfortable feelings (Koenig, 2008). Further, Koenig stated, “When clients equate mental health and emotional well-being with total self-sufficiency, they are cutting off half their emotional selves” (p. 94).

Group therapy may help AN clients reflect on their difficulties with emotions and understand the role of emotional avoidance. For most, group sessions may help members 
to recognize and express feelings, diminishing their need to act out on unexpressed emotions (Wanlass et al., 2005). As dialogue within the group continues, members are invited to relate more honestly to each other using their whole range of emotions, and as they become occupied with their feelings, thoughts, and each other, the hope is their preoccupation with food diminishes (Johnson \& Parkinson, 1999).

Group therapy also has the potential to establish norms of honest and direct expression of emotion in a safe and nurturing environment (Russell \& Arthur, 2000) as well as link past and present behaviour in the group process (Wanlass et al., 2005). Further, strong emotions can be processed in a safe group environment and the experience may convey the possibility that emotions are manageable (Russell \& Arthur, 2000). Relating honestly to other group members may be difficult, in part, due to a low self-esteem. The next section reviews the characteristic of self-esteem that may be identified in an individual with AN.

\section{Self-Esteem}

Self-esteem includes self-beliefs, appraisals, and efficacy (Paterson, Power, Yellowlees, Park, \& Taylor, 2007). Self-esteem reflects how others react to the individual; this perceived rejection may cause lower self-esteem and maladaptive behaviours, including AN (Polivy \& Herman, 2002). Gilbert and Procter (2006) asserted that people with low self-esteem experience a greater loss of energy to a mood lowering setback than high self-esteem people. Furthermore, people with low self-esteem "struggle with far more self-criticism than high self-esteem people, setting up a vicious circle of a dip in mood triggering self-criticism that triggers a further dip in mood” (Gilbert \& Procter, 2006, p. 354). 
Karpowicz, Skarsater, and Nevonen (2009) asserted that the concept of selfesteem has two meanings: how a person regards her capacity to do things, and the value she ascribes to herself. People with low self-esteem see themselves as worse than others, are dissatisfied with themselves, self-loathing, and lack respect for their own persona (Karpowicz et al., 2009). Paterson et al. (2007) further proposed that self-esteem comprises two distinct but related subtypes, self-competence and self-liking. Selfcompetence refers to one's sense of having instrumental value, while self-liking refers to one's sense of having intrinsic value (Paterson et al., 2007). Thus, self-competence has to do with our appraisals and beliefs of our abilities, and self-liking is our feelings of selfworth and social identity based on our desire to be accepted (Paterson et al., 2007).

Low self-esteem plays an important role in understanding psychological issues, psychopathology, and maladjustment through loneliness, depression, and anxiety (Karpowicz et al., 2009). Paterson et al. (2007) suggested that by considering a model of self-esteem that includes self-belief, appraisals and efficacy, it could be postulated that low self-esteem in relation to disordered eating facilitates the use of maladaptive coping strategies or hindering implementation of effective techniques.

In the AN sample in Paterson et al.'s (2007) study, the self-competence component of self-esteem, and not the self-liking component was found to correlate significantly with disordered eating. Furthermore, "the results also suggested that elements of self-esteem that are related to self-appraisal, self-efficacy, and confidence in one's ability may play a more important role in disordered eating than one's sense of selfworth and social conformity” (Paterson et al., 2007, p. 75). Paterson et al.’s study confirmed that AN individuals have a tendency to be highly self-critical and 
perfectionistic. An anorexic individual's sense of inefficacy and lack of self-confidence may impact their ability to acknowledge problems and tolerate difficult situations (Paterson et al., 2007). The inability to form a healthy sense of self creates psychological distress for clients and the perceived notion that they are inadequate and dietary restriction may be an expression of a self that is not otherwise known (Morgan, 2008). Consequently the group program developed for this project, Coming Together to Calm the Hunger: Group Therapy Program for Adults Diagnosed with Anorexia Nervosa focuses on increasing member's sense of self within the lessons. Tolerating difficult situations or emotions may be, in part, due to feelings of shame. The following section identifies the characteristic of shame that may be considered by group therapists. Shame

According to Gilbert and Procter (2006), shame influences vulnerability to mental health problems, which affects expression of symptoms, abilities to reveal painful information, various forms of avoidance, and problems in help seeking. Although there is no commonly agreed definition of shame, it is often seen to involve two componentsexternal shame and internal shame (Gilbert \& Procter, 2006). External shame, as identified by Gilbert and Procter, is marked by thoughts and feelings that others view the self negatively or the self is seen as having characteristics that make one unattractive and thus rejectable or vulnerable to attacks from others. With internal shame, the focus of attention is on the self, with self-directed attention, feelings, and evaluations of self as inadequate, flawed, or bad (Gilbert \& Procter, 2006).

Since AN is concerned with gaining control over impulses, feelings of hunger, and the body as a whole, AN becomes very internally focused (Grabhorn, Stenner, 
Stangier, \& Kaufhold, 2006). An example of being internally focused is that successful restriction may be associated with a sense of satisfaction in the ability to control one's impulses and feelings of hunger. Troop, Allan, Serpell, and Treasure (2008) speculated, "Symptoms of AN are particularly sensitive not only to issues concerning social rank but, in particular, to low rank that is perceived to be imposed by others, rather than individuals simply perceiving themselves to be inadequate” (p. 485). In working with individuals diagnosed with AN, Gilbert and Procter (2006) suggested that it is important to create, within themselves, a focus for self-soothing and compassion that would reduce the sense of threat, increase a sense of safeness, and thus work with shame material.

Troop et al. (2008) asserted that the anorexic or restrictive symptoms might be involved in a shame-pride cycle. Feelings of internal and external shame may lead to restriction and the subsequent weight loss may lead to feelings of pride, which develops where shame negatively reinforces and pride positively reinforces the primary symptoms of restriction and weight loss (Troop et al., 2008). Paradoxically, “differences in levels of shame may influence AN symptoms, while changes in AN may influence the levels of shame experienced” (Troop et al., 2008, p. 485). For example, perfectionists are afraid of feeling ashamed. Thus, they are driven to do well so that they do not have to feel the shame that hides close to the surface (Koenig, 2008). The perception, to an anorexic individual, may be that other people see the anorexic individual as being of low social status, which may trigger weight loss (Troop et al., 2008).

Shame cannot help but emerge in the realm of eating and weight, as emotions require one to attend to them (Koenig, 2008). Further, Koenig suggested that when a 
client struggles with shame, there would always be some behaviour in life that leads back to that emotion.

Troop et al.'s (2008) research indicated that when individuals diagnosed with AN perceive the self as inferior (external shame), it tends to be associated with the severity of AN symptoms. Aspects of shame, including bodily characteristics, nonphysical characteristics, general behaviour, and behaviour around eating, have been found to be significantly high with individuals diagnosed with AN (Swan \& Andrews, 2003). In Swan and Andrews's study, the "levels of bodily shame did not differ between the recovered and symptomatic women, although characterological shame and shame around eating were significantly lower in recovered women compared with those still symptomatic" (p. 375). Swan and Andrews suggested that shame might be long-lived and difficult to change.

In this chapter, I have identified four characteristics in AN clients that need to be addressed in treatment programs for those wishing to recover from AN. There are a variety of ways to address these issues in a group therapy program and the group manual (see the Appendix) offers the readers this type of variety, through the session objectives, content, processing of the recommended activities, and homework assignments.

The next section continues to address characteristics, but the focus is more on thoughts and relational factors. Four topics are addressed, which also have direct implications for treatment. The first topic addresses the belief system of those struggling with overcoming AN. 


\section{Cognitions}

According to Koenig (2008), one of the most obvious personality traits that permeate disordered eating is black-and-white or all-or-nothing thinking. For anorexic individuals, it is difficult to identify others who are of average weight or who seem comfortable around food, as anorexic individuals fail to notice eating and weight spectrums and are only able to identify the extremes.

AN individual's do not polarize only in the weight arena: much of life is viewed in extremes of good or bad, on or off, in or out, and easy or impossible (Koenig, 2008). Dichotomous thinking has been identified as a key maintaining factor in cognitive behavioural models of eating disorders (Byrne, Allen, Dove, Watt, \& Nathan, 2008). Dichotomous thinking is also viewed as an all-or-nothing cognitive style (Byrne et al., 2008). According to Polivy and Herman (2002), anorexics feature several cognitive aberrations, including obsessive thoughts, inaccurate judgments, and rigid thinking patterns.

Core beliefs are deep, usually longstanding, beliefs about the self and in AN individual's they are usually negative and may be related to competence or self-worth (Gilbert, 2008). Gilbert asserted that many dysfunctional attitudes or assumptions often connect these beliefs to the person's behaviour. These dysfunctional attitudes or assumptions can produce expectations about the self, or rules, which help to maintain the disorder (Gilbert, 2008). Individuals with AN may feel that people in their lives would not like them if those people knew who they really were.

Involvement in a group allows different or alternative responses to the narrow focus of personal perspectives, which may enhance problem solving ability by 
heightening awareness of various possibilities (Russell \& Arthur, 2000). Undoing the irrational beliefs of AN may also be supported by the less tangible aspects of being nurtured by the softly spoken words — as opposed to direct confrontations—of trusted others, such as group members (Lamoureux \& Bottorff, 2006).

The results of Inbody and Ellis’s (1984) study identified that, in working within a group, the clients slowly became aware of their marked distortion concerning their body image. This awareness stemmed from the interaction among the group members (Inbody \& Ellis, 1984). The clients could see how emaciated the other anorexics were and, as they began to identify with each other, they generally came to the realization that perhaps they also looked similar to their peers (Inbody \& Ellis, 1984). Actually seeing that their peers could achieve and maintain a target weight was meaningful to AN clients as well as the ability to vicariously confront their deepest fears and, in turn, put to rest many of their own (Inbody \& Ellis, 1984).

According to Lamoureux and Bottorff (2006), trust in others allowed the participants to begin to take in what others said and to consider alternate perspectives (e.g., about the dangers of AN). Experiencing trust made it possible for the clients to engage in the other essential work of recovery, including challenging their anorexic thoughts, reclaiming power, and examining their own worth (Lamoureux \& Bottorff, 2006).

The results of Black’s (2003) and Inbody and Ellis’s (1984) studies suggested that the group process is an effective and efficient vehicle for confronting basic cognitive distortions and emotional conflicts. Exploring dysfunctional cognitions will help a client in identifying, refuting, and replacing irrational beliefs (Matto, 1997). Matto asserted that 
providing counter arguments to such beliefs through positive self-statements, visualization of negative thoughts and feelings, relaxation training, mindfulness, and giving information would help educate a client about body image disturbance. The group program manual developed for this project, Coming Together to Calm the Hunger: Group Therapy Program for Adults Diagnosed with Anorexia Nervosa (see the Appendix) provides mindfulness activities to aid in the development of counter arguments. Another characteristic, which may be identified with individuals diagnosed with AN, is isolation.

\section{Isolation}

A sense of isolation may contribute to the difficulties that individuals with eating disorders have in developing healthy intimate relationships (Russell \& Arthur, 2000). An individual diagnosed with AN may present as articulate and well groomed despite severe social isolation and self-neglect (Arkell \& Robinson, 2008). Keeping one’s distance from others, being highly self-reliant, or being a self-concealer can lead to feelings of emotional isolation and never really feeling part of relationships (Gilbert \& Procter, 2006). According to Stewart's (2004) study, there is limited direct research that measures the levels of aloneness and isolation in connection with the manifestation or recurrence of AN symptoms, yet the implications appear to be there. The implementation of less traditional types of support for this disorder seemed to benefit clients, especially in offsetting the isolation to which they are so frequently prone (Stewart, 2004). It is apparent in the cases presented by Stewart that loneliness and isolation were major triggering factors. How the personality structure of the eating disordered individuals contributes to the establishment of isolation is of clinical significance as well (Stewart, 
2004). A review of the literature suggested that group therapy may be particularly useful for combating the isolation of individuals struggling from AN (Lenihan \& Sanders, 1984; Russell \& Arthur, 2000; Wanlass et al., 2005). The social context of group therapy offers a unique opportunity to break the secrecy and combat isolation through attendance and participation (Russell \& Arthur, 2000).

Russell and Arthur (2000) asserted that group therapy could provide a collaborative environment where individuals could express themselves without judgment. This group context could offer opportunities for altruism and practicing social skills, such as giving and receiving peer reinforcement and feedback (Russell \& Arthur, 2000). The group program manual (see the Appendix) includes activities that illicit feedback from other members.

Decreasing the likelihood of isolation and perceived aloneness needs to be considered crucial to the recovery process in this disorder (Stewart, 2004). In fact, many clients with AN may have never admitted their eating disorder to anyone before, furthering their isolation. In Inbody and Ellis’s (1985) study, group clients were vastly relieved to find others like them in the world, and the sharing of a syndrome contributed to the group's cohesiveness. Additionally, Wanlass et al.'s (2005) study found that group members felt the group was an opportunity to assist others, which increased hope in their own ability to recover. This feeling of connectedness within the group will be reviewed next.

\section{Connectedness}

Many clients diagnosed with AN have never experienced a close relationship with a peer, in part because of their difficultly dealing with people on anything other than on a 
superficial level (Inbody \& Ellis, 1985). Deficits in emotional processing are intensely discussed as an important underlying factor or a consequence of disturbed eating behaviour (Joos, Cabrillac, Hartmann, Wirsching, \& Zeech, 2009). All of the AN participants in Patching and Lawler’s (2009) study described a strong sense of being misunderstood and of not belonging. These participants believed that engaging in disordered eating behaviours would address the issue of lack of connectedness by providing them with a sense of connectedness to the self and others and allow them to develop a stronger sense of self (Patching \& Lawler, 2009). Perhaps more importantly, AN is used to shield the self from underlying fears that loved ones will fail to appreciate the inner struggle of unmet needs or emotions, thereby protecting the self from being exposed to potentially unbearable disappointments. AN participants in Patching and Lawler's study as well as participants in Lamoureux and Bottorff's (2006) qualitative study highlighted the fact that one of the most helpful methods of recovery is to talk with people who understand the illness. Wanlass et al. (2005) study reflected the importance of a group by increasing a group member's sense of belonging, providing support and perspective, and offering opportunities to honestly self-disclose and test new behaviours. Achieving a sense of belonging and emotional connection to other group members is a crucial component of the value participants place on the group experience (Wanlass et al., 2005). The following section explores the characteristic of control that may be found in individuals diagnosed with AN.

\section{Control}

According to Russell and Arthur (2000), control seems to play an important role in the symptomatology of AN. The issue of control permeated the lives of the women 
before these women engaged in disordered eating behaviours (Patching \& Lawler, 2009); this issue was exacerbated throughout the experience of living with the condition. Lamoureux and Bottorff (2006) and Patching and Lawler asserted the reason why some women choose to engage in disordered eating behaviours, as opposed to other behaviours to address feelings of lack of control has continued to elude clinicians and researchers for decades.

Rezek and Leary’s (1991) study supported the relationship between self-restricted eating and control. Gaining a sense of control of internally aversive experiences may result in restrictive eating. The participants in Patching and Lawler’s (2009) study believed that if they could achieve a sense of control over their food intake and their exercise regimes, then this would generalize to a sense of control over their lives and, ultimately, lead to a stronger sense of self. The issue of control appears to change throughout the course of the disorder. Initially, a sense of control, afforded by their eating disorder, would assist them in developing their sense of self (Patching \& Lawler, 2009). Paradoxically, recovery may be achieved when the client is able to relinquish that sense of control in search of a sense of self devoid of their eating disorder (Patching \& Lawler, 2009). The group experience can offer opportunities to challenge this need to be in control as there is a certain amount of risk taking that is involved through enrolling in a group and interacting with members (Russell \& Arthur, 2000). The group program manual developed for this project, Coming Together to Calm the Hunger: Group Therapy Program for Adults Diagnosed with Anorexia Nervosa (see the Appendix) contains the objective of exploring members' sense of control. The final characteristic of the relationship experience of an individual diagnosed with AN is identified next. 


\section{Relationships}

Within group work, one of the central themes is the recognition that eating behaviour may be the way women cope with the internal conflict experienced throughout their lives (Black, 2003). Therefore, in a world were a woman feels powerless, eating issues can represent a woman’s attempt to assert her identity and to gain control (Black, 2003). Black asserted that the use of group work with individuals with $\mathrm{AN}$ is to provide a mini community, which may create an alternative place to discuss their struggles other than through food and their bodies. According to Wanlass et al. (2005), many individuals with AN have difficulty relating with family members, friends, and significant others. Group therapy may provide an avenue for exploring basic communication skills such as reflective listening, assertive confrontation, and conflict resolution (Wanlass et al., 2005). Situations within group therapy provided members with information about their impact on and reactions to other people and prompted some members to change old communication patterns and try new behaviours in an appropriate, supportive environment (Wanlass et al., 2005). Russell and Arthur (2000) asserted that group therapy offers opportunities for AN individual's to deal with their anxiety, ambivalence, and their feelings about close, healthy relationships — fearing them, while also desiring them.

This extensive section reviewed commonly found personality traits in individuals with AN. These are important topics to recognize to guide treatment options for individuals with AN. The next section in the literature review explores mediating factors that may contribute to the development, maintenance, or both the development and maintenance of AN in female adults. 


\section{Mediating Factors}

Various empirical and survey-based studies examined possible mediating factors that promote the onset and maintenance of AN. The topic of mediating factors is worthy of exploring as it might aid counsellors helping those with AN if an anorexic client has a history of childhood sexual abuse, OCD, depression, borderline personality disorder, or posttraumatic stress disorder (Everill \& Waller, 1995; Wonderlich et al., 2001). It is also a necessary to present the mediating factors, as they may help guide treatment options and intervention techniques. For example, in the group program manual associated with this project, topics such as posttraumatic stress disorder and abuse can be addressed. The following sections explore the mediating factors in further detail. Specifically, the next section will address the prevalence of childhood sexual abuse in AN clients.

\section{Childhood Sexual Abuse}

Clinicians have long argued that childhood sexual abuse is a risk factor for the development of AN (Ackard \& Neumark-Sztainer, 2003; Barnes, Emberson, Golding, 2005; Briere \& Scott, 2007; Cachelin, Schug, Juarez, \& Monreal, 2005; Everill \& Waller, 1995; Johnson et al., 2002; Smolak \& Murnen, 2001; Wonderlich et al., 2001). The issue is whether a meaningful relationship exists between the two phenomena, or whether it is merely an illusory one because of the prevalence of both in a female population (Connors \& Morse, 1993). Some studies have failed to identify a link between childhood sexual abuse and eating disorders (Connors \& Morse; Palmer \& Oppenheimer, 1992). Cachelin et al. (2005) and Fullerton, Wonderlich, and Gosnell (1995) asserted that from the data it is clear that childhood sexual abuse is neither necessary nor sufficient for the development of AN; however, in a number of cases it may be an important etiological 
factor (Connors \& Morse, 1993). Cachelin et al.'s study found that not all of the AN participants reported childhood sexual abuse and that some of the control participants did. What seemed to differentiate the two groups was the amount of abuse. The women with AN reported more separate instances and longer duration of sexual abuse than did healthy controls and were more likely to have been revictimized (Cachelin et al., 2005). Cachelin et al.'s (2005) study supported Wonderlich et al.'s (2001) research by finding that the individuals who had experienced both childhood sexual abuse and sexual assault in adulthood showed the highest rates of AN behaviour and associated impulsivity, which also support the concept that early trauma may sensitize an individual's reaction to later adversity or traumatic experience. The results of these studies indicated a need for clinicians to be aware that repeated or prolonged abuse may increase the risk for developing AN. Therefore, screening questions that ask about abuse should be included during intake sessions.

Varner (1999) stated that pathological eating and other self-destructive behaviours may be a maladaptive mechanism for avoiding or dealing with the overwhelming depression and anxiety that accompany memories of abuse. The group program developed for this project, Coming Together to Calm the Hunger: Group Therapy Program for Adults Diagnosed with Anorexia Nervosa (see the Appendix) provides a venue for the recognition and exploration of overwhelming emotions that member's may feel. The following section reviews the mediating factor of OCD that may be present in individuals with AN. 


\section{Obsessive-Compulsive Disorder}

OCD involves a combination of dysfunctional thoughts and behaviours (Steinglass \& Walsh, 2006). Furthermore, Steinglass and Walsh asserted the obsessions of OCD are "persistent thoughts, impulses, or images that are intrusive or unwanted such that the client has some degree of insight that their worries are unrealistic” (p. 268). Individuals diagnosed with AN have persistent and intrusive thoughts about food and repetitive concerns about gaining weight (Halmi et al., 2003; Steinglass \& Walsh, 2006). An individual with AN may avoid meals with friends or family in an attempt to reduce their anxiety; Steinglass and Walsh asserted this type of behaviour is associated with an obsession characteristic of the disorder.

Compulsions, also part of OCD, are repetitive, purposeful actions that are usually intended to reduce anxiety raised by the obsessions (Steinglass \& Walsh, 2006). Compulsions and obsessions can also be identified within individuals diagnosed with AN. For example, an AN client might disclose how she is frequently spending her time considering how she is going to structure her day around food avoidance.

Halmi et al. (2003), Halmi, Tozzi, et al. (2005), Sallet (2010), and Wu (2008) identified that OCD is comorbid with AN, however, there appears to be distinct differences in the desire for change. Steinglass and Walsh (2006) asserted the motivation for change is often a critical component of treatment of AN, in a way that is qualitatively different from OCD. In OCD clients, there may be high degree of motivation to change (Steinglass \& Walsh, 2006). However, those with AN may have difficulty identifying their behaviours and thoughts as being maladaptive and thus do not see a need to change. 
Furthermore, it appears that clients with AN are unable to see the physical dangers associated with their dietary restrictions.

Depression

Depression has been found to coexist with AN at a relatively high rate such as 50\% (Kent \& Waller, 2000; Varner, 1999). Features that are common to both eating disorders and depression (i.e., weight change, social withdrawal, decreased self-esteem, sleep disturbance, and concentration problems) can make differential diagnosis of depression difficult (Varner, 1999). Depressive symptoms that do not meet full criteria for an affective disorder, such as low mood, sleep changes, and experiencing less pleasure in one's life, are also common in AN clients (Brewerton, 2004). Individuals suffering from depression are reported to have higher than expected rates of a history of trauma or victimization, and more often than not the trauma occurred during childhood or adolescence (Brewerton, 2004; Gucciardi, Celasum, Ahmad, \& Stewart, 2004).

The implications for clinicians is that it would be advisable to assess and treat depressive disorders among those who present with eating or weight problems as this may also facilitate recovery from AN (Johnson et al., 2003). Posttraumatic stress disorder is another mediating factor in the development of AN and is identified next.

\section{Posttraumatic Stress Disorder}

Posttraumatic stress disorder is currently conceptualized as a complex anxiety disorder with an oscillation between reexperiencing the trauma in memories and dreams, on one hand, and generalized avoidance of stimuli reminiscent of the event on the other (Mantero \& Crippa, 2002). According to Levitt (2007), trauma-related symptoms are generally diagnosed under either acute stress disorder or posttraumatic stress disorder. 
Acute stress disorder and posttraumatic stress disorder are quite similar in

symptomatology; however, acute stress disorder is only used for diagnosis during the first month after a traumatic event and acute stress disorder tends to have a great emphasis on dissociative symptoms (Levitt, 2007). While a person with posttraumatic stress disorder may present with dissociative features, it is not a requirement for the diagnosis (Levitt, 2007). Levitt stated that the individual who experiences a traumatic event may, soon after the experience, develop and present with a variety of symptoms including anxiety, depression, and dissociative symptoms along with other trauma-related symptoms.

Despite their apparent distance in presentation and clinical picture between PTSD and AN, there are similarities (Mantero \& Crippa, 2002). According to Mantero and Crippa, both posttraumatic stress disorder and AN disorders contain ruminations, and these ruminations tend to be called obsessive by AN individuals and intrusive in posttraumatic stress disorder individuals. When compared with typical obsessions, both the intrusive thoughts of individuals with posttraumatic stress disorder and the obsessive thoughts of anorexics have a stronger link with objective external reality (Anxiety Disorders Association of America, n.d.; Mantero \& Crippa, 2002). Mantero and Crippa asserted that in both AN and posttraumatic stress disorder the resulting aggravated symptoms may worsen self-esteem and depressive states and the interruption of this vicious circle is vital to improvement.

\section{Borderline Personality Disorder}

Highly variable rates of comorbidity, ranging from $21 \%$ to $57 \%$ have been reported for the presence of any personality disorder in patients with a range of eating disorder diagnoses (Jackson \& Jovev, 2006). Sansone and Sansone (2007) asserted that 
childhood trauma is a potential etiological factor in the development of both AN and borderline personality disorder. The relationship between childhood abuse and eating disorders may be mediated by personality dysfunction (Sansone \& Sansone, 2007). Sansone and Sansone further postulated, “At the outset of life’s journey, one’s endowment with low adaptive genetics and exposure to an unstable family environment highlighted by abuse appears to establish the risk for personality disorder” (p. 71). In turn, this consolidated personality disorder may enhance the risk for AN (Sansone \& Sansone, 2007). However, not all traumatized individuals develop personality disorders, and not all individuals with personality disorders develop AN (Sansone \& Sansone, 2007). Sansone and Sansone suggested further research is needed to explore the various protective and augmenting factors for this pathway.

\section{Summary}

As the current literature has shown, AN is a very complex disorder. Genetics, environment, personality traits, and coexisting conditions add to this intricacy. The complexity found in attempting to understand the development and maintenance of AN reinforces the need for an integrative and multifaceted approach to the treatment of such disorders, a treatment approach that accounts for the many aspects of the disorder itself (Matto, 1997). The difficulty both in treating clients with AN and in evaluating the effectiveness of current treatments indicates a need for more research and for more randomized clinical trials to effectively guide treatment and interventions. Furthering therapists understanding of AN will have beneficial implications for clinical practice by providing a holistic approach to healing offered to clients. It is hoped that the proposed group program in the appendix addresses a holistic and effective method of treating AN. 
The next chapter presents a comprehensive literature review that examines the effectiveness of group psychotherapy, specific therapists' variables, and the therapeutic group factors that may contribute to the efficacy of group treatment. The following chapter also explores how therapy groups often develop and the stages that are characteristic of this treatment modality. 


\section{Chapter 3: Literature Review of Key Group Therapy Practices}

This chapter provides a comprehensive literature review that examines the effectiveness of group psychotherapy, therapist roles and responsibilities, and the therapeutic group factors that may contribute to the efficacy of group treatment. Further, this chapter explores how therapy groups often develop and the stages that are characteristic of this treatment modality. To begin this chapter, the efficacy of group psychotherapy is reviewed.

\section{Group Psychotherapy}

Researchers' understanding regarding the effectiveness of group psychotherapy has evolved over the past century (Burlingame, Fuhriman, \& Mosier, 2003). Although the empirical evidence for the effectiveness of group psychotherapy is strong (Burlingame et al., 2003; Chen \& Mallinckrodt, 2002; Davies, Burlingame, Johnson, Gleave, \& Barlow, 2008), the mechanisms underlying these effects are less clear. "The debate about the existence and operation of unique therapeutic factors for group therapy has a continuous, complex, and contradictory history in the professional literature” (Bernard et al., 2008, p. 464). To increase the effectiveness of group therapy, it is important to review key group therapeutic change factors.

Bernard et al. (2008) recommended that group therapists become aware of key group therapeutic change factors as they develop group manuals and programs. There appears to be a growing interest in utilizing group therapy for individuals diagnosed with AN as the research shows this population is difficult to treat successfully, and group therapy may add a more holistic approach to healing. Furthermore, Burlingame et al. (2003) asserted that two factors often contribute to the increase of participation in a group 
counselling format: (a) the current health care climate with its emphasis on the efficacy and cost of services, and (b) the group psychotherapy literature demonstrating the effectiveness of this treatment approach for clients with particular disorders.

The next section of this chapter addresses therapist roles and responsibilities. Specifically, the three critical roles are explored and the therapist responsibilities as the group develops are addressed.

\section{Therapist Roles and Responsibilities}

Group therapists have a number of critical roles and responsibilities when facilitating a group. Three roles are described in this section. To begin, the perspectives that may be required to understand the whole group are identified, then understanding the mechanisms of member change follows, and, finally, the stages that the group may experience are explored.

\section{The Group Experience}

It is commonly understood that a group is more than the sum of its members. To understand the group experience and dynamics, it is useful to examine the group from three different perspectives (Knauss, 2005). The first perspective involves the personalities of the different members. Knauss stated that a member’s internalized network of beliefs, feelings, and actions based on past and present relationships might be reactivated in a group. This reactivation may be related to the discrepancy between selfappraised interpersonal problems and external perceptions of others (Chen \& Mallinckrodt, 2002; Knauss, 2005). This is an important piece of information for group counsellors to consider because it may provide an opportunity to gently encourage members reporting to other members on these discrepancies. 
The second perspective is the interaction, or the interrelatedness, between different members (Knauss, 2005). The sequence, structure, and emotional quality of these interactions are used to facilitate the therapeutic processes (Knauss, 2005).

The third perspective is the system of the whole group within its context (Drumm, 2006; Knauss, 2005). The group therapists attend to each individual in the group as well as the group as a whole (Drumm, 2006). To accomplish this, facilitators need to take into account vicarious learning, role flexibility, universality, altruism, and interpersonal learning. All these are potential mechanisms of client change within a group therapy program (Bernard et al., 2008; Moreno, Fuhriman, \& Hileman, 1995).

These three perspectives may help the therapist understand the whole group. Therapists also need to understand the mechanisms of member change and the stages of group development, which will be explored next.

To facilitate the timing and effectiveness of group interventions, Bernard et al. (2008) suggested that therapists pay careful attention to the mechanisms of member change including the relational bond between the member and the therapist's, the member and other members, and the member to the group as a whole. Other mechanisms of member change include the therapeutic alliance and negative factors such as hidden agendas of members, conflict, and feelings of mistrust.

Overall, therapists' awareness of how people behave during the group can greatly benefit any group (Drumm, 2006). Ample attention in the group therapy literature has addressed the various stages of development groups tend to travel over time. Therapists aim to support members ease during the beginning of the group and encourage group members to air conflict and explore issues to resolve problems during the middle stage 
(Drumm, 2006). During the final phase of a group, the therapists facilitate members consolidating their learning and developing strategies for transferring what they learned in the group to daily life (Corey et al., 2010).

Knauss (2005) believed that in order to understand the group process, all three stages have to be taken into consideration by the therapists during the planning and implementation of the group program. Furthermore, the political, cultural, and social contexts of a unique group also need to be considered by the facilitator in order to understand how this effects the development of a group therapy program (Knauss, 2005). For instance cultural factors may influence members’ readiness to participate in a group (Corey et al., 2010).

Overall, stages of a group provide valuable information for facilitators in managing group dynamics. Another area that facilitators would be wise to pay attention to is the therapeutic factors that support change within a group therapy program, discussed in the next section of this chapter.

\section{Therapeutic Group Factors}

Yalom (1995) highlighted unique group therapeutic factors that they believed contributed to effective group treatment, which several authors have supported as being valid (Bernard et al., 2008; Burlingame et al., 2003; Holmes \& Kivlighan, 2000; Johnson, Burlingame, Olsen, Davies, \& Gleave, 2005). It is important to address these factors in this project because, as Yalom indicated, “there are considerable advantages in approaching the complex through the simple, the total phenomenon through its basic component processes” (p. 1). 
The next section explores a selection of the core group therapeutic factors in the following order: instillation of hope, universality, imparting information, altruism, corrective recapitulation of primary family experience, development of socializing techniques, interpersonal learning, and cohesion.

Instillation of Hope

According to Yalom (1995), the instillation and maintenance of hope is crucial in all psychotherapy. Not only is hope required to keep the client engaged in therapy so that other therapeutic factors may take effect, but faith in the treatment mode can also enhance therapeutic effectiveness (Yalom, 1995).

Yalom (1995) believed that group therapists could capitalize on this factor by doing whatever they could to increase clients' confidence in the efficacy of the group experience. Group therapy draws from members’ positive expectations and also benefits from a source of hope that is unique to the group format (Yalom, 1995).

Therapy groups invariably contain individuals who are at different points along a coping-collapse continuum, yet each individual has likely connected with others who have improved as a result of therapy (Yalom, 1995). Hope may occur as the result of seeing the benefits of therapy with others along with the therapist's belief that every group member has the ability improve. Members may recognize other members’ therapy successes and from this may develop optimism for their improvement, thus further instilling hope (Yalom \& Leszcz, 2005). For example, in an AN group, members may share or acknowledge any past therapeutic gains with other members, which may instill hope in their recovery process. 


\section{Universality}

Fuhriman and Burlingame (1990) identified universality as a therapeutic factor associated with group psychotherapy. Universality is described as group members’ realizations that other members are struggling with similar problems (Fuhriman \& Burlingame, 1990). Group members often have a heightened sense of uniqueness and their interpersonal difficulties may have previously precluded the attainment of interpersonal support and connections (Yalom, 1995). In a group setting, according to Yalom, group members will have the opportunity to learn about others' analogous feelings and experiences and are invited to allow themselves the opportunity to confide in and be validated and accepted by others.

The ability to promote universality in a group can often bring a powerful source of relief to group members (Yalom, 1995), as providing an opportunity for members to recognize that their issues or concerns may be similar to other members. Yalom further asserted clients' perceptions of their similarities to others and the sharing of their deepest concerns would facilitate other therapeutic factors such as catharsis and ultimate acceptance from other members. For example, in an AN group, members may feel very alone and ashamed of their disorder or their behaviours and may have not discussed this with another person in their lives. Sharing personal information in the group context, may allow for a sense of relief hearing similar struggles or concerns.

\section{Imparting Information}

Yalom (1995) believed that many group therapy approaches include formal instruction, or psychoeducational information, as an important part of the group program. Group therapists may include a cognitive therapeutic approach by offering explicit 
instruction about the nature of clients' concerns or life situations and examining clients' misconceptions and self-defeating responses (Yalom, 1995).

Yalom (1995) asserted that direct advice from the group members might occur throughout a therapy group with such advice being an invariable part of the early life of the group. Member advice-giving occurs with such regularity that its presence can be used to estimate a group’s developmental stage (Yalom, 1995). Yalom stated that groups that are noninteractionally focused make explicit and effective use of direct suggestions and guidance. Furthermore, Yalom felt that advice is common, but it is differentially useful. The least effective form of advice is a direct suggestion and the most effective are more systematic, operationalized instructions or a series of alternative suggestions about how to achieve a desired goal (Flowers, as cited in Yalom, 1995). For example, in an AN group, a member may share strategies surrounding food that they may have found to calm their anxiety and another member may consider if these tools may be effective for them. Altruism

Group members receive through giving, not only as part of the reciprocal givingreceiving sequence, but also from the intrinsic act of giving (Yalom, 1995). Clients can be very helpful to one another in the group therapeutic process by offering support, reassurance, suggestions, insight, and by sharing their experience with similar problems (Yalom, 1995). The therapist is often seen as the paid professional, but the group members represent the real world and can be counted on for spontaneous and truthful reactions and feedback (Yalom, 1995). According to Yalom, clients who reflect upon their experiences in group therapy often credit other members as having been important contributors to their improvement. Members may gain improvements to their self-esteem 
through extending help to other group members (Yalom \& Leszcz, 2005). For example, in an AN group, a member who is recently eating enough calories might share how she accomplished this significant task. In this act of helping it may allow the member to reflect on her progress and also help her feel more connected to the group. Corrective Recapitulation of Primary Family Experience

According to Yalom (1995), the great majority of clients who enter groups have backgrounds of highly unsatisfactory experiences in their first and most important group, the primary family. The therapy group can resemble a family in many respects; there are authority or parental figures, peer siblings, deep personal revelations, strong emotions, and deep intimacy, as well as hostile and competitive feelings (Chen \& Mallinckrodt, 2002; Yalom, 1995). Yalom believed that group members would interact with leaders and other group members in similar ways to which they once interacted with their parents and siblings. Yalom further suggested that what is important is not only that early familial conflicts are relived but that they are relived correctively. There are more opportunities for repeated corrective emotional experiences in group therapy than in the dyad of psychoanalysis due to the greater number of members, the richness of perspectives, and the emotions that are often triggered within these interactions (Willis, 1999). Fixed roles must be constantly explored and challenged and the ground rules for investigating relationships and testing new behaviours must be repeatedly encouraged (Yalom, 1995).

Yalom (1995) believed that working through here and now problems with therapists and other group members is also working through unfinished historical business. In short, corrective recapitulation of one’s primary family experience allows members to reenact critical family dynamics with group members in a corrective manner 
(Yalom \& Leszcz, 2005). For example, Tina, a member in an AN group is reminded of her mother due to the presence of another member, Karen, who in some way resembles Tina's mother. Exploring this relationship within the safety of the AN group may lead to a new, relived experience for Tina and her mother.

Development of Socializing Techniques

Yalom (1995) described social learning as a therapeutic factor that operated in all therapy groups, although the nature of the skills taught and the explicitness of the process may vary greatly depending on the type of group. An explicit emphasis on the development of social skills may include preparing hospitalized clients for discharge, role playing a prospective employer, or asking someone out on a date (Yalom, 1995).

Social learning may also be more indirect by encouraging open feedback that may help members obtain considerable information about maladaptive social behaviour (Johansson \& Werbart, 2009; Yalom, 1995). Group-level-process feedback serves to establish and maintain norms (Davies et al., 2008; Yalom, 1995), particularly with regard to the role of interpersonal feedback. For example, in an AN group, members receive feedback on how their secretiveness impacts the other group members. This feedback may allow for the member to transmit that feedback into relationships outside the group. In summary, the therapeutic factor of the development of socializing techniques provides members with an environment that fosters adaptive and effective communication (Yalom \& Leszcz, 2005).

\section{Interpersonal Learning}

Interpersonal learning, in the social microcosm of the therapy group, is among the most influential explanations of change processes that operate within group therapy 
(Chen \& Mallinckrodt, 2002). Group member's interactions with one another may reflect their maladaptive interpersonal patterns (Yalom, 1995). Members often hold perceptions of themselves that are discrepant in some important respects from the perceptions that others may have of them (Chen \& Mallinckrodt, 2002).

Furthermore, Chen and Mallinckrodt (2002) stated that group therapists focus clients on their here-and-now interactions and encourage the exchange of feedback about mutual perceptions. Receiving and giving feedback from other members is an important condition for change (Davies et al., 2008; Johansson \& Werbart, 2009). When clients compare perceptions, begin to identify perceptual distortions, and examine their recurring interactional patterns, interpersonal learning often occurs (Chen \& Mallinckrodt, 2002; Holmes \& Kivlighan, 2000). For example, Tina, a member in an AN group, may speak about how selfish she feels for always focusing on herself through her disorder. Other group members may share that their experience of Tina is not similar thus providing Tina with another's perception. The change process is further accelerated when members use interpersonal learning to develop new ways of relating to others, first with fellow group members, and then with significant others outside of the group (Chen \& Mallinckrodt, 2002).

\section{Cohesion}

The final therapeutic group factor to be explored is cohesion. Cohesion may be the critical therapeutic change factor as it initiates other change factors (Bernard et al., 2008; Dion, 2000). Knauss (2005) suggested that groups develop through a clash of centripetal and centrifugal forces, which are balanced by the constantly changing structure of the group. The shared goals and the cohesion of the group are considered 
centripetal forces, whereas different norms, different roles, and individuals’ deviation from group norms are centrifugal forces that initiate change and development (Knauss, 2005). Group cohesiveness is often regarded as a necessary precondition for other therapeutic factors to function optimally (Bernard et al., 2008; Yalom, 1995) as it creates conditions in which risk taking, catharsis, and intrapersonal, and interpersonal exploration may unfold (Yalom, 1995).

Cohesion defines the therapeutic relationship in groups comprised of multiple alliances, such as member to member, member to group, and member to leader, can be observed from three structural perspectives (Bernard et al., 2008). Cohesion, according to Bernard et al., is the equivalent to the concept of therapeutic alliance in individual psychotherapy, where the strength of the alliance is generally linked to positive therapeutic outcomes. Bernard et al. asserted that these cohesion perspectives include intrapersonal, intragroup, and interpersonal.

Client improvement has been directly related to intrapersonal cohesion interventions that focus on members' sense of belonging, acceptance, commitment, and allegiance to their group (Bernard et al., 2008; Johnson et al., 2005). For example, in an AN group, members may feel the are understood beyond their disorder, which may have been their experience with significant others in their lives. Definitions of intragroup cohesion include attractiveness and compatibility felt by the group as a whole, mutual liking and trust, support, caring, and commitment to work as a group (Bernard et al., 2008; Dion, 2000). Finally, interpersonal cohesion focuses on positive and engaging behavioural exchanges between members, which have been linked to symptomatic improvement (Bernard et al., 2008; Chen \& Mallinckrodt, 2002). 


\section{Summary of the Therapeutic Group Factors}

The eight therapeutic factors that Yalom (1995) described as facilitating change in group therapy, especially interpersonal learning, can be viewed as serving to alter negative working models of self or others (Chen \& Mallinckrodt, 2002). Chen and Mallinckrodt asserted that outside of group therapy, clients' daily social interactions often do not last long enough to provide disconfirming evidence of negative working modes and may be defensively rejected. "Clients in group therapy are systematically exposed to powerful continuing experiences that supportively challenge negative working models of self or others, thereby promoting interpersonal learning through means not ordinarily available outside of therapy” (Chen \& Mallinckrodt, 2002, p. 313). According to Johansson and Werbart (2009), “The experiences in group therapy facilitated clients’ ability to see, grab, and benefit from the helpful aspects already present, but undetected in their outside world, and that the changes in the interpersonal environment cause further intrapersonal changes” (p. 134).

Successful group therapy provides the activation of interpersonal learning that closes the gap between self-perceptions and the perceptions of others (Chen \& Mallinckrodt, 2002). An example, in an AN group, is a member who believes she is selfish; however, other member’s feedback may allow provide the opportunity to recognize she is not selfish all of the time. Essentially, interpersonal learning encourages members to gain personal insight about their interpersonal impact through feedback provided by others and also provides an environment that allows members to interact in more adaptive ways (Yalom \& Leszcz, 2005). 
The following section explores the group developmental issues and stages.

Finally, the importance of the therapist's role in responding to the stages is reviewed.

\section{Group Development Issues and Stages}

"Knowledge of group development can help the group therapists discern if member behaviors reflect personal and individual or group developmental issues" (Bernard et al., 2008, p. 484). Bernard et al. noted the value of group facilitators recognizing how members cope with group developmental issues as this can aid therapists in formulating specific interventions that are directed to the developmental stage of the group. There are numerous models that explain the stages of a group’s life. These models generally share the view that group development occurs in a systematic manner, advancing through phases or stages (Bernard et al., 2008). Although these stages are presented as distinct in group development theory, in practice, they are fluid and are rarely definite or linear (Chen \& Rybak, 2004). The following section reviews the developmental stages identified within group therapy.

At the beginning of its life, the group is in a forming stage, which is characterized by members' anxiety, seeking guidance from the group therapists on appropriate behaviours, and engagement in cautious self-disclosures and sharing (Tuckman, as cited in Bernard et al., 2008). At this point, the therapist's role is primarily educative, with leaders clarifying the group's purpose and the leaders' roles, and offering guidelines for the engagement of the group and member participation (Bernard et al., 2008; Chen \& Rybak, 2004). Bernard et al. stated that at this stage, the group therapists allow for regulation of interpersonal distance, but also invite trust, assisting the members to identify personal goals and recognizing commonalities between the members. For 
example, AN group members may benefit from knowing that they will not be weighted during the group program and that their family members will not know, from the facilitators, what issues are talked about in the group setting.

The next stage is the storming stage where the members begin to engage emotionally (Bernard et al., 2008). Bernard et al. and Chen and Rybak (2004) asserted that group characteristics at this stage include competition and conflict among the members, anxiety about the safety of the group, and challenges to the authority of the therapists, such as group members wondering if the therapists who do not have experience with AN can they truly help clients with AN. During this stage, the therapists promote group cohesion and interpersonal learning among the members and ensure that the group passes safely and successfully through this stage, while developing a strong working alliance among the members (Bernard et al., 2008).

Norming is the third stage in which a consensus on the group tasks and the working process develops (Bernard et al., 2008). This stage is characterized by the successful negotiation of the conflicts of the preceding stage, member trust, commitment, and an increase in the willingness to cooperate (Bernard et al., 2008; Chen \& Rybak, 2004). The therapists can support groups in this stage by assuming a less active role (Bernard et al., 2008). Therapists can also focus on facilitating the working process of members by providing feedback, promoting insight, and encouraging problem solving (Bernard et al., 2008). In the group program manual (see the Appendix), lessons five to nine are much more active and require more risk taking as the assumption is made that the group participants will have, for the most part, reached this stage of group development. 
The final stage is often described as termination. In this stage, the group members may experience sadness, anxiety, and anger (Bernard et al., 2008), yet there is some recognition among the members of the group’s strengths and limitations. For example, AN group members may feel anxiety realizing the group is coming to a close and feelings of loneliness may resurface. The members will typically be future orientated and engage in plans for maintaining gains (Bernard et al., 2008; Chen \& Rybak, 2004). “The therapists facilitate a systematic review and evaluation of the group’s progress, encourages planning for the post-group period, and facilitates involvement in the process of saying goodbye” (Bernard et al., 2008, p. 490).

\section{Summary}

In both group and individual therapy the development of a positive relationship between the therapist and the client is fundamental. The therapist must demonstrate acceptance, genuineness, and empathy. The therapist has a very important role in facilitating groups, as group psychotherapy is considerably different from individual counselling. The group process requires a skilled, supervised facilitator. The three fundamental tasks of the therapist are the creation and maintenance of the group, building the group’s culture, and the activation and illumination of the here and now.

As reviewed, therapy groups can exert its chief therapeutic power through a host of factors such as interpersonal learning and group cohesiveness (Yalom, 1995). The dynamics of group therapy may be thought of as changing, non-static, evolving psychotherapy: clients change, the group goes through a developmental sequence, and the therapeutic factors shift in primacy and influence during the course of therapy (Yalom, 1995). 
The group program manual that has been created for women diagnosed with AN takes into account the therapeutic factors that appear to facilitate change (see the Appendix). For example, the activities within each lesson were developed to increase the instillation of hope, universality, and cohesiveness.

The next chapter, chapter 4, identifies how the project literature reviews and manual were researched and developed. This information will serve to create a very strong foundation for the presentation of the 14 lesson plans for the treatment of AN. 


\section{Chapter 4: Research Methodology}

This chapter identifies how the background information and manual were researched. The research completed on AN examined what factors and personality traits may contribute to an individual developing restrictive and dangerous eating behaviour as well as treatment of AN in the group format. Most of the research obtained was from the United States of America; one study was conducted in Canada (Sinclair \& Pettifor, 2001). The literature utilized focused on the areas of counselling, psychology, and social work. The description of how the literature was located for this project is discussed below.

\section{Research Process}

The collection of resources for this literature review was conducted using the PsycINFO, Academic Search Complete, Medline, Ovid, and EBSCOHost databases. The search terms utilized included: anorexia nervosa, isolation and anorexia nervosa, control and anorexia nervosa, group therapy and eating disorders, group psychotherapy and eating disorders, group work and eating disorders, group therapy and anorexia nervosa, group counselling and anorexia nervosa, and group analysis and anorexia nervosa.

The University of Lethbridge library was accessed using the same search terms. By obtaining the books located through the library and cross-referencing their names with the reference lists from the articles, further resources were located on group therapy and AN. The search then included locating other books or articles these researchers had written. A review of reference lists led to the location of other sources of the current literature on eating disorders and group therapy. 
Google was accessed using the same search terms as above. Suitable web resources were located; however, this search also provided direction for locating more scholarly articles on this topic. This led back to accessing the PsycINFO database to locate the articles identified through Google. This process evolved over 8 months. Common researchers emerged as well as the increased ability to locate a wider range of scholarly work, including articles with a broader cultural perspective.

The research completed on group counselling examined why this therapy format is successful for many individuals. All of the research obtained was from the United States of America in journals published internationally. The literature utilized focused on the areas of counselling, psychology, and social work.

As with my research into AN, a collection of resources were used for this literature review including PsycINFO, Academic Search Complete, Medline, Ovid, and EBSCOHost databases. The search terms utilized included: group counselling, group counseling, group therapy, group psychotherapy, group analysis, and group work.

Once again I accessed the University of Lethbridge library using the search terms: using psychotherapy, group analysis, and group work. Again, I obtained the books located through the library and cross-referencing their names with the reference lists from the articles and further resources were located on group therapy. I expanded this search to include other books or articles by these same researchers. A review of the references lists in this works led me to other sources of current literature on group therapy.

Google was accessed using the same search terms as above. Suitable web resources were located; however, this search also provided direction for locating more scholarly articles on this topic. This led back to accessing the PsycINFO database to 
locate the articles identified through Google. This process evolved over 8 months. Overlapping researchers emerged as well as the increased ability to locate a wider range of scholarly work.

The development of this research project did not involve the use of human subjects. This research project focused on a thorough literature review. Part of the group therapy manual for individuals with AN (see the Appendix) was originally completed for part of an assignment in the author's Group Counselling and Process Skills (CAAP 6637). However, the group manual included in the appendix has been significantly expanded, redesigned, and revised to form a complete group program. Overall, this is a stand-alone document that exercises flexibility in its format and design, while still adhering to American Psychological Association (2002) standards.

\section{Summary}

This project and manual were developed to be an important addition to the research and resources available to group counsellors who work with individual's diagnosed with AN. The review of the literature was extensive and thorough. Based on the literature, there is a vast amount of research on the development of AN, yet much less on the treatment of AN. The next chapter, chapter 5, identifies why I choose to develop a group therapy program for individuals with AN based on experiential activities and also reviews the outline of the group manual (see the Appendix). 
Chapter 5: Overview of the Group Manual

The previous chapters served as a foundation for the development of a 14-session group therapy program for women with AN. This chapter provides a detailed review of the manual developed for this project. This chapter addresses the value of experiential activities in group therapy and also reviews the outline of the group program manual for facilitators (see the Appendix). For each session the objectives, time frames, activity instructions, facilitators' notes, homework exercises, questions for reflection and content delivery, references, and further resources are explained. The final section addresses ethical issues in the proposed group program. To begin with, the rationale for experiential group activities is identified.

\section{Rationale for Experiential Group Activities}

In experiential therapies, clients communicate symbolically through nonverbal forms of expression (Rumney, 2009). According to Rumney, individuals with AN may at one time have been verbally facile and communicative, yet at the height of their disease they tend to be introverted and reticent. Researchers have identified that clients with AN often have limited awareness and understanding of their feelings (Hinz, 2006; RehaviaHanauer, 2003; Rumney, 2009). Experiential therapy, such as artwork, provides an opportunity for the client to create something that symbolizes her inner world (Rumney, 2009). Further, Rumney asserted that expressive therapy can sometimes bypass the anorexic’s critic, which otherwise can stifle her expression and undermine her accomplishments. I support using art as an alternative means of expression and exploration of feelings, which may help make clients connect between their inner experiences and outer experiences. I also believe that using art, in addition to talk 
therapy, may also allow for free association through the body instead of through words (Frisch, Franko, \& Herzog, 2006).

Each of the sessions in this group program incorporates a variety of experiential activities (see the Appendix). The following section provides more information about the group program.

\section{Outline of the Group Manual}

The manual-based group treatment program for AN is appended to this project (see the Appendix). This manual is a compilation of 14 lesson plans to be utilized in a group therapy program for adult female clients with AN. This manual contains 12 weeks of group lesson plans as well as a pre- and post-group lesson for individuals diagnosed with AN. Each lesson plan contains the session’s objectives, time frames, activity instructions, facilitators' notes, homework exercises, questions for reflection and content delivery, references, and further resources for review. Each session can be a stand-alone document and can be altered slightly to be more suitable to the group needs and experiences. The next section explores each aspect of the lesson plans in greater detail.

\section{Session Objectives}

Each lesson contains two identified objectives and the activities within the lesson reflect the stated objectives. The rationales for the objectives within each lesson have been explored thoroughly in previous chapters, particularly in chapter 3.

\section{Time Frames}

Each lesson plan has identified a time frame for each activity as well as the complete session suggested length. The times provided are flexible and can be adapted based on the group's needs and stage of development. The group members may require 
the suggested time frame for completion of the activity; however, facilitators are encouraged to alter the time frame based on the group’s needs. For example, the group may benefit from less time on the experiential modality and more time on the processing of what the completing the exercise was like.

Activity Instructions and Facilitators’ Notes

The lesson plans, based on the course objectives, contain the titles of each activity as well as instructions on how to implement the activity. These plans provide the facilitators with clear directions as to how the activity is to be completed. Within the lesson plans under the instruction section activities that require additional information for the facilitators are noted and included in the later portion of the lesson plan.

Questions for Reflection and Content Delivery

After each lesson plan there are three suggested sample questions for facilitators’ reflection and three suggested sample questions for debriefing the lesson content delivery. The facilitator reflection questions are designed to begin a dialogue on how the group experience is affecting the facilitators. The lesson content delivery questions are designed to recognize what appeared to work well within the lesson and what could be modified for future groups. These questions are not exclusive and facilitators who implement this group within their counselling practice are encouraged to modify or add questions that invite the facilitators to process their experience facilitating this type of group.

\section{Handouts and Homework Exercises}

Within the lesson plans are the handouts for the group members. These are included directly after the relevant lesson plan. If there is a homework assignment for a 
specific lesson, this is indicated under the instruction section of the lesson plans. The hard copies of these the homework tasks are located after the facilitator notes and before the references for each lesson.

References and Resources for the Group Leader

The final section of each lesson plan contains the references and resources used in the development of the lesson. Facilitators are encouraged to locate these resources for further information. The next section addresses ethical issues in the proposed group program.

\section{Addressing Ethical Practice in the Proposed Group Program}

In the planning, implementation, and duration of the group program group leaders are encouraged to adhere to the professional conduct and guidelines mandated by the “Canadian Psychological Association's Code of Ethics” found in the Companion Manual to the Canadian Code of Ethics for Psychologists (Sinclair \& Pettifor, 2001). In the group treatment manual, special consideration is given to general respect, informed consent, privacy, confidentiality, minimizing harm, consent issues, and the avoidance of conflicts of interest.

To ensure that the dignity of all participants will be upheld, the facilitators are asked to provide the participants with the information needed to provide informed consent. Furthermore, facilitators are asked to ensure all participants are informed of their rights to refuse to participate in the group, answer any questions participants may have about participating in the group, and that participants can discontinue their participation in the group without consequence from the facilitators. 
In addition to the Canadian Psychological Association’s Code of Ethics (as cited in Sinclair \& Pettifor, 2001), the group facilitators are strongly encouraged to adhere to The Association for Specialist in Group Work Best Practice Guidelines (Thomas \& Pender, 2007), as it is recognized that one code may not be exhaustive in its coverage as well as include specific group therapy guidelines. The best practices included in this group manual relate to informed consent, confidentiality, freedom to withdraw from a group, psychological risks for members, and dual relationships.

\section{Summary}

This project is a manual-based group treatment program for AN (see the Appendix). The manual is based on current, existing literature as outlined in chapters 2 and 3 as well as innovative exercises designed by me, the author. The manual is user friendly with clearly stated objectives, content, activities, and instructions.

The next chapter explores the strengths and limitations of the project. It also identifies future areas for research that may strengthen and broaden the therapeutic interventions for working with individuals diagnosed with AN. 
Chapter 6: Synopsis

This chapter identifies the strengths and limitations of the project. Developed from the identified limitations, future areas for research are suggested as to how to develop and work with individuals with AN in a group format. The chapter concludes with a summary of why Coming Together to Calm the Hunger: Group Therapy Program for Adults Diagnosed with Anorexia Nervosa (see the Appendix) could be a valuable resource for therapists working with individuals diagnosed with AN.

\section{Group Psychotherapy}

A review of the literature, as clearly documented in chapters 2 and 3, asserted that group psychotherapy can be a valuable therapeutic intervention for AN (O’Brien \& LeBow, 2007; Tasca, 2007; Wanlass et al., 2005; Yellowlees, 1988). The results of Weber, Davis, and McPhie’s (2006) study indicated that it was important to group therapy members that there were common and shared experiences, which gave them a sense of not being alone and being understood. Thus, it is important that facilitators invite disclosure and use skills of validation to create the experience of connectedness with a group environment. Creating a group climate where clients feel connected to each other appears to be essential for success with AN clients (Wanlass et al., 2005). The following section of this chapter explores the project strengths.

\section{Project Strengths}

A significant strength of this project is that the literature reviews (see chapters 2 and 3) were an extremely thorough review of the research currently available on group therapy for AN. Furthermore, relevant and current literature was utilized for the content of the lesson plans (see the Appendix). I strongly believe this manual is a compliment to 
the current research on working with client's diagnosed with AN. The current literature identified how difficult AN is to treatment and how a holistic approach, including, but not limited to, group therapy, may be required for a more effective method to support those recovering from AN.

Facilitators will likely remark that the manual is user friendly because of the layout, the written hints for facilitators, and the reminders of group stages located throughout. In addition, the handouts of the exercises and homework are attached after every lesson, allowing facilitators the convenience to remove and photocopy for the members and replace back into the manual.

Another strength of this project is that the program could be updated or altered at any time based on the need of the group members or the agency with relative ease because the session themes are clearly identified and the sessions are not mutually dependent on each other. The lesson plans may also be altered based on the experience of the facilitators. For example, those facilitators with strong process skills may require more time than allotted for the processing of the activity. In this case, facilitators can shorten the time provided for the completion of the activity and lengthen the processing time.

Alternatively, the group members may need a lesson that does not contain an experiential activity. This may arise when members want to feel heard or want to process something that occurred in the previous lesson. Essentially, the program manual has been designed so that facilitators, while working within the objectives, can change the activity based on the needs of the members. 
Thus, there are many strengths associated with this project. And, there are some limitations. The next section describes the limitations of the project.

\section{Project Limitations}

There are four main limitations associated with this project. The first limitation pertains to the reliability of the material used to compose the literature reviews and the lesson plans. Most of the scholarly research reviewed had small sample sizes involving individuals with AN. Consequently, until there is more empirical research on the treatment of AN, the research findings and recommendations reported in research need to be cautiously depended upon. Likewise, there is a lack of empirically supported treatments or recovery process from $\mathrm{AN}$, so therapists need to use their judgment about what psychological treatments would best help an individual with AN based on their education and training.

Another limitation that is important to note is that the lesson plans of this group therapy program have not been implemented as of yet; so I, as the author, cannot be sure of the success of this program. The use of experiential activities found in the manual has not been proven to be effective with AN clients, yet. In addition, no feedback on the quality and feasibility of the lesson plans has been obtained other than the feedback provided by the project committee. Furthermore, the success of this program requires skilled group facilitators with excellent process skills. Counsellors who are beginners or more content focused may find the lesson plans to be scarce.

As the author, my natural filtering bias must also be addressed. References used in the literature reviews and the development of the manual does not encompass all of the 
available research on AN. The references utilized may have been located and chosen based on my judgments about relevancy and importance.

Although the limitations are serious, they do provide opportunities for future research. It is important that clinicians and research invest in research as AN clients deserve to have treatment that is empirically sound and effective.

\section{Areas of Future Research}

Future research must include how much training is necessary to implement a manual-based treatment program and provide evidence that manualized treatments can be effectively applied in a clinical setting, even by those with little clinical experience when offered in conjunction with regular supervision (Simmons, Milnes, \& Anderson, 2008). Future studies should examine clinicians’ awareness of the literature on eating disorder treatment efficacy when selecting treatments for clients and how this impacts healing from AN (von Ranson \& Robinson, 2006). Future research is needed to explore and identify an optimal treatment delivery to alleviate the suffering of individuals diagnosed with AN.

Another very important area for future research is in the realm of prevention. The number of individuals with AN is on the rise and providing empirically supported prevention programs within schools and communities may allow for early treatment, increased awareness, and increased understanding of AN. Halmi, Agras, et al. (2005) asserted the difficulty both in treating clients with chronic AN and in the consequent difficulty in evaluating the effectiveness of treatments in randomized clinical trials leads inexorably to the conclusion that prevention of chronicity should be major aim. 
Within the literature, it is apparent that there are high dropout rates for the studies being completed. Understanding the factors involved as to why some individuals diagnosed with AN dropout and others do not would benefit the current research and would also provide more information on how to successfully treat each group. Innovations in the treatment of AN promises to advance the field toward the point at which full recovery becomes the expected outcome for all clients with AN (Kotler et al., 2003).

Future research is needed that includes ethnic minorities and should consider how cultural differences for a specific ethnic group could affect group treatment programs (Rodriguez, Marchand, Ng, \& Stice, 2008). The current literature located and reviewed for this project contained very few ethnic minority individuals. It is also important that future research that involves this proposed group program being tested for client and facilitator satisfaction, effectiveness (short and long term), and areas noted for improvement.

\section{Summary}

There are numerous advantages of group treatment for clients who have been diagnosed with AN. One of the most important advantages is the personal contact with other sufferers and the experience of sharing their fear and their positive progress (Lenihan \& Sanders, 1984). Another advantage is the high level of identification that can build cohesive groups that are able to overcome highly developed defense systems (Lenihan \& Sanders, 1984). It would be important to offer a group, such as this, consecutively as the literature suggested that AN can be difficult to treat. With therapist preparation, a recruitment campaign, careful client selection, and appropriate group 
composition, group treatment for individuals with AN can be very powerful (Lenihan \& Sanders, 1984).

Given its relatively low implementation cost and established clinical effectiveness, group therapy for people with AN likely will continue to be utilized as a significant treatment option (Wanlass et al., 2005). Coming Together to Calm the Hunger: Group Therapy Program for Adults Diagnosed with Anorexia Nervosa (see the Appendix) is an important addition to the resources, based on current research, available to group counsellors. This group program will be an effective tool for settings which work with many young adult women who have been diagnosed with AN.

Overall, this project has made a very strong case for the need for group therapy for $\mathrm{AN}$ and has created a foundation for the objectives and activities within the program. The Appendix contains the 14 lesson plans as well as a statement on the use of the group program. 


\section{References}

Ackard, D. M., \& Neumark-Sztainer, D. (2003). Multiple sexual victimizations among adolescent boys and girls: Prevalence and associations with eating behaviours and psychological health. Journal of Child Sexual Abuse, 12, 17-37. doi:10.1300/J070v12n01_02

American Psychiatric Association. (2000). Diagnostic and statistical manual of mental disorders (4th ed.). Washington, DC: Author.

American Psychological Association. (2002). Publication manual of the American Psychological Association (5th ed.). Washington, DC: Author.

Anxiety Disorders Association of America. (n.d). Anxiety and eating: The relationship between anxiety disorders and eating disorders. Retrieved September 23, 2009, from http://www.adaa.org/understanding-anxiety/related-illnesses/eatingdisorders

Arkell, J., \& Robinson, P. (2008). A pilot case series using qualitative and quantitative methods: Biological, psychological and social outcome in severe and enduring eating disorder (anorexia nervosa). International Journal of Eating Disorders, 41, 650-656. doi:10.1002/eat.20546

Barnes, R. S., Emberson, J. R., \& Golding, J. (2005). Early experiences and their relationship to maternal eating disorder symptoms, both lifetime and during pregnancy. British Journal of Psychiatry, 187, 268-273.

doi:10.1192/bjp.187.3.268 
Bernard, H., Burlingame, G. M., Flores, P., Greene, L., Joyce, A., Kobos, J. C., et al. (2008). Clinical practice guidelines for group psychotherapy. International Journal of Group Psychotherapy, 58, 455-542. doi:10.1521/ijgp.2008.58.4.455

Beumont, P. J., \& Touyz, S. W. (2003). What kind of illness is anorexia nervosa? European Child \& Adolescent Psychiatry, 12, 20-24. doi:10.1007/s00787-0031103-y

Black, C. (2003). Creating curative communities: Feminist group work with women with eating issues. Australian Social Work, 56, 127-140. doi:10.1046/j,0312407X.2003.00061.X

Brewerton, T. D. (2004). Eating disorders, victimization, and comorbidity: Principles of treatment. In T. Brewerton (Ed.), Clinical handbook of eating disorders: An integrated approach (pp. 509-567). New York: Marcel Dekker.

Briere, J., \& Scott, C. (2007). Assessment of trauma symptoms in eating-disordered population. Eating Disorders, 15, 347-358. doi:10.1080/10640260701454360

Burlingame, G. M., Fuhriman, A., \& Mosier, J. (2003). The differential effectiveness of group psychotherapy: A meta-analytic perspective. Group Dynamics: Theory, Research, and Practice, 7, 3-12. doi:10.1037/1089-2699.7.1.3

Byrne, S., Allen, K., Dove, E., Watt, F., \& Nathan, P. (2008). The reliability and validity of the dichotomous thinking in eating disorders scale. Eating Behaviors, 9, 154162. doi:10.1016/j.eatbeh.2007.07.002

Cachelin, F. M., Schug, R. A., Juarez, L. C., \& Monreal, T. K. (2005). Sexual abuse and eating disorders in a community sample of Mexican American women. Hispanic Journal of Behavioral Sciences, 27, 533-546. doi:10.1177/0739986305279022 
Cassin, S. E., \& von Ranson, K. M. (2005). Personality and eating disorders: A decade in review. Clinical Psychology Review, 25, 895-916. doi:10.1016/j.cpr.2005.04.012

Chen, E. C., \& Mallinckrodt, B. (2002). Attachment, group attraction, and self-other agreement in interpersonal circumplex problems and perceptions of group members. Group Dynamics: Theory, Research, and Practice, 6, 311-324. doi:10.1037//1089-2699.6.4.311

Chen, M., \& Rybak, C. (2004). Group leadership skills: Interpersonal process in group counselling and therapy. Toronto, ON, Canada: Thomson Nelson.

Connors, M. E., \& Morse, W. (1993). Sexual abuse and eating disorders: A review. International Journal of Eating Disorders, 13, 1-11. Retrieved from Academic Search Complete database.

Corey, M., Corey, G., \& Corey, C. (2010). Groups: Process and practice (8th ed.). Belmont, CA: Brooks/Cole.

Davies, D. R., Burlingame, G. M., Johnson, J. E., Gleave, R. L., \& Barlow, S. H. (2008). The effects of a feedback intervention on group process and outcome. Group Dynamics: Theory, Research, and Practice, 12, 141-154. doi:10.1037/10892699.12.2.141

Dion, K. L. (2000). Group cohesion: From ‘field of forces’ to multidimensional construct. Group Dynamics: Theory, Research, and Practice, 4, 7-26. doi:10.1037//1089-2699.4.1.7

Drumm, K. (2006). The essential power of group work. Social Work with Groups, 29(2/3), 17-31. doi:10.1300/J009v29n0202 
Everill, J. T., \& Waller, G. (1995). Reported sexual abuse and eating psychopathology: A review of the evidence for a causal link. International Journal of Eating Disorders, 18(1), 1-11. Retrieved from Academic Search Complete database.

Forbush, K., Heatherton, T., \& Keel, P. (2007). Relationships between perfectionism and specific disordered eating behaviors. International Journal of Eating Disorders, 40, 37-41. doi:10.1002/eat.20310

Frisch, M. J., Franko, D. L., \& Herzog, D. B. (2006). Arts-based therapies in the treatment of eating disorders. Eating Disorders, 14, 131-142. doi:10.1080/10640260500403857

Fuhriman, A., \& Burlingame, G. M. (1990). Consistency of matter: A comparative analysis of individual and group process variables. Counseling Psychologist,18, 663. doi:10.1177/0011000090181002

Fullerton, D. T., Wonderlich, S. A., \& Gosnell, B. A. (1995). Clinical characteristics of eating disorder patients who report sexual or physical abuse. International Journal of Eating Disorders, 17, 243-249. doi:10.1002/1098108X(199504)17:3<243::AID-EAT2260170305>3.0.CO;2-Z

Geller, J., Brown, K. E., Zaitsoff, S. L., Goodrich, S., \& Hastings, F. (2003). Collaborative versus directive interventions in the treatment of eating disorders: Implication for care providers. Professional Psychology: Research and Practice, 34, 406-413. doi:10.1037/0735-7028.34.4.406

Gilbert, P., \& Procter, S. (2006). Compassionate mind training for people with high shame and self-criticism: Overview and pilot study of a group therapy approach. Clinical Psychology and Psychotherapy, 13, 353-379. doi:10.1002/cpp.507 
Gilbert, S. (2008). Counselling for eating disorders (2nd ed.). Thousand Oaks, CA: Sage. Grabhorn, R., Stenner, H., Stangier, U., \& Kaufhold, J. (2006). Social anxiety in anorexia and bulimia nervosa: The mediating role of shame. Clinical Psychology and Psychotherapy, 13, 12-19. doi:10.1002/cpp.463

Grogan, S. (2008). Understanding body dissatisfaction in men, women, and children. New York: Routledge.

Gucciardi, E., Celasum, N., Ahmad, F., \& Stewart, D. (2004). Eating disorders. BMC Women's Health, 4, S21. doi:10.1186/1472-6874-4-S1-S21

Halmi, K. A., Agras, W. S., Crow, S., Mitchell, J., Wilson, T., Bryson. S. W., et al. (2005). Predictors of treatment acceptance and completion in anorexia nervosa. Archives of General Psychiatry, 62, 776-781. Retrieved from Psychology and Behavioral Science Collection database.

Halmi, K. A., Sunday, S. R., Klump, K. L., Strober, M., Leckman, J. F., Fichter, M., et al. (2003). Obsessions and compulsions in anorexia nervosa subtypes. International Journal of Eating Disorders, 33, 308-319. doi:10.1002/eat.10138

Halmi, K. A., Tozzi, F., Thornton, L. M., Crow, S., Fichter, M. M, Kaplan, A. S., et al. (2005). The relation among perfectionism, obsessive-compulsive personality disorder and obsessive-compulsive disorder in individuals with eating disorders. International Journal of Eating Disorders, 38, 371-374. doi:10.1002/eat.20190

Harrison, A., Sullivan, S., Tchanturia, K., \& Treasure, J. (2009). Emotion recognition and regulation in anorexia nervosa. Clinical Psychology and Psychotherapy, 16, 348356. doi:10.1002/cpp.628 
Hinz, L. D. (2006). Drawing from within: Using art to treat eating disorders. London, UK: Jessica Kingsley.

Holmes, S. E., \& Kivlighan, D. M. (2000). Comparison of therapeutic factors in group and individual treatment processes. Journal of Counseling Psychology, 47, 478484. doi:10.1037/0022-0167.47.4.478

Hund, A. R., \& Espelage, D. L. (2006). Childhood emotional abuse and disordered eating among undergraduate females: Mediating influence of alexithymia and distress. Child Abuse and Neglect, 30, 393-407. doi:10.1016/j.chiabu.2005.11.0033

Inbody, D., \& Ellis, J. (1985). Group therapy with anorexic and bulimic patients: Implications for therapeutic intervention. American Journal of Psychotherapy, 39, 411-421. Retrieved from Academic Search Complete database.

Jackson, H. J., \& Jovev, M. (2006). Personality disorder construct and conceptualizations. In R. Sansone \& J. Levitt (Eds.), Childhood trauma, personality disorders, and eating disorders (pp. 3-20). New York: Routledge.

Jacobi, C., Morris, L., \& de Zwann, M. (2004). An overview of risk factors for anorexia nervosa, bulimia nervosa, and binge eating disorder. In T. Brewerton (Ed.), Clinical handbook of eating disorders: An integrated approach (pp. 117-163). New York: Marcel Dekker.

Johansson, L., \& Werbart, A. (2009). Patients’ views of therapeutic action in psychoanalytic group psychotherapy. Group Analysis, 42, 120-142. doi:10.1177/0533316409104361

Johnson, J. E., Burlingame, G. M., Olsen, J. A., Davies, D. R., \& Gleave, R. L. (2005). Group climate, cohesion, alliance, and empathy in group psychotherapy: 
Multilevel structural equation models. Journal of Counseling Psychology, 52, 310-321. doi:10.1037/0022-0167.52.3.310

Johnson, J. G., Cohen, P., Kasen, S., \& Brook, J. S. (2002). Childhood adversities associated with risk for eating disorders or weight problems during adolescence or early adulthood. American Journal of Psychiatry, 159, 394-400. doi:10.1176/appi.ajp.159.3.394

Johnson, K., \& Parkinson, S. (1999). There's no point raging on your own: Using art therapy in groups for people with eating disorders. Group Analysis, 32, 87-96. doi:10.1177/0533316499321007

Joos, A. A., Cabrillac, E., Hartmann, A., Wirsching, M., \& Zeech, A. (2009). Emotional perception in eating disorders. International Journal of Eating Disorders, 42, 318-325. Retrieved from Academic Search Complete database.

Karpowicz, E., Skarsater, I., \& Nevonen, L. (2009). Self-esteem in patients treated for anorexia nervosa. International Journal of Mental Health Nursing, 18, 318-325. doi:10.111/j.1447-0349.2009.00621.x

Kent, A., \& Waller, G. (2000). Childhood emotional abuse and eating psychopathology. Clinical Psychology Review, 20, 887-903. doi:10.1016/S02727358\%2899\%2900018-5

Klump, K. L., Wonderlich, S., Lehoux, P., Lilenfeld, L. R., \& Bulik, C. (2002). Does environment matter? A review of nonshared environment and eating disorders. International Journal of Eating Disorders, 31, 118-135. doi:10.1002/eat.10024 
Knauss, W. (2005). Group psychotherapy. In G. O. Gabbard, J. S. Beck, \& J. Holmes (Eds.), Oxford textbook of psychotherapy (pp. 35-44). New York: Oxford University.

Koenig, K. R. (2008). What every therapist needs to know about treating eating and weight issues. New York: W. W. Norton \& Company.

Kong, S. (2005). Day treatment programme for patients with eating disorders: Randomized controlled trial. Journal of Advanced Nursing, 51, 5-14. doi:10.1111/j.1365-2648.2005.03454.x

Kotler, L. A., Boudreau, G. S., \& Devlin, M. J. (2003). Emerging psychotherapies for eating disorders. Journal of Psychiatric Practice, 9, 431-441. doi:10.1097/00131746-200311000-00006

Krause, E., \& Robins, C. (2000). A mediational model relating sociotropy, ambivalence over emotional expression and disordered eating. Psychology of Women Quarterly, 24, 328-335. doi:10.1111/j.1471-6402.2000.tb00215.x

Lamoureux, M., \& Bottorff, J. (2006). Becoming the real me: Recovering from anorexia nervosa. Health Care for Women International, 26, 170-188. Retrieved from CINAHL Plus with Full Text database.

Lenihan, G. O., \& Sanders, C. D. (1984). Guidelines for group therapy with eating disorder victims. Journal of Counselling and Development, 63, 252-254. Retrieved from Professional Development Collection database.

Levitt, J. L. (2007). Treating eating disorder patients who have had traumatic experiences: A self-regulatory approach. Eating Disorders, 15, 359-372. doi:10.1080/10640260701454378 
Mantero, M., \& Crippa, L. (2002). Eating disorders and chronic post traumatic stress disorder: Issues of psychopathology and comorbidity. European Eating Disorders Review, 10, 1-16. doi:10.1002/erv.453

Matthews, D. D. (2001). Eating disorder sourcebook. Detroit, MI: Omnigraphics.

Matto, H. C. (1997). An integrative approach to the treatment of women with eating disorders. The Arts in Psychotherapy, 24, 347-354. Retrieved from Academic Search Complete.

Moreno, J. K., Fuhriman, A., \& Hileman, E. (1995). Significant events in a psychodynamic psychotherapy group for eating disorders. Group, 19, 56-62. doi:10.1007/BF01458191

Morgan, K. J. (2008). The anorexic self vs. the authentic self: A systematic and integrative guide in the adult treatment of anorexia nervosa. Lethbridge, $\mathrm{AB}$, Canada: University of Lethbridge.

O’Brien, K. M., \& LeBow, M. D. (2007). Reducing maladaptive weight management practices: Developing a psychoeducational intervention program. Eating Behaviors, 8, 195-210. doi:10.1016/j.eatbeh.2006.06.001

Palmer, R., \& Oppenheimer, R. (1992). Childhood sexual experience with adults: A comparison of women with eating disorders and those with other diagnoses. International Journal of Eating Disorders, 12, 359-364. doi:10.1002/1098108X(199212)12:4<359::AID-EAT2260120403>3.0.CO;2-O

Patching, J., \& Lawler, J. (2009). Understanding women's experiences of developing an eating disorder and recovering: A life-history approach. Nursing Inquiry, 16, 1021. doi:10.1111/j.1440-1800.2009.00436.x 
Paterson, G., Power, K., Yellowlees, A., Park, K., \& Taylor, L. (2007). The relationship between two-dimensional self-esteem and problem solving style in an anorexic inpatient sample. European Eating Disorders Review, 15, 70-77. doi:10.1002/erv.708

Polivy, J., \& Herman, C. P. (2002). Causes of eating disorders. Annual Review of Psychology, 53, 187-213. doi:10.1146/annurev.psych.53.100901.135103

Rehavia-Hanauer, D. (2003). Identifying conflicts of anorexia nervosa as manifested in the art therapy process. The Arts in Psychotherapy, 30, 137-149. doi:10.1016/S0197-4556(03)00049-2

Rezek, P., \& Leary, M. (1991). Perceived control, drive for thinness, and food consumption: Anorexic tendencies as displaced reactance. Journal of Personality, 59, 129-142. doi:10.1111/1467-6494.ep9106030317

Rodriguez, R., Marchand, E., Ng, J., \& Stice, E. (2008). Effects of a cognitive dissonance-based eating disorder prevention program are similar for Asian American, Hispanic, and white participants. International Journal of Eating Disorders, 41, 618-625. doi:10.1002/eat.20532

Rumney, A. (2009). Dying to please: Anorexia, treatment and recovery (2nd ed.). Jefferson, NC: McFarland \& Company.

Russell, S., \& Arthur, N. (2000). The contribution of a reflecting team to group therapy for eating disorders. Guidance \& Counseling, 16(1), 24-32. Retrieved from Academic Search Complete database. 
Sallet, P. C., de Alvarenga, P. G., Ferrao, Y., de Mathis, M. A., Torres, A. R., \& Marques, A. (2010). Eating disorders in patients with obsessive-compulsive disorder: Prevalence and clinical correlates. International Journal of Eating Disorders, 43, 315-325. doi:10.1002/eat.20697

Sansone, R. A., \& Sansone, L. A. (2007). Childhood trauma, borderline personality, and eating disorders: A developmental cascade. Eating Disorders, 15, 333-346. doi:10.1080/10640260701454345

Simmons, A., Milnes, S., \& Anderson, D. (2008). Factors influencing the utilization of empirically supported treatments for eating disorders. Eating Disorders, 16, 342354. doi:10.1080/10640260802116017

Sinclair, C., \& Pettifor, J. (Eds.). (2001). Companion manual to the Canadian code of ethics for psychologists (3rd ed.). Ottawa, ON, Canada: Canadian Psychological Association.

Smolak, L., \& Murnen, S. K. (2001). Risk factors for eating pathology: Recent advances and future directions. In R. Striegel-Moore \& L. Smolak (Eds.), Eating disorders: Innovative directions in research and practice (pp. 91-110). Washington, DC: American Psychological Association.

Stein, K. F., \& Corte, C. (2003). Reconceptualizing causative factors and intervention strategies in the eating disorders: A shift from body image to self-concept impairments. Archives of Psychiatric Nursing, 17, 57-66. Retrieved from Science Direct database. 
Steinglass, J., \& Walsh, B. T. (2006). Habit learning and anorexia nervosa: A cognitive neuroscience hypothesis. International Journal of Eating Disorders, 39, 267-275. doi:10.1002/eat

Stewart, W. (2004). The role of perceived loneliness and isolation in the relapse from recovery in patients with anorexia and bulimia nervosa. Clinical Social Work Journal, 32, 185-196. doi:10.1023/B:CSOW.0000024327.55424.a9

Striegel-Moore, R. H., \& Bulik, C. M. (2007). Risk factors for eating disorders. American Psychologist, 62, 181-198. doi:10.1037/0003-066X.62.3.181

Swain, P. I. (2003). Focus on eating disorder research. Hauppauge, NY: Nova Biomedical.

Swan, S., \& Andrews, B. (2003). The relationship between shame, eating disorders and disclosure in treatment. British Journal of Clinical Psychology, 42, 367-378. Retrieved from Science Direct database.

Tasca, G. A. (2007). Individual versus group psychotherapy for eating disorders. International Journal of Group Psychotherapy, 57, 399-403. doi:10.1016/S0193953X\%2805\%2970232-X

Thomas, R. V., \& Pender, D. A. (2007). Association for Specialists in Group Work best practice guidelines. Retrieved April 19, 2010, from http://www.asgw.org/PDF/Best_Practices.pdf

Troop, N. A., Allan, S., Serpell, L., \& Treasure, J. L. (2008). Shame in women with a history of eating disorders. European Eating Disorders Review, 16, 480-488. doi:10.1002/erv.858 
Varner, L. M. (1999). When an eating disorder “isn’t just” an eating disorder. Topics in Clinical Nutrition, 14(3), 4-13. Retrieved from Academic Search Complete database.

von Ranson, K. M., \& Robinson, K. E. (2006). Who is providing what type of psychotherapy to eating disorder clients? A survey. International Journal of Eating Disorders, 39, 27-34. doi:10.1002/eat.20201

Wanlass, J., Moreno, J. K., \& Thomson, H. M. (2005). Group therapy for eating disorders: A retrospective case study. Journal for Specialist in Group Work, 30, 47-66. doi:10.1080/01933920590908697

Weber, M., Davis, K., \& McPhie, L. (2006). Narrative therapy, eating disorders and groups: Enhancing outcomes in rural NSW. Australian Social Work, 59, 391-405. doi:10.1080/03124070600985970

Willis, S. (1999). Group analysis and eating disorders. Group Analysis, 32, 21-35. Retrieved from Academic Search Complete.

Wonderlich, S. A., Crosby, R. D., Mitchell, J. E., Thompson, K. M., Redlin, J., Demuth, G., et al. (2001). Eating disturbance and sexual trauma in childhood and adulthood. International Journal of Eating Disorders, 30, 401-412. doi:10.1002/eat.1101

Wu, K. D. (2008). Eating disorders and obsessive-compulsive disorder: A dimensional approach to purported relations. Journal of Anxiety Disorders, 22, 1412-1420. doi:10.1016/j.janxdis.2008.02.003

Yalom, I. D. (1995). The theory and practice of group psychotherapy (4th ed.). New York: Basic Books. 
Yalom, I. D., \& Leszcz, M. (2005). The theory and practice of group psychotherapy (5th ed.). New York: Basic Books.

Yellowlees, P. (1988). Group psychotherapy in anorexia nervosa. International Journal of Eating Disorders, 7, 649-655. Retrieved from Psychology and Behavioral Science Collection database. 


\section{Appendix \\ Adalt Female Anorexia Nerwosa Group: Coming Together to Calm the Hanger}

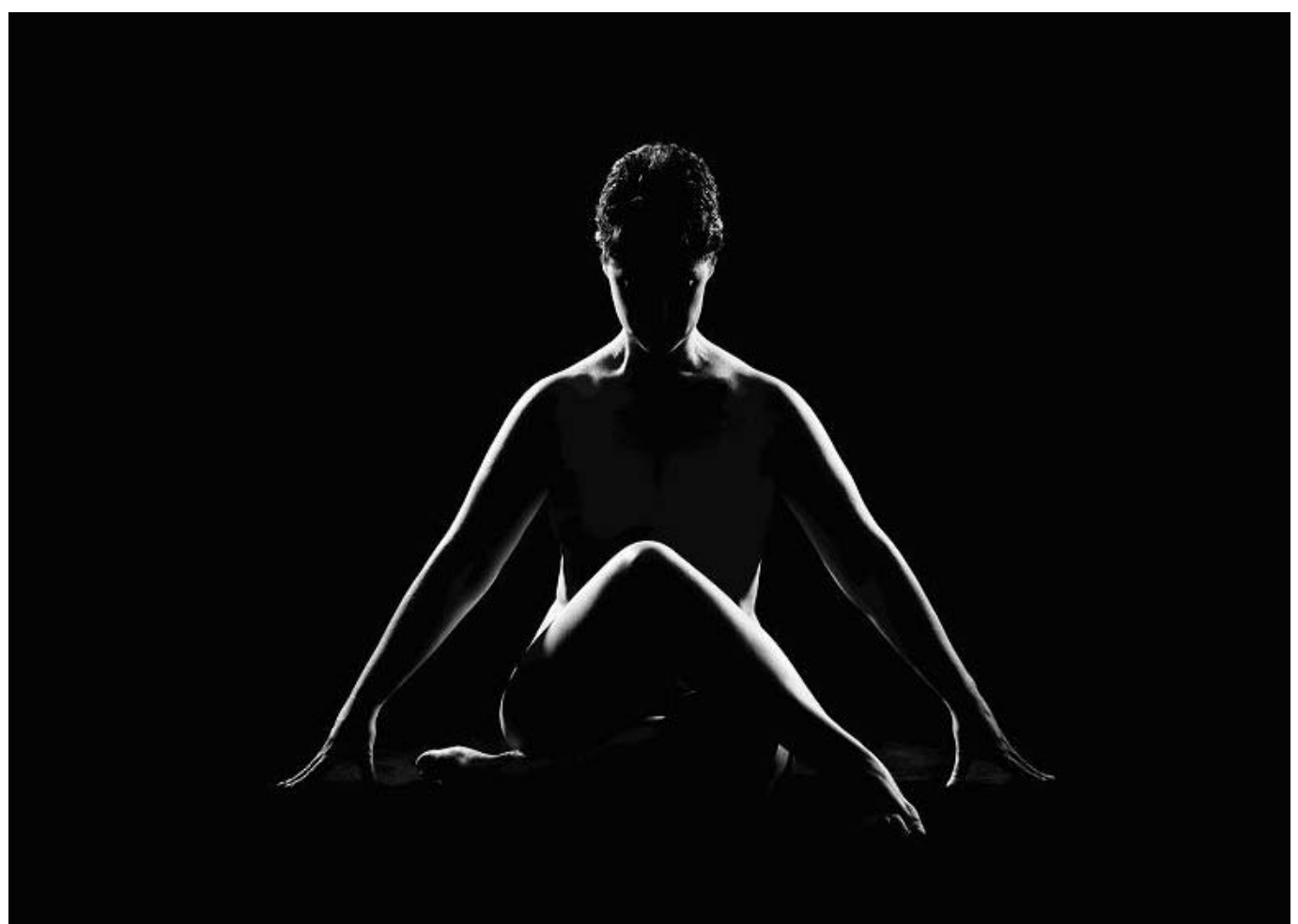

Picture reprinted with the photographer’s permission. Baron PhotoGraphics www.baronphotographics.com

\section{Group Membership and Screening}

The material included in this appendix are subject to copyright and may not be used outright without permission of the author or the author's supervisor (Professor Dawn L. McBride). Please email the author's supervisor at dawn.mcbride@uleth.ca for permission.

The reader may use ideas from this manual providing they are referenced as:

In-text Citation: (Ponech, 2010)

Reference: $\quad$ Ponech, H. (2010). Coming together to calm the hunger. Group therapy program for adults diagnosed with anorexia nervosa. Master of Counselling Project: University of Lethbridge, Alberta, Canada. 


\section{Group Membership and Screening}

\section{Inclusion Criteria}

- Group members must be female and over 18 years of age.

- All group members must meet DSM-IV (American Psychiatric Association, 2000) criteria for anorexia nervosa within the past 12 months.

- Inclusion criteria are motivation toward personal change, absence of severe resistance and denial for 3 to 12 months, medically stable for 6 months, and a desire to meet and help others with anorexia (Lenihan \& Sanders, 1984).

- Assessment measures will be completed in the pre-group meeting as well after the group is over. The Eating Disorder Inventory-3 (EDI)-3 focuses on cognitive and behavioural dimensions that could differentiate subgroups of eating disorders (Garner, 2004). It stipulates that there is a continuum of eating concerns that may begin with mild dieting behaviour and progress to the more serious restrictive and purgative behaviours that meet the diagnostic criteria for eating disorders (Weber, Davis, \& McPhie, 2006). The EDI-3 identifies three eating disorder risk scales: (a) drive for thinness, (b) bulimia, and (c) body dissatisfaction. In addition, there are nine further psychological scales and six composite scales (Weber et al., 2006). Weber et al. postulated that the EDI-3 is a tool sensitive enough to detect change as a result of treatment.

- The other measure is the Eating Disorder Examination (EDE), which is an interviewbased, semi-structured measure that was developed to assess the core symptomatology of eating disorders (Fairburn \& Cooper, 1993). Items on the EDE will be compared to DSM-IV criteria in order to make or rule out an eating disorder diagnosis (O'Brien \& LeBow, 2007). The use of this interview will assist in ensuring that the individuals chosen for this group were, indeed, subclinical in their levels of eating pathology, and will be a powerful adjunct to self-report questionnaire data (O’Brien \& LeBow, 2007).

\section{Exclusion Criteria}

- A group member's inability to commit to change, which would include a commitment to weight restoration.

- Disclosure of current substance abuse use, schizophrenia, or other psychotic disorders.

- Current suicidal ideation or intent (O’Brien \& LeBow, 2007).

- Individuals who are extremely fragmented or acutely psychotic, sociopathic, facing extreme crises, highly paranoid, or extremely self centered (Yalom, 1995). 


\section{Structure and Organization of the Group}

\section{Facilitation Issues}

- Two therapists of mixed gender are required to facilitate this group. Each facilitator is required to have a Master's degree in Counselling Psychology or Social Work and have had experience in working with eating disorder clientele. The facilitators will be required to have training in eating disorders, have a basic understanding of the etiology of this disease, and experience in leading eating disorder groups. Any training qualifications required to administer and interpret the psychometric tests will be completed by the counsellors prior to the start of the group.

- It would be effective if the two facilitators have a balancing style in the approaches. When one embodies patience and support, the other is freed to challenge and confront without risking a member's full retreat (Lenihan \& Sanders, 1984). According to Lenihan and Sanders, as the clients learn to trust both facilitators and relate to the other group members, then they can more safely begin to give up the rigid selfcontrol that has governed their relationships prior to treatment.

- An atmosphere of warmth, support, and genuine human contact will be expected. Both facilitators must be comfortable touching these clients. As Lenihan and Sanders (1984) reported, this is especially important for individuals with anorexia. Acceptable touching would include hand holding, an arm on a group member's back, or a hug if a client provides this permission.

\section{Location and Room Set up}

- The chairs will be arranged in a circle with a blanket/wrap over the back, as research indicated that AN individuals have reduced basal temperatures and intolerance to cold (Nishita, Ellinwood, \& Rockwell, 1985). The beverage station would be in the farthest corner away from the door and would include an assortment of tea, coffee, and cold water. One Kleenex box between two chairs will be set out. Within the room, there will be a projector, whiteboard, flip chart, and a CD player.

\section{Group Member Characteristics}

- This group will have a minimum of seven and a maximum of ten members. The group members must be female and over the age of 18 . They must be able to speak and understand English. There are no cultural limitations of the group membership.

\section{Expectations for Group Members}

- There are rules and guidelines for the group members to adhere to, which are included within the manual. It is expected the group will develop additional group rules during the first session. 


\section{Length}

- This group will run for 12 consecutive weeks. It is suggested that each session be two hours in length. Members will no longer be able to join the week after the first two sessions. If two sessions are missed consecutively, the member will be asked to join the next group offered. The pre- and post-group meeting will commence two weeks prior to, and two weeks after, respectively. It is also encouraged that another group run consecutively after this, which will provide additional support to those who require it.

\section{Learning Diversity}

- Creative arts processes will be a regular feature of this group work, enabling women an alternative means of expression other than cognitive expression, through transference, or their relationship with food and their body (Black, 2003).

- Journaling or voice recording will be utilized as a way to increase the likelihood of the members participating in this activity outside of the group.

- In recognizing that people have different attention spans, the group will have one 10minute break, dyadic exercises, as well as group-building activities.

- The whiteboard, projector, or flip chart will be utilized in conjunction with auditory material to provide alternative learning methods.

\section{Multicultural Diversity}

- Facilitators and group members will seek to understand the worldview of the clients in the group and learn about their clients' cultural backgrounds.

- Facilitators will use a variety of culturally appropriate and relevant interventions, which may include consulting with traditional healers and religious and spiritual healers (Corey, Corey, \& Corey, 2010).

- It is recommended that the facilitators use methods, strategies, and defined goals consistent with the life experiences and cultural values of the group members (Corey et al., 2010).

- The facilitators have a commitment to understand themselves as racial and cultural beings (Corey et al., 2010).

- The facilitators are advised to actively seek out educational experiences that foster their knowledge and skills for facilitating groups across differences (Corey et al., 2010).

\section{Drop out Policy}

- Regular attendance is a requirement. 
- Group members will be asked to contact one of the facilitators if they will be absent from a group meeting.

File Notes

- Session notes will record information for a reasonable expectation of privacy. The following are recommended expectations of note taking are taken from McBride (2009):

1. The records will only contain the information the leaders require and will be written to protect the group member's privacy.

2. Provision of context in the notes, which will be linked to theory.

3. Emotionally neutral record of the group member's behaviour.

4. Notes will be distinguished clearly between observations and interpretations.

5. Notes will avoid the use of client quotations.

6. Group member notes will be completed immediately after the group's session.

7. All contact on behalf of a group member and outside session contact will be recorded.

\section{Preparation and Debriefing Time for Facilitators}

Throughout the duration of the group, the facilitators are encouraged meet one hour prior to the group for preparation and one hour after for note taking and one hour for debriefing. If one or both facilitators feel more time is required under certain circumstances, then the time can be extended. Topics that are encouraged to be discussed during these times include:

1. Ongoing evaluation of the group. Facilitators will make it a practice to devote some time to appraising the direction the group is taking and its level of productivity (Corey et al., 2010).

2. Discussion of techniques and leadership styles of the facilitators (Corey et al., 2010).

3. Discussion of how theoretical orientation applies to the work completed within the group (Corey et al., 2010).

4. Explore transference or counter-transference reactions.

5. Discussion of cultural differences within the group.

\section{Client Measurement and Feedback}

The practice of building evaluation into this program provides for a procedure for accountability purposes, but also help sharpen the leadership skills, enabling facilitators to see more clearly the changes we might want to make in the format for future groups (Corey et al., 2010).

- Member-specific feedback form included in the manual is to be distributed after each session. 
- Group-specific measure feedback form included in the manual is to be distributed after completion of the group.

\section{Supervision}

- It is suggested that facilitators meet with their supervisor for 60 minutes within 24 hours of the ending of the group. It would be beneficial if the supervisor has an extensive background in eating disorders, group work, and supervision.

- Topics that are encouraged to be included in the supervision session include:

(a) a presentation of the narrative of the meeting;

(b) discussion of each client's verbal and non verbal contribution, as well as the facilitator's contribution; and

(c) exploration in depth their counter-transference and realistically based feelings toward each of the members and to each other (Yalom, 1995).

- Supervision will be process focused. 


\section{References and Resources for Group Leaders: Group Membership and Screening}

Black, C. (2003). Creating curative communities: Feminist group work with women with eating issues. Australian Social Work, 56, 127-140. doi:10.1046/j,0312407X.2003.00061.x

Corey, M., Corey, G., \& Corey, C. (2010). Groups: Process and practice (8th ed.). Belmont, CA: Brooks/Cole.

Garner, D. M. (2004). EDI-3, Eating disorder inventory-3: Professional Manual. Odessa, FL: Psychological Assessment Resources.

Fairburn, C. G., \& Cooper, Z. (1993). The eating disorder examination (12th ed.). In C. G. Fairburn \& G. T. Wilson (Eds.), Binge eating: Nature, assessment, and treatment (pp. 317-360). New York: Guilford Press.

Lenihan, G. O., \& Sanders, C. D. (1984). Guidelines for group therapy with eating disorder victims. Journal of Counselling and Development, 63, 252-254. Retrieved from Professional Development Collection database.

McBride. D. (2009). CAAP 6603: Lesson 1 overview [course materials]. Retrieved April 21, 2010, from University of Lethbridge, Campus Alberta Applied Psychology Web site: www.ulethbridge.ca/edu/master-counselling

Nishita, K. J., Ellinwood, E., \& Rockwell, K. W. (1985). Hypothermia in anorexia nervosa: An increase in nonshivering thermogenesis? International Journal of Eating Disorders, 4, 307-319. Retrieved from Academic Search Complete database.

O’Brien, K. M., \& LeBow, M. D. (2007). Reducing maladaptive weight management practices: Developing a psychoeducational intervention program. Eating Behaviors, 8, 195-210. doi:10.1016/j.eatbeh.2006.06.001

Weber, M., Davis, K., \& McPhie, L. (2006). Narrative therapy, eating disorders and groups: Enhancing outcomes in rural NSW. Australian Social Work, 59, 391-405. doi:10.1080/03124070600985970

Yalom, I. D. (1995). The theory and practice of group psychotherapy (4th ed.). New York: Basic Books. 


\section{Adabt Female Anorexia Nervosa Group: Coming Together To Calm the Hanger}

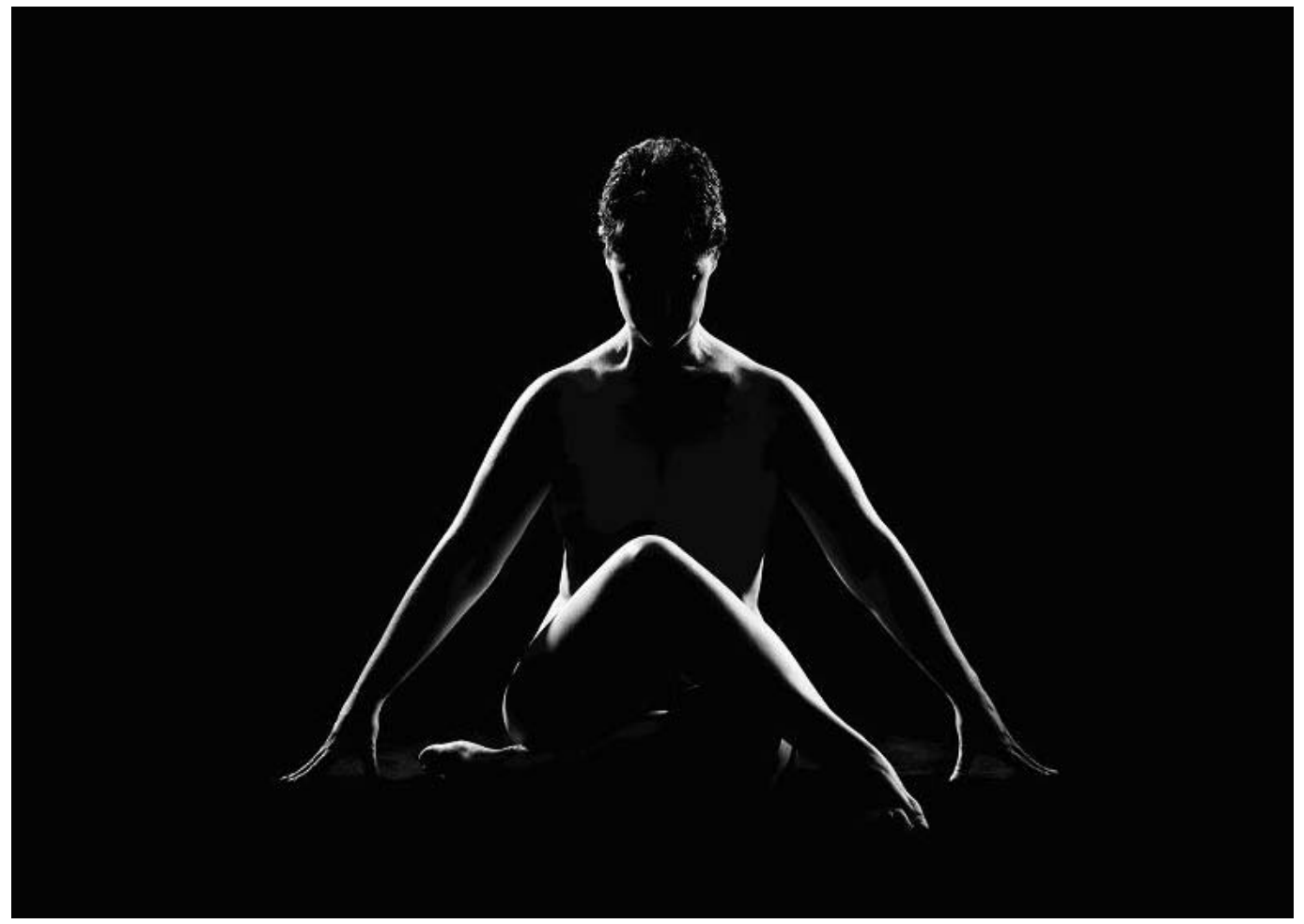

Picture reprinted with the photographer’s permission. Baron PhotoGraphics www.baronphotographics.com

\section{PRE GROUP SESSION}




\section{PRE-GROUP SESSION}

\section{Advance Preparation Required for this Group Session:}

Eating Disorder Inventories:

Pencils

4 Pairs of scissors

8 Journals

Variety of stickers/labels

Construction paper
24 Colourful markers

4 Glue sticks

\section{Important:}

Initial stage of group Bring handouts of group rules/informed consent

\section{Session Length: 2 hours}

Objectives for today's session:

1. Provide structure for the group.

2. Begin to create an atmosphere of cohesion, trust, and safety.

\begin{tabular}{|c|c|c|c|}
\hline $\begin{array}{c}\text { Time } \\
\text { (Minutes) }\end{array}$ & Theme / Goal & Activity & $\begin{array}{l}\text { Brief Instructions I } \\
\text { Notes of Interest I } \\
\text { Handout Material }\end{array}$ \\
\hline 15 & $\begin{array}{l}\text { Introduction and } \\
\text { welcome }\end{array}$ & $\begin{array}{l}\text { Group members state } \\
\text { their name and } \\
\text { something unique or } \\
\text { different about } \\
\text { themselves or a } \\
\text { situation they have } \\
\text { been in. }\end{array}$ & $\begin{array}{l}\text { One facilitator will go first, then } \\
\text { around the circle. } \\
\text { Introduction of facilitators to } \\
\text { the group. }\end{array}$ \\
\hline 20 & $\begin{array}{l}\text { Discussion/process } \\
\text { of group } \\
\text { expectations } \\
\text { (Objective \#1) }\end{array}$ & $\begin{array}{l}\text { Handout \#1 attached. } \\
\text { Encourage the } \\
\text { members to ask } \\
\text { questions as well as } \\
\text { add other guidelines } \\
\text { members may find } \\
\text { suitable. }\end{array}$ & $\begin{array}{l}\text { Encourage } \\
\text { discussion/questions with each } \\
\text { other as well as the facilitators. } \\
\text { Note any additional } \\
\text { expectations the group } \\
\text { developed and let the } \\
\text { members know they will be } \\
\text { provided with an updated copy } \\
\text { at the next meeting. }\end{array}$ \\
\hline 25 & $\begin{array}{l}\text { Discussion/process } \\
\text { of informed consent } \\
\text { (Objective \#1) }\end{array}$ & $\begin{array}{l}\text { Hand out informed } \\
\text { consent; review each } \\
\text { item. Encourage } \\
\text { members to ask } \\
\text { questions. Handout } \\
\# 2, \# 3 \text {, and \#4 } \\
\text { attached. }\end{array}$ & $\begin{array}{l}\text { Link concerns with } \\
\text { confidentiality, risks, and } \\
\text { expectations. How can } \\
\text { members increase the safety } \\
\text { of the group? }\end{array}$ \\
\hline
\end{tabular}




\begin{tabular}{|c|c|c|c|}
\hline $\begin{array}{c}\text { Time } \\
\text { (Minutes) }\end{array}$ & Theme / Goal & Activity & $\begin{array}{l}\text { Brief Instructions I } \\
\text { Notes of Interest I } \\
\text { Handout Material }\end{array}$ \\
\hline 10 & Break & & \\
\hline 25 & $\begin{array}{l}\text { Administer the EDI-3 } \\
\text { (Garner, 2004). }\end{array}$ & $\begin{array}{l}\text { Each member will be } \\
\text { given the self-report } \\
\text { questionnaire to be } \\
\text { completed at their } \\
\text { own pace. Move to } \\
\text { the next activity after } \\
\text { the member has } \\
\text { completed their } \\
\text { assessment. Invite } \\
\text { them to a table that } \\
\text { contains a journal, } \\
\text { markers, stickers, } \\
\text { construction paper, } \\
\text { and scissors. Have } \\
\text { them decorate their } \\
\text { journal that they will } \\
\text { write in when they } \\
\text { choose to. }\end{array}$ & $\begin{array}{l}\text { The members will be } \\
\text { contacted to meet with a } \\
\text { facilitator to discuss the results } \\
\text { as well as complete the EDE } \\
\text { (Fairburn \& Cooper, 1993). }\end{array}$ \\
\hline 20 & $\begin{array}{l}\text { Journal decorating } \\
\text { and homework } \\
\text { assignment }\end{array}$ & $\begin{array}{l}\text { Provide each } \\
\text { member with a } \\
\text { journal and have } \\
\text { them decorate the } \\
\text { cover how they } \\
\text { choose. Provide a } \\
\text { journal, markers, } \\
\text { stickers, construction } \\
\text { paper, and scissors. }\end{array}$ & $\begin{array}{l}\text { Invite members to write in their } \\
\text { journals everyday. } \\
\text { Acknowledge their journals are } \\
\text { private and they can share } \\
\text { anything from their journal at } \\
\text { anytime. }\end{array}$ \\
\hline $5-10$ & Session feedback & $\begin{array}{l}\text { Distribute session } \\
\text { feedback form. }\end{array}$ & $\begin{array}{l}\text { Evaluation of tonight's session. } \\
\text { Feedback from attached: } \\
\text { Handout \#5 }\end{array}$ \\
\hline
\end{tabular}

Sample Debriefing Questions for Facilitators

1. Were there members who each facilitator felt more connected to? not connected with? missed a connection?

2. How did each facilitator feel about the safety of the group?

3. How did we work as a team? How might the group members rate us for team work? 


\section{Facilitators' Reflections on the Lesson Delivery}

1. Did members appear comfortable taking the EDI-3 (Garner, 2004) and if not, would that be better suited before the pre group meeting?

2. How was the time allotment for processing time in comparison to teaching time?

3. How was the level of variety in the lesson for different learning styles? 


\section{Handout \#1: Pre-Group}

\section{Pre group Session: Expectations of Group Members}

1. Please contact one of the therapists prior to the scheduled group time if you are unable to attend a group meeting. This demonstrates respect for the therapists and group members and also allows the therapists to plan the group accordingly.

2. The therapists have scheduled the group to begin at 7:00 pm. Please arrive on time, as we have a short time together, and this allows the group to begin on time with fewer interruptions.

3. Please turn off cell phones and iPods while in group in order to avoid distractions and show respect for the group members.

4. What occurs in this group must remain private and confidential. What each person discloses is not to be shared with anyone outside of the group. The importance of confidentiality will be discussed throughout the group's life. Maintaining confidentiality is essential in the development of feelings of safety and cohesion.

5. Group members control what and how much to disclose to the group.

6. There may be disagreements with group members; however, group members will be treated with respect.

7. If for some reason you will no longer be participating in the group, we ask that you come to the group and say goodbye and receive goodbyes

8. Contact outside the therapy group may occur, and this may effect what occurs in the group. If this happens, we ask that you bring it to the group for discussion.

9. It is important for group members to set guidelines that may be important to them. We will spend time adding to the group rules and etiquette where you see fit. 


\section{Handout \#2: Pre Group}

\section{Pre Group Session: Group Counselling Information Sheet and Consent for Treatment Form \\ Facilitators Name: \\ Date of Group:}

In order to make this experience beneficial to you, we would like to provide you with some information about this group. This information will be discussed with you during the pre-screening process and during the pre-group session. If you have any questions or require further information, please let us know.

\section{What is Group Therapy?}

Group therapy is an excellent treatment choice to grow emotionally, solve personal problems, and for helping people change. This group will provide solutions and strategies that could help you in your recovery from anorexia nervosa. In order for group therapy to be successful, it will require you to take an active role. This includes discussing your concerns and struggles openly, completing assignments, and providing feedback to the therapist's about your progress in the group. We recognize this may be challenging for you, and we are willing to help you take an active role.

\section{Group Leader Information and Qualifications}

This group will be facilitated by two therapists of mixed gender. Each co-leader is required to have a Master's degree in Counselling Psychology or Social Work and has had experience in working with eating disorder clientele. Both leaders have training in eating disorders, have a basic understanding of the etiology of this disease, and experience in leading eating disorder groups. Sub-therapists may be utilized due to illness or emergencies.

\section{Goals and Purpose of the Group}

This group is designed for females over 18 years of age. All group members must meet set criteria for anorexia nervosa within the past 12 months. We require group members to be motivated toward personal change, abstinence of severe resistance, as well as a desire to help others with anorexia. The following are the specific goals of the group:

1. Normalizing and reducing the shame surrounding an eating disorder.

2. Exploring group member's motivation to change.

3. To understand how body distortions maintain an eating disorder.

4. The development of self-care activities that nourish the spirit. 


\section{Sessions}

There are 12 required weekly group therapy sessions.

If you need to miss a session, please contact either co-facilitator ahead of time. If you miss two consecutive sessions, you will be asked to join the next available group because each session builds on the previous session and absences affect group dynamics and cohesion.

\section{Confidentiality and Records}

The importance of confidentiality will be discussed in the first session as well as intermittently throughout the group sessions.

Your personal records will be stored on site in a locked cabinet. You have the right to review your file and request a copy of it. Your records may only be released with your written consent or by a court order.

Group therapy involves sharing sensitive, personal, and private information. Recognizing this, laws and ethical guidelines require that all interactions, including the content of the sessions, your records, attendance, and progress are confidential. Information will not be released without your written permission except in a few circumstances as outlined in the exceptions to confidentiality noted below.

To provide you with the best possible treatment, we may confer with clinical professionals within this counselling centre, including the clinical team and the group leader’s supervisor, Jane Smith, Clinical Psychologist (see consent form: Handout \#3).

The two group leaders may also videotape the group sessions (see consent form: Handout \#4).

The counselling centre is unable to be absolutely certain that the group members will always keep what is said in the group confidential, even though every group member will have agreed to confidentiality, as this is a condition of group membership.

\section{Exceptions to Confidentiality}

We are legally required and/or have a policy to disclose information to relevant authorities/supervisors when we believe we need to:

a. Protect you, someone else, or an animal from imminent danger or a threat of danger.

b. Protect any suspicion of children, the elderly, or dependent adult who are being abused (or at risk of being abused).

c. Respond to a court subpoena.

d. Report physical violence or threatened violence toward your therapists or other group members.

e. Contact someone, on your behalf, in case of a health emergency. 
In any of these situations, the therapists will only reveal the information needed to resolve this immediate crisis or risk of danger.

\section{Freedom to Withdraw from the Group}

Group members have the right to leave the group at anytime. It is requested that you inform the group leaders and the group members before making your final decision by attending your last group. If you do decide to leave the group, the group leaders will discuss the possible risks for choosing to leave the group early.

\section{Being Asked to Leave the Group}

Group leaders reserve the right to ask group members to leave the group. Situations where this might occur include if a member arrives under the influence of a substance or the safety of the individual or group members are at risk.

\section{Risks of Counselling}

Within group therapy, you risk learning things about yourself or your relationships that you may find helpful and not helpful (e.g., you may discover something you do not like about yourself). Often growth cannot occur until you confront issues that cause you to feel sadness, sorrow, anxiety, and pain.

Your therapists will be there to support you as you accept the responsibility for making the choices and changes that are required to achieve your goals. There is also a risk that therapy may not resolve your problem or that group therapy alone may not be sufficient. If this is the case, the therapists will explore alternative plans with you.

Another risk that needs to be stated is the importance of not talking about group members or their stories to others. Even with this very strict rule, The Counselling Centre is unable to be absolutely certain that the group members will always keep what is said in the group confidential even though every group member has agreed to confidentiality.

\section{In Case of Emergency}

Please contact the group leaders if an emergency arises. If you have an emergency after group or when the agency is closed please contact the crisis line at 403-320-1234.

\section{ACKNOWLEDGEMENT/CONSENT FOR TREATMENT:}

I acknowledge that I have read and understand the information described above, and I authorize the Counselling Center to provide for my care. I understand that I may withdraw this consent in writing and terminate treatment at any time.

\section{Print Name:}

\section{Signature:}

\section{Date:}




\section{Handout \#3: Pre-Group}

\section{Pre-Group Session: Consent for Release of Information}

Throughout your group therapy participation, group therapists will be supervised from the Clinical Psychologist, xxxxx. During consultation with the supervisor, your name will not be used and only the necessary information will be discussed.

If you have any concerns with the therapists, you may contact the Clinical Supervisor, $\mathrm{xxx}$ at 403-xxx-Xxxx.

This consent is effective from to or two weeks upon discontinuation of counselling, whichever occurs first.

\section{ACKNOWLEDGEMENT/CONSENT FOR SUPERVISION:}

I acknowledge that I have read and understand the information described above, and I authorize the Counselling Center to provide for my care. I understand that I may withdraw this consent in writing and terminate treatment at any time.

\section{Print Name:}

\section{Signature:}

Date: 


\section{Handout \#4: Pre-Group}

\section{Pre-Group Session: Consent for Videotaping}

The Counselling Centre may make videotape recording of the group sessions. These tapes are used as valuable tools for education, research, and study purposes. We must adhere to very strict rules about the use of recordings, which are outlined below.

WHAT TYPE OF RECORDINGS? Audio taping (voice only), videotaping, or both. Videotaping will record our faces, bodies and voices. If you do not want the front of your body recorded, we can angle the camera so it is not focused on you. You can check at any time to make sure the angle is OK. Note: we are never permitted to take the recordings off site unless you give us written permission to do so. And, the recordings will be securely stored in a locked cabinet onsite.

WHO WILL WATCH THE RECORDINGS? The recordings will be reviewed by your therapists, within 14 days of the recording and then erased. Other people who may view our session recordings to give us feedback on our skills include our supervisor, and if relevant, our peer supervision group at the agency. They will review the full recordings and/or selected segments of a recording. They will be listening/viewing the tape to guide us in how we can work with you in a more successful and valuable way. These people, including ourselves, are bound by a very strict code of ethics to not disclose your name or what you said in session to anyone (unless we are required to do so by law - which is a separate form that you have already signed).

\section{IF I GIVE YOU PERMISSION TO RECORD OUR COUNSELLING SESSIONS, WHAT ARE MY RIGHTS?}

- You have the right to ask us to stop the recording at any time, even in the middle of a session.

- $\quad$ You have the right to ask us to erase or destroy a recording at any time.

- You have the right to withdraw you consent for us to record our session, at any time.

- If you have any concerns or complaints in how I am recording or using the recording, you are welcome to contact my agency supervisor, or the agency's director/manager.

- You have the right to ask to watch or listen to a recording of our sessions before we destroy the recording after 14 days of recording the session. If you make this request, we will discuss how watching or listening to a past session might affect you and we will also have to get feedback from our supervisor.

WHEN WILL THE RECORDINGS BE ERASED/DESTROYED? All recordings will be erased or destroyed within 14 days of being made. Remember, the tapes can never be removed off site and will be securely stored.

Videotape consent form modified by Heather Ponech from Seeking Your Consent To Record Our Sessions, by D. McBride, 2010, Unpublished manuscript, University of Lethbridge, AB, Canada. 
WHAT ARE THE RISKS \& BENEFITS OF RECORDING? Some of the risks might be that you experience nervousness and fear being recorded. You may also find it difficult to share things with us that you might otherwise be ok with, if we were not taping the session. If you like, you are welcome to view or listen to a recording of one of our sessions. However, keep in mind this might be triggering or upsetting to you.

Some of the benefits are that we will likely be able to offer you more effective counselling services because we will be able to receive supervision about how we are working with you. You are also helping us gain competency so I can be of help to other clients. And, if you ever view one of your tapes, you might gain some new information about yourself and/or of the counselling experience. It is important for us to stress that at all times we will always strive to protect the privacy of your recordings.

DO YOU HAVE QUESTIONS? Your questions and comments are welcome about this consent form before you sign and anytime thereafter. You are also welcome to have a copy of this form. The signed copy will be placed in your client file.

Thank you for reading the information so you are clear on why your permission is being sought

and what your rights are around this request. 


\section{GRANTING CONSENT, Part I to V}

Date:

Agency:

Client Name: Therapist's Names:

Part I of V: We, the group therapists, have discussed the issues outlined in this form with the client. Our observations of this person's behavior and responses give us no reason to believe that this person is not fully competent to give informed and willing consent. Further, we agree to fiercely protect the privacy of this client's recordings and to destroy all recordings after 14 days.

Therapist's signatures:

Part II of V: This recording consent form, if signed, will expire on (month, day, \& year) before the above noted expiry date.

or 50 days after the client's last session if this date occurs

Part III of V: I, the client, give my consent for the above therapist's to record my sessions for the strict purpose of supervision, consultation and training, as described above. I am giving recording consent for:

\section{$\square$ Audio taping $\quad \square$ Video taping}

Client initials:

Part IV of V: I, the client, understand I have rights worthy of being protected if I give consent for my sessions to be recorded. Some of these rights I know I have include but are not limited to:

- I have the right to ask my therapist's to stop the recording at any time, even in the middle of a session.

- I have the right to ask my therapist's to erase or destroy a recording at any time.

- I have the right to withdraw my consent for you to record our session, at any time.

- For my therapist's to fiercely protect the security of the session's recordings and that I have the right to say who can watch/listen to the recording.

Client initials: 


\section{Part V of V:}

I, the client, give consent for the following people to view the recordings made of my sessions:

\begin{tabular}{|c|c|c|}
\hline $\begin{array}{c}\text { Therapist's } \\
\text { Supervisor's } \\
\text { Full Name }\end{array}$ & $\begin{array}{c}\text { Full Names of the Therapist's } \\
\text { Peer Supervision Group } \\
\text { Who Will Review Some of the } \\
\text { Recordings at the Agency }\end{array}$ & $\begin{array}{c}\text { Names of the } \\
\text { Therapists/Supervisors } \\
\text { Who Will View } \\
\text { Some of the Recordings at the } \\
\text { Agency }\end{array}$ \\
\hline & & \\
& & \\
& & \\
\end{tabular}

Client initials:

Client's signature acknowledging s/he understands the content in this form including the information listed in Parts II, III, IV \& V:

Client's signature:

Date Signed:

- Copy of this consent provided to the client: $\square$ yes $\square$ no, client declined a copy

- Copy of this consent will be put in the client's file: $\square$ yes 


\section{Handout \#5: Pre-Group Session}

\section{Feedback on the Pre-Group Session}

Please do not record your name. This feedback will help us know what worked and what did not worked for you as a result of attending today's group session.

1. Based on today's Pre-Group Session, how helpful was it for you?
No
A little
Somewhat
Yes

2. In one word, please describe how you felt at the end of this pre-group session.

3. I recognize that I have disordered eating habits.
Yes
Sometimes
Rarely
No

4. I felt the group members were / will be accepting of me.

Yes No

Why or why not?

5. I believe that this group program will help me achieve one or more of my goals for change.

Yes Maybe Doubtful No

6. What did you most like about this session?

7. What did you like least about this session?

Thank you for taking the time to complete this feedback form 


\section{References and Resources for Group Leaders: Pre-Group Session}

Fairburn, C. G., \& Cooper, Z. (1993). The eating disorder examination (12th ed.). In C. G. Fairburn \& G. T. Wilson (Eds.), Binge eating: Nature, assessment, and treatment (pp. 317-360). New York: Guilford Press.

Garner, D. M. (2004). EDI-3, Eating disorder inventory-3: Professional manual. Odessa, FL: Psychological Assessment Resources.

University of Texas Dallas Student Counseling Center. (n.d.). Counseling information and consent for treatment. Retrieved April 21, 2010, from http://www.utdallas.edu/counseling/docs/ConsentForm.pdf 


\section{Adabt Female Anorexia Nervosa Group: Coming Together To Calm the Harger}

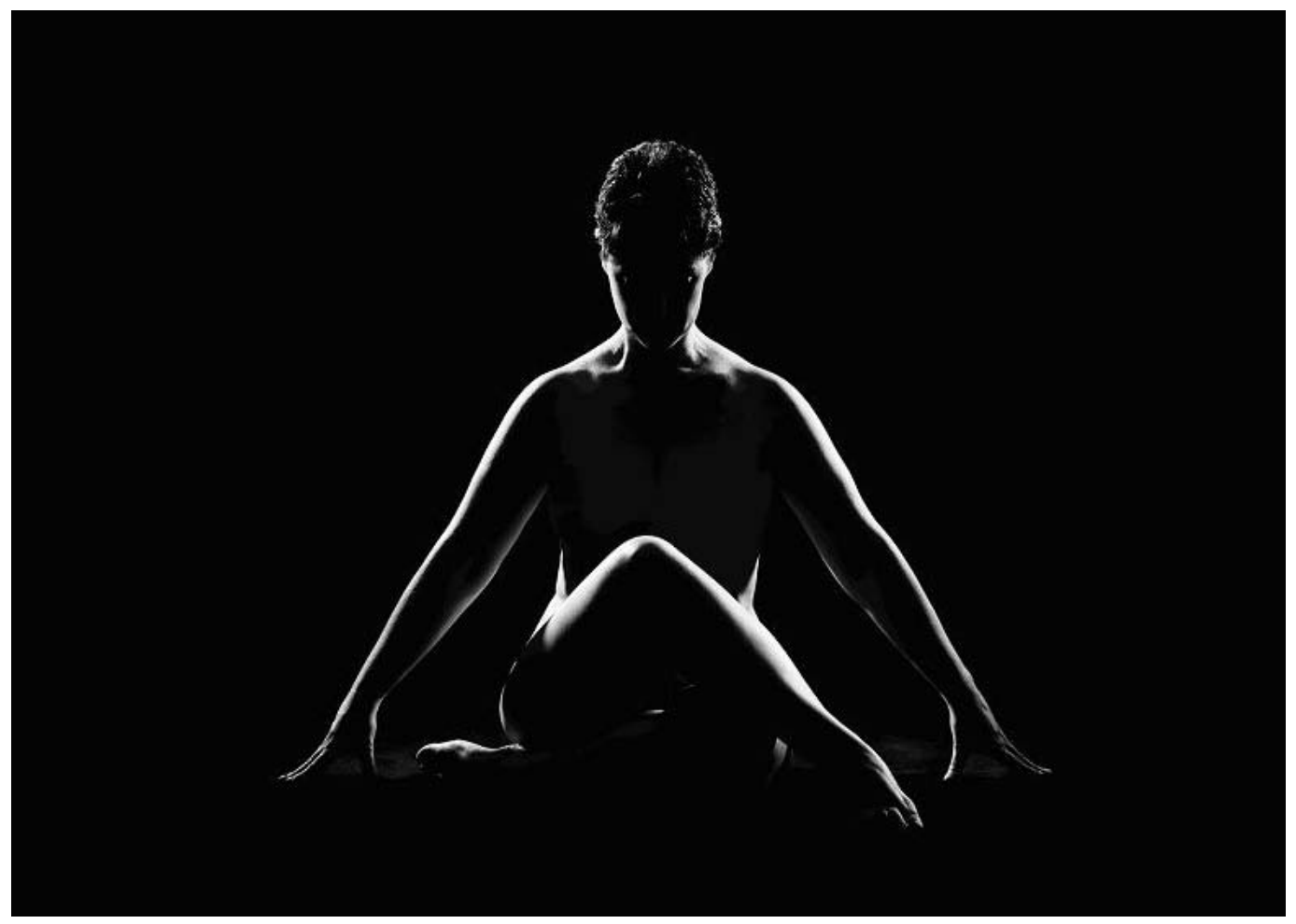

Picture reprinted with the photographer’s permission. Baron PhotoGraphics www.baronphotographics.com

\section{FIRST GROUP SESSION}


LESSON PLAN \#1

\section{Advance Preparation Required for this Group Session: \\ Copies of handouts \\ 4 boxes of Kleenex \\ DVD/Audio copies \\ Paper and pens}

\section{Session Length: 2 hours}

Objectives for today's session:

1. Create a sense of emotional safety within a therapy group.

2. Actively promote discussion of client problems.

3. Create and share personal goals.

4. Examine commonalities and differences in anorexia nervosa (AN) experiences.

\begin{tabular}{|c|l|l|l|}
\hline $\begin{array}{c}\text { Time } \\
\text { (Minutes) }\end{array}$ & Theme / Goal & \multicolumn{1}{|c|}{ Activity } & $\begin{array}{c}\text { Brief Instructions I } \\
\text { Notes of Interest I } \\
\text { Handout Material }\end{array}$ \\
\hline $\mathbf{1 5}$ & Check-in activity & $\begin{array}{l}\text { Check in to help } \\
\text { members identify } \\
\text { feelings. Everyone writes } \\
\text { one fear being involved } \\
\text { in this group. Place in a } \\
\text { box, and each member } \\
\text { then takes one out and } \\
\text { reads it to the group. }\end{array}$ & $\begin{array}{l}\text { - One feeling word describing } \\
\text { how they are feeling today } \\
\text { about the group. } \\
\text { Link common } \\
\text { feelings/themes within the } \\
\text { group. }\end{array}$ \\
\hline $\mathbf{2 0}$ & $\begin{array}{l}\text { Review/process } \\
\text { content from pre- } \\
\text { session } \\
\text { (Objective \#1) }\end{array}$ & $\begin{array}{l}\text { Open discussion in } \\
\text { regards to the pre-group } \\
\text { session. }\end{array}$ & $\begin{array}{l}\text { Review group rules-- } \\
\text { confidentiality, respect, self- } \\
\text { disclosure. Hand out updated } \\
\text { group expectations completed } \\
\text { in the pre-group session. }\end{array}$ \\
\hline $\mathbf{2 0}$ & Activity in dyads & $\begin{array}{l}\text { Let members choose a } \\
\text { partner and identify five } \\
\text { things that are common } \\
\text { and five things that are } \\
\text { different with their AN } \\
\text { experiences. Report one } \\
\text { of each of these back to } \\
\text { the group. }\end{array}$ & $\begin{array}{l}\text { Discussion of similarities/ } \\
\text { differences within the group. }\end{array}$ \\
$\begin{array}{l}\text { Facilitators need to ensure the } \\
\text { discussion does not turn } \\
\text { competitive, etc. }\end{array}$ \\
\hline
\end{tabular}




\begin{tabular}{|c|c|c|c|}
\hline $\begin{array}{c}\text { Time } \\
\text { (Minutes) }\end{array}$ & Theme / Goal & Activity & $\begin{array}{l}\text { Brief Instructions I } \\
\text { Notes of Interest / } \\
\text { Handout Material }\end{array}$ \\
\hline 15 & Break & & \\
\hline 20 & $\begin{array}{l}\text { Process } \\
\text { (Objective \#3) }\end{array}$ & $\begin{array}{l}\text { Invite discussion about } \\
\text { the dyad experience and } \\
\text { commonalities and } \\
\text { differences with their AN } \\
\text { experiences. }\end{array}$ & $\begin{array}{l}\text { Have each member contribute } \\
\text { one commonality and one } \\
\text { difference that were identified } \\
\text { within the dyads. }\end{array}$ \\
\hline 15 & $\begin{array}{l}\text { Goal setting } \\
\text { (Objective \#2) }\end{array}$ & $\begin{array}{l}\text { Discussion of each } \\
\text { member's goals. Start } \\
\text { with one member } \\
\text { acknowledging one of } \\
\text { theirs and continue } \\
\text { around the circle. }\end{array}$ & $\begin{array}{l}\text { Remember: help members } \\
\text { translate vague ideas into } \\
\text { clear and workable personal } \\
\text { goals (Corey, Corey, \& Corey, } \\
\text { 2010). Collaborative process. } \\
\text { Group member's goal setting: } \\
\text { Handout \#1. }\end{array}$ \\
\hline 5 & $\begin{array}{l}\text { Homework } \\
\text { Assignment }\end{array}$ & $\begin{array}{l}\text { Change process balance } \\
\text { sheet and adjust the } \\
\text { rules worksheet } \\
\text { (Fursland, Nathan, } \\
\text { Byrne, \& Lim, 2007) to } \\
\text { be given. }\end{array}$ & $\begin{array}{l}\text { Each member receives a } \\
\text { change process balance } \\
\text { sheet/audio/DVD: Handout } \\
\text { \#2. Identifying the negative } \\
\text { consequences of experiencing } \\
\text { their eating disorder and the } \\
\text { positive consequences of } \\
\text { experiencing their eating } \\
\text { disorder (Fursland et al., } \\
\text { 2007). List the personal } \\
\text { benefits that they expect if } \\
\text { they change themselves and } \\
\text { the personal costs that they } \\
\text { expect if they change } \\
\text { themselves. } \\
\text { Hand out Adjusting the Rules } \\
\text { worksheet/audio/DVD: } \\
\text { Handout \#3, explaining that } \\
\text { challenging their rules and } \\
\text { assumptions for living can be } \\
\text { done in a step-by-step way } \\
\text { (Fursland et al., 2007). }\end{array}$ \\
\hline 5 & $\begin{array}{l}\text { Check-Out } \\
\text { Question }\end{array}$ & $\begin{array}{l}\text { One-word feeling check- } \\
\text { out }\end{array}$ & Popcorn round. \\
\hline 5 & $\begin{array}{l}\text { Session } \\
\text { Feedback }\end{array}$ & $\begin{array}{l}\text { Distribute session } \\
\text { feedback form }\end{array}$ & $\begin{array}{l}\text { Evaluation of tonight's } \\
\text { session. Feedback form } \\
\text { attached: Handout \#4. }\end{array}$ \\
\hline
\end{tabular}


Sample Debriefing Questions for Facilitators:

1. To what extent were the facilitators attuned to the questions and concerns from the group members?

2. Who were the facilitators most aware of in the group tonight? Least aware? Why?

3. To what extent were the facilitators able to share there own reactions and emotional experiences in balanced way?

Facilitators' Reflections on the Lesson Delivery

1. What was the level of involvement by group members? Which activity?

2. How well did the facilitators provide structure, yet encourage, members to accept responsibility?

3. What impressions are we left with regarding members able to actively listen and respond to each other? 


\section{Handout \#1: Lesson 1}

\section{Goal Setting Worksheet}

It is important that you identify your personal goals in group counselling and what actions are required to meet these goals. Please be specific in your goals and if you have any questions, please ask the group members or facilitators during the exercise.

One Meaningful Goal I Have That I am Prepared to Work On During The Next 12 Week Is:

This Goal Is:

๑ Realistic

a Manageable

- Able to be Broken Into Parts

a Achievable

口 Requires at Least 5/10 Energy and Motivation

- Can be Shared in a Public Forum (Group)

What Actions I am Willing to Take to Meet My Goal During the Group/Outside the Group?

1.

2.

3.

What Resources do I Need To Meet My Goal?

1.

2.

3.

Who Can Help Me Reach My Goal?

1.

2.

3. 
Handout \#2: Lesson 1

Change Process Balance Sheet

\begin{tabular}{|c|c|}
\hline $\begin{array}{l}\text { List the negative consequences } \\
\text { of experiencing your eating } \\
\text { disorder. } \\
\text { Think about the difficulties that } \\
\text { you are currently experiencing } \\
\text { such as the inability to } \\
\text { concentrate on anything other } \\
\text { than food and/or weight. }\end{array}$ & $\begin{array}{l}\text { List the positive aspects of } \\
\text { experiencing your current } \\
\text { problem. } \\
\text { There are positive and negatives } \\
\text { about almost every situation. An } \\
\text { example would be using your } \\
\text { eating disorder to avoid } \\
\text { remembering a traumatic event. }\end{array}$ \\
\hline $\begin{array}{l}\text { List the personal benefits that } \\
\text { you expect if you change } \\
\text { yourself. } \\
\text { Think about one of your goals } \\
\text { from the pre-group session and } \\
\text { how you will have to change in } \\
\text { order to achieve it. }\end{array}$ & $\begin{array}{l}\text { List the personal costs that } \\
\text { you expect if you change } \\
\text { yourself. } \\
\text { What do you think you'll need } \\
\text { to give up in order to change? }\end{array}$ \\
\hline
\end{tabular}

Adapted from Overcoming Disordered Eating: Improving Low Self-Esteem, by A. Fursland, S. Byrne, P. Nathan, and L. Lim, 2007, retrieved June 28, 2009, from http://www.cci.health.wa.gov.au/docs/6\%20Improving\%20low\%20self-esteem.pdf 


\section{Handout \#3: Lesson 1}

\section{Adjusting the Rules Information and Worksheet}

Rules and assumptions can be changed. You can work at challenging your rules and assumptions for living in a step-by-step way, using this worksheet.

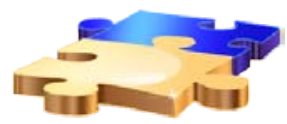

1. Identify any unhelpful rule and/or assumption for living that you would like to challenge.

2. Think about how this rule and/or assumption have impacted your life. Ask yourself: How has this rule affected my relationships, work, or studies, how I take care of myself, or engage in social or leisure activities?

3. Ask yourself how you know when this rule is active in your life. How do you feel? What are the things you do and say (to yourself and others)?

4. Ask yourself, "Where did the rules come from?" It is helpful to understand how the rule developed and what might have kept it going. Unhelpful rules and assumptions may have made sense in the past, and you may have adopted them to cope from dayto-day. However, the rule may not still be relevant now. Ask yourself, "Is this rule still necessary? Is it useful?”

5. Next, ask yourself, "In what ways are this rule and/or assumption unreasonable?" Unhelpful rules and assumptions are inflexible and rigid. You do not have to live according to the rules you made in the past.

6. Although unhelpful rules and assumptions are not beneficial in the long term, there might be certain advantages in living according to these rules. Make a list of these advantages.

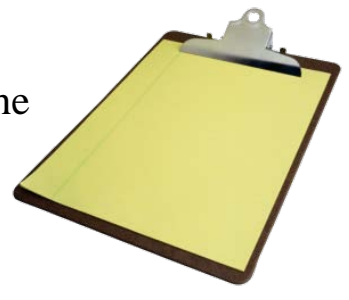


7. What are the disadvantages of living according to this rules and/or assumption? Ask yourself how this rule and/or assumption might limit your opportunities, prevent you from experiencing fun and pleasure, negatively impact your relationships, or prevent you from achieving your goals. Write these down and compare them with the advantages you had identified.

8. Now, think about what might be a more balanced rule and/or assumption? Consider using less extreme terms such as "sometimes," “prefer," "it would be nice if....” Try and put it in practice for a week or so, as you may revise your rules as you become more familiar with the process.

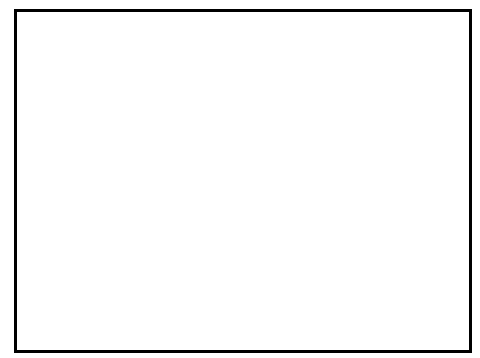


Rule and/or Assumption I would like to Adjust:

What impact has this rule and/or assumption had on my life:

When do I use this rule and/or assumption?

Where did this rule and/or assumption come from?

In what ways are this rule and/or assumption unreasonable to me? 
Advantages of this rule and/or assumption for myself:

Disadvantages of this rule and/or assumption for myself:

What may be an alternative rule and/or assumption that are more balanced and flexible? 


\section{Handout \#4: Group One}

Feedback on the Group One Session Date:

Please do not record your name. This feedback will help us know what worked and what did not worked for you as a result of attending today's group session.

1. Based on today’s Group One session, how helpful was it for you?

No A little Somewhat Yes

2. In one word, please describe how you felt at the end of this Group One session.

3. I recognize that I have disordered eating habits.

Yes Sometimes Rarely No

4. I felt the group members were / will be accepting of me.

Yes No

Why or why not?

5. I believe that this group program will help me achieve one or more of my goals for change.

Yes Maybe Doubtful No

6. What did you most like about this session?

7. What did you like least about this session?

Thank you for taking the time to complete this feedback form 


\section{References and Resources for Group Leaders: Group One Session}

Corey, M., Corey, G., \& Corey, C. (2010). Groups: Process and practice (8th ed.). Belmont: CA: Brooks/Cole.

Fursland, A., Byrne, S., Nathan, P., \& Lim, L. (2007). Overcoming disordered eating: Improving low self-esteem. Retrieved June 28, 2009, from Centre for Clinical Interventions: Psychotherapy, Research, Training Web site: http://www.cci.health.wa.gov.au/docs/6\%20Improving\%20low\%20selfesteem.pdf 


\section{Adabt Female Anorexia Nervosa Group: Coming Together To Calm the Hanger}

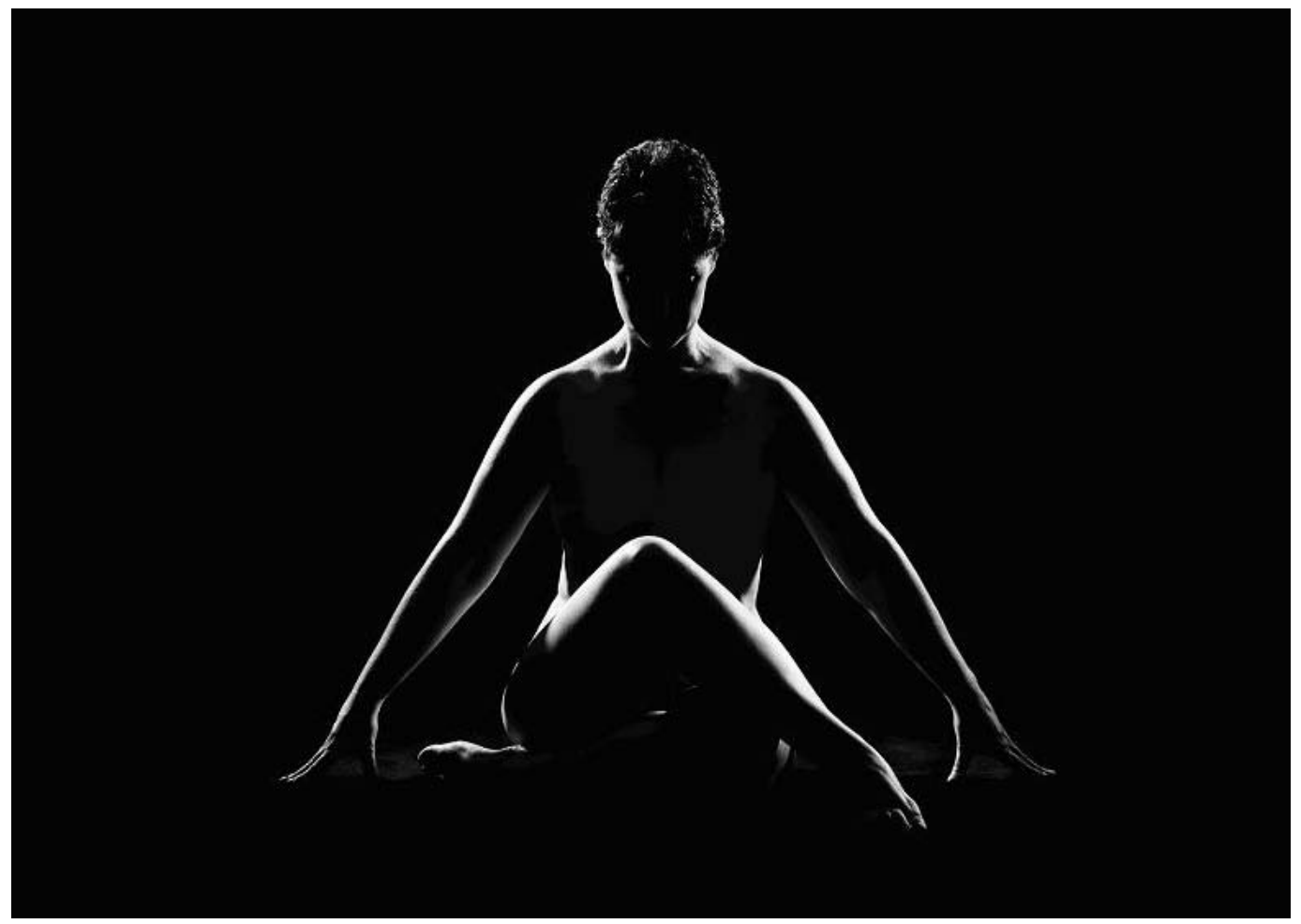

Picture reprinted with the photographer’s permission. Baron PhotoGraphics www.baronphotographics.com

\section{SECOND GROUP SESSION}




\section{LESSON PLAN \#2}

\section{Advance Preparation Required for this Group Session:}

Large paper sheets

4 boxes of Kleenex

20 magazines
4 glue sticks

CD player with music

\section{:}

\section{Important:}

Initial Stage of the

Group. Development of

cohesion, safety, trust, norms, and expectations.

\section{Session Length: 2 hours}

Objectives for today's session:

1. Provide information on the mediating factors co-morbid with AN.

2. Invite group members to examine and explore internalized body images.

3. Provide the opportunity to recognize feelings associated with the body map.

4. Introduce an emotional regulation strategy of journaling.

\begin{tabular}{|c|l|l|l|}
\hline $\begin{array}{c}\text { Time } \\
\text { (Minutes) }\end{array}$ & Theme / Goal & \multicolumn{1}{|c|}{ Activity } & $\begin{array}{l}\text { Brief Instructions I } \\
\text { Notes of Interest I } \\
\text { Handout Material }\end{array}$ \\
\hline $\mathbf{1 0}$ & Activity & $\begin{array}{l}\text { Invite members to } \\
\text { name three television } \\
\text { shows that make } \\
\text { them doubt their body } \\
\text { satisfaction. }\end{array}$ & $\begin{array}{l}\text { Proceed clockwise for the } \\
\text { first question and then } \\
\text { popcorn session for the } \\
\text { second question. }\end{array}$ \\
\hline $\mathbf{1 0 - 1 5}$ & $\begin{array}{l}\text { Review/process } \\
\text { content from session } \\
\text { two and homework } \\
\text { assignments. }\end{array}$ & $\begin{array}{l}\text { Invite members to } \\
\text { discuss thoughts } \\
\text { about last week. }\end{array}$ & $\begin{array}{l}\text { Link concerns of members } \\
\text { as well as encourage } \\
\text { members to be responsible } \\
\text { for what they want to bring } \\
\text { up. Members will be invited } \\
\text { to share their worksheets, } \\
\text { discuss what it was like to } \\
\text { complete them, or what } \\
\text { they learned about } \\
\text { themselves by completing } \\
\text { them. Remind members to } \\
\text { share what they are } \\
\text { comfortable sharing. }\end{array}$ \\
\hline
\end{tabular}




\begin{tabular}{|c|c|c|c|}
\hline $\begin{array}{c}\text { Time } \\
\text { (Minutes) }\end{array}$ & Theme / Goal & Activity & $\begin{array}{l}\text { Brief Instructions I } \\
\text { Notes of Interest I } \\
\text { Handout Material }\end{array}$ \\
\hline 20 & $\begin{array}{l}\text { Discussion of } \\
\text { mediating factors with } \\
\text { AN (see Chapter 2). } \\
\text { Topics include } \\
\text { childhood sexual } \\
\text { abuse, obsessive- } \\
\text { compulsive disorder, } \\
\text { depression, post- } \\
\text { traumatic stress } \\
\text { disorder, and } \\
\text { borderline personality } \\
\text { disorder. }\end{array}$ & $\begin{array}{l}\text { Open discussion on } \\
\text { mediating factors } \\
\text { (Objective \#1). }\end{array}$ & $\begin{array}{l}\text { Each member is provided } \\
\text { with } 5 \text { index cards and } \\
\text { invited to write any } \\
\text { questions they may have in } \\
\text { regards to mediating } \\
\text { factors of AN without } \\
\text { including their name. For } \\
\text { more information on } \\
\text { mediating factors, refer to } \\
\text { Chapter } 2 \text { and the } \\
\text { references and resources } \\
\text { for facilitators at the end of } \\
\text { this lesson. }\end{array}$ \\
\hline 20 & $\begin{array}{l}\text { Recognizing } \\
\text { internalized message } \\
\text { about body image } \\
\text { (Objective \#2) }\end{array}$ & $\begin{array}{l}\text { Body map: Complete } \\
\text { trace of their body } \\
\text { diagram and one of } \\
\text { another group } \\
\text { member. }\end{array}$ & $\begin{array}{l}\text { Facilitator to divide the } \\
\text { group into pairs. Have a } \\
\text { range of colour markers to } \\
\text { choose from. Heightened } \\
\text { awareness of the illness as } \\
\text { lived through the body } \\
\text { offers a way to connect } \\
\text { with members about their } \\
\text { experience of an eating } \\
\text { disorder (Brett-MacLean, } \\
\text { 2009). }\end{array}$ \\
\hline 15 & $\begin{array}{l}\text { Process body map } \\
\text { (Objective \#3) }\end{array}$ & $\begin{array}{l}\text { Discussion of feelings } \\
\text { and thoughts in } \\
\text { completing the map. } \\
\text { Ask what it was like } \\
\text { in completing this } \\
\text { map? }\end{array}$ & $\begin{array}{l}\text { Link similarities and } \\
\text { differences in tracing their } \\
\text { own bodies as well as } \\
\text { others bodies. Were } \\
\text { members able to recognize } \\
\text { their distorted body image? } \\
\text { Encourage feedback from } \\
\text { other group members in } \\
\text { regards to their own and } \\
\text { other member's maps. } \\
\text { Discuss personal space } \\
\text { issues as being the drawer } \\
\text { and drawee. }\end{array}$ \\
\hline 10 & Break & & \\
\hline 20 & $\begin{array}{l}\text { Journal writing, check- } \\
\text { in, and homework } \\
\text { assignment (Objective } \\
\# 4)\end{array}$ & $\begin{array}{l}\text { Open forum in } \\
\text { regards to their } \\
\text { journals. }\end{array}$ & $\begin{array}{l}\text { Homework assignment: } \\
\text { Encourage members to } \\
\text { write down the thoughts } \\
\text { that immediately come to }\end{array}$ \\
\hline
\end{tabular}




\begin{tabular}{|c|l|l|l|}
\hline $\begin{array}{c}\text { Time } \\
\text { (Minutes) }\end{array}$ & Theme / Goal & Activity & $\begin{array}{l}\text { Brief Instructions / } \\
\text { Notes of Interest / } \\
\text { Handout Material }\end{array}$ \\
\hline $\mathbf{1 0}$ & Closing round & Human chain. & $\begin{array}{l}\text { mind when they feel hunger } \\
\text { over the next week. }\end{array}$ \\
& $\begin{array}{l}\text { Have members stand in a } \\
\text { circle and join one hand } \\
\text { with another group member } \\
\text { and the other hand with } \\
\text { another group member. } \\
\text { Have the group try to get } \\
\text { into a circle. } \\
\text { Ensure members know this } \\
\text { is a choice activity given } \\
\text { human contact is required. }\end{array}$ \\
\hline $\mathbf{5}$ & Session feedback & $\begin{array}{l}\text { Distribute session } \\
\text { feedback form }\end{array}$ & $\begin{array}{l}\text { Evaluation of tonight's } \\
\text { session. Feedback form } \\
\text { attached Handout \#1. }\end{array}$ \\
\hline
\end{tabular}

\section{Sample Debriefing Questions for Facilitators:}

1. Is the group working well together? How? How not?

2. What member personalities stand out for the facilitators and how might this impact the group dynamics and the interactions the facilitators have with these individuals?

3. Is there a positive foundation for continuing to build safety and trust? Why or why not? What examples show the facilitators are fostering an environment of safety and trust?

\section{Facilitators' Reflections on the Lesson Delivery:}

1. How was the check-in activity? Did any member include food as their hobby?

2. Is there a time where the group energy was highest and lowest? What triggered this? What role did we (the facilitator) play in this? What did the low energy try to tell us and were we successful in getting the message?

3. Was the human chain activity suitable for closing the session? Why or why not? 


\section{Handout \#1: Group Two}

Feedback on the Group Two Session Date:

Please do not record your name. This feedback will help us know what worked and what did not work for you as a result of attending today's group session.

1. Based on today's Group Two session, how helpful was it for you?

No A little Somewhat Yes

2. In one word, please describe how you felt at the end of this Group Two session.

3. I recognize that I have disordered eating habits.

Yes Sometimes Rarely No

4. I felt the group members were / will be accepting of me.

Yes No

Why or why not?

5. I believe that this group program will help me achieve one or more of my goals for change.

Yes Maybe Doubtful No

6. What did you most like about this session?

7. What did you like least about this session?

Thank you for taking the time to complete this feedback form 


\section{References and Resources for Group Leaders: Group Two Session}

Brett-MacLean, B. (2009). Body mapping: Embodying the self living with HIV/AIDS. Canadian Medical Association Journal, 180, 740-741. doi:10.1503/cmaj.090357

Brewerton, T. D. (2004). Eating disorders, victimization, and comorbidity: Principles of treatment. In T. Brewerton (Ed.), Clinical handbook of eating disorders: An integrated approach (pp. 509-567). New York: Marcel Dekker.

Cachelin, F. M., Schug, R. A., Juarez, L. C., \& Monreal, T. K. (2005). Sexual abuse and eating disorders in a community sample of Mexican American women. Hispanic Journal of Behavioral Sciences, 27, 533-546. doi:10.1177/0739986305279022

Mantero, M., \& Crippa, L. (2002). Eating disorders and chronic post traumatic stress disorder: Issues of psychopathology and comorbidity. European Eating Disorders Review, 10(1), 1-16. doi:10.1002/erv.453

Sansone, R. A., \& Sansone, L. A. (2007). Childhood trauma, borderline personality, and eating disorders: A developmental cascade. Eating Disorders, 15, 333-346. doi:10.1080/10640260701454345

Wu, K. D. (2008). Eating disorders and obsessive-compulsive disorder: A dimensional approach to purported relations. Journal of Anxiety Disorders, 22, 1412-1420. doi:10.1016/j.janxdis.2008.02.003 


\section{Adabt Female Anorexia Nervosa Group: Coming Together To Calm the Hanger}

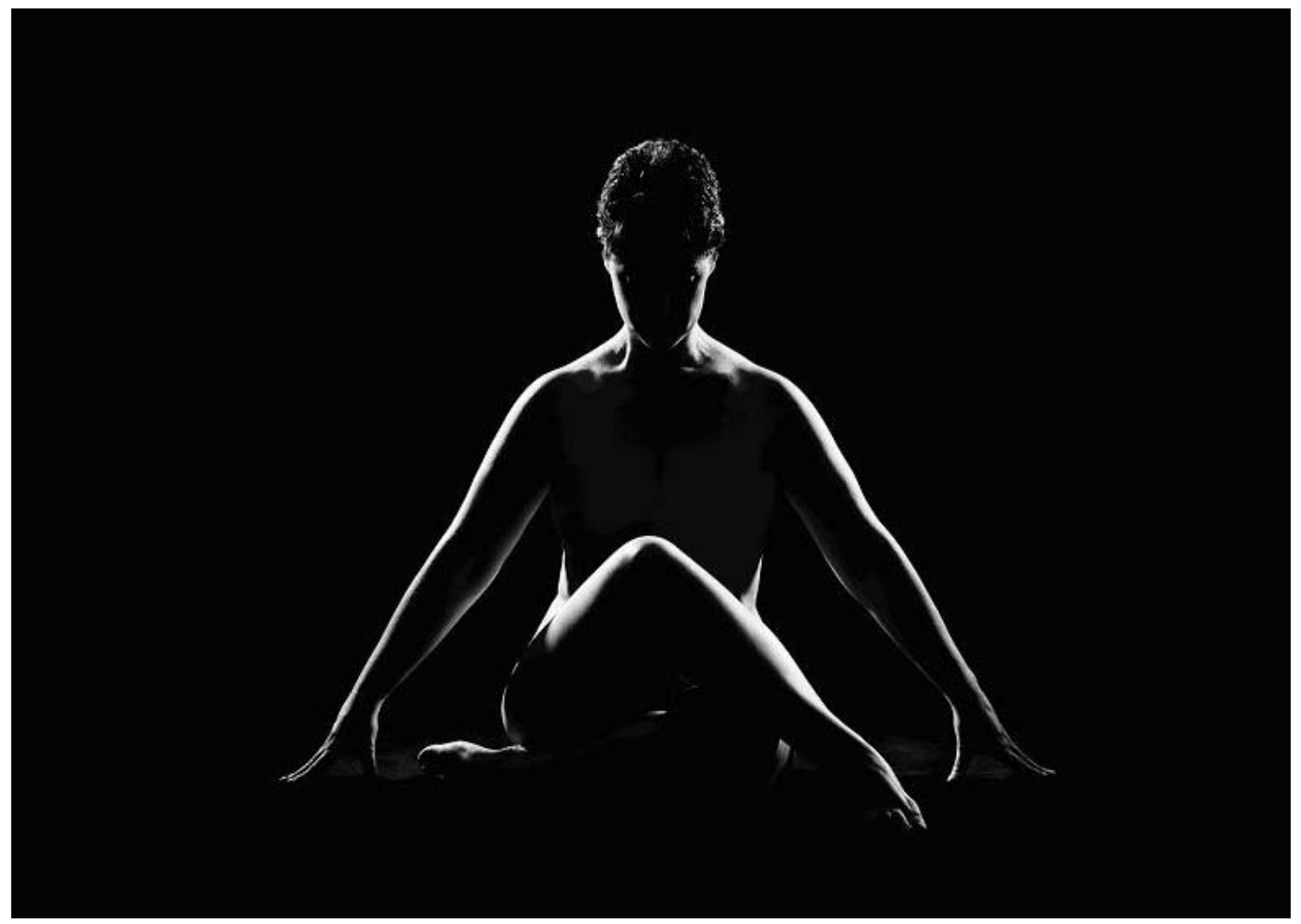

Picture reprinted with the photographer’s permission. Baron PhotoGraphics www.baronphotographics.com

\section{THIRD GROUP SESSION}




\section{LESSON PLAN \#3}

\section{Advance Preparation Required for this Group Session:}

Individual body maps

4 boxes of Kleenex

20 magazines
4 glue sticks

4 pairs of scissors

\section{Important:}

Transition Stage of

Group:

Further trust building

Creating safety

Notice signs of resistance

Deal openly with conflicts

\section{Session Length: 2 hours}

Objectives for today's session:

1. Recognition and discussion of the positive and negative aspects of their eating disorder.

2. To invite group members to recognize the role of control in sustaining their eating disorder.

3. Encourage processing of affect in relation to the positive/negative aspects of their eating disorder and the role of control.

4. Introduction of mindfulness through a description of observing, describing, and participating skills of mindfulness.

\begin{tabular}{|c|l|l|l|}
\hline $\begin{array}{c}\text { Time } \\
\text { (Minutes) }\end{array}$ & Theme / Goal & \multicolumn{1}{|c|}{ Activity } & $\begin{array}{l}\text { Brief Instructions I } \\
\text { Notes of Interest I } \\
\text { Handout Material }\end{array}$ \\
\hline $\mathbf{1 0}$ & Check-in activity & $\begin{array}{l}\text { Members finish the } \\
\text { sentence "One thing I } \\
\text { am looking forward to in } \\
\text { this group experience } \\
\text { and one thing I am not } \\
\text { looking forward to in this } \\
\text { group..." }\end{array}$ & $\begin{array}{l}\text { Link similar/different } \\
\text { motivations of the members. }\end{array}$ \\
\hline $\mathbf{2 5}$ & $\begin{array}{l}\text { Review/process of } \\
\text { content from last } \\
\text { group and the } \\
\text { journaling } \\
\text { homework. }\end{array}$ & $\begin{array}{l}\text { Invite members to } \\
\text { discuss thoughts about } \\
\text { last week and how it } \\
\text { was to complete the } \\
\text { homework. }\end{array}$ & $\begin{array}{l}\text { Lomk concerns of members as } \\
\text { well as encourage members } \\
\text { to be responsible for what } \\
\text { they want to bring up. } \\
\text { Normalizing the thoughts that }\end{array}$ \\
\hline $\mathbf{1 0}$ & $\begin{array}{l}\text { Break } \\
\text { arose from the homework } \\
\text { assignment. }\end{array}$ \\
\hline
\end{tabular}




\begin{tabular}{|c|c|c|c|}
\hline $\begin{array}{l}\text { Time } \\
\text { (Minutes) }\end{array}$ & Theme / Goal & Activity & $\begin{array}{l}\text { Brief Instructions I } \\
\text { Notes of Interest I } \\
\text { Handout Material }\end{array}$ \\
\hline 30 & $\begin{array}{l}\text { Positive/negative } \\
\text { effects of the eating } \\
\text { disorder (Objective } \\
\text { \#1). The role of } \\
\text { control in sustaining } \\
\text { the eating disorder } \\
\text { (Objective \#2). }\end{array}$ & $\begin{array}{l}\text { Collage on the body } \\
\text { map completed in } \\
\text { session two (Delahunt, } \\
\text { 2008). }\end{array}$ & $\begin{array}{l}\text { Hand out magazines, } \\
\text { coloured markers, and glue to } \\
\text { use to place on body map. }\end{array}$ \\
\hline 25 & $\begin{array}{l}\text { Process } \\
\text { (Objective \#3) }\end{array}$ & $\begin{array}{l}\text { Invite members to } \\
\text { discuss their thoughts } \\
\text { and feelings of the } \\
\text { collage }\end{array}$ & $\begin{array}{l}\text { Link common themes and } \\
\text { ideas. } \\
\text { Discussion of } \\
\text { similarities/differences in the } \\
\text { collages. What stood out for } \\
\text { the members in doing this? } \\
\text { How do they understand the } \\
\text { role of control in their lives } \\
\text { and in sustaining their eating } \\
\text { disorder? What did group } \\
\text { members learn? What do they } \\
\text { wish they would have } \\
\text { learned? }\end{array}$ \\
\hline 5 & $\begin{array}{l}\text { Homework } \\
\text { Assignment } \\
\text { (Objective \#4) }\end{array}$ & $\begin{array}{l}\text { Introduction to } \\
\text { mindfulness: } \\
\text { mindfulness skills } \\
\text { practice }\end{array}$ & $\begin{array}{l}\text { Describe observing, } \\
\text { describing, and participating } \\
\text { skills of mindfulness } \\
\text { (Fursland, Byrne, Nathan, } \\
\text { Craigie, \& Lim, 2007). See } \\
\text { facilitator notes: Facilitator } \\
\text { notes \#1. Mindfulness Skills } \\
\text { Practice: Handout \#1. }\end{array}$ \\
\hline 10 & Check-out question & $\begin{array}{l}\text { Members are asked } \\
\text { "Even though we have } \\
\text { been together for only a } \\
\text { short time, what is one } \\
\text { thing you are learning } \\
\text { about yourself?" (Corey, } \\
\text { Corey, Haynes, 2000). }\end{array}$ & $\begin{array}{l}\text { Reflect on what is occurring } \\
\text { within the group (Corey, } \\
\text { Corey, Corey, 2010). }\end{array}$ \\
\hline 5 & Session feedback & $\begin{array}{l}\text { Distribute session } \\
\text { feedback form }\end{array}$ & $\begin{array}{l}\text { Evaluation of tonight's } \\
\text { session. Feedback form } \\
\text { attached: Handout \#2. }\end{array}$ \\
\hline
\end{tabular}


Sample Debriefing Questions for Facilitators:

1. Were conflicts dealt with openly?

2. Were the facilitators supportive when members expressed their anxieties? What can be done to lead to more expression of anxiety?

3. Did the facilitator's body language reflect their verbal language?

4. Which member stands out for each facilitator?

Facilitators' Reflections on the Lesson Delivery

1. Was there enough time in the session for processing the previous session and the activities? Why or why not?

2. How effective was the use of time to do the collage and process the collage?

3. Was the question used at checkout suitable for the stage? Why or why not? 


\section{Facilitator Notes \#1: Lesson 3}

\section{Facilitator Notes for Mindfulness Homework Assignment}

Mindfulness is about living with awareness. It helps one to be aware of what they are doing so that they can change their behaviours. Mindfulness skills involve taking a step back and observing oneself neutrally. Mindfulness involves observing, describing, and participating in a way that is non-judgmental, focusing on one thing at a time, and doing what is effective. These are described in more detail below.

Observing:

Describing:

Participating:
Notice what you are experiencing, without getting caught up in the experience. Just observe and be aware of your feelings and any physical sensations. Imagine your mind as clouds in the sky--feelings and thoughts come (are observed) and the go (fade away).

As you observe your experiences, put words to them. Just notice and describe what is in your thoughts--don't get involved in the content of your thoughts.

When you do something, do it with all your attention. Participate in the activity with awareness. Notice your feelings and any thoughts that come to mind--if your attention strays, then gently bring it back to the task. 


\section{Handout \#1: Lesson 3}

\section{Mindfulness Skills Practice Information and Worksheet}

Practice doing mindful eating for about 5 minutes at a time at first, and then gradually increase to longer periods. It is important to adopt a posture that is relaxed, alert, attentive, and interested. Proceed through the practice in a slow, careful, and gentle manner. Start by just spending a little time bringing your awareness to your posture and your relationship to the food you intend to eat.

After a little time of being aware of your posture, start moving your focus of attention to observing the food. Observe the visual sensations for about a minute or so. Notice the detailed shapes, colours, and textures. Move your focus to particular aspects of the food.

Then move your focus of attention to the qualities of the particular smells. Allow yourself time to be fully aware of the smells that may be there and the detailed sensations in your nose.

If thoughts or particular emotions enter your mind, acknowledge that they are there, and then let them go and return your attention to observing the food and to the experience of smelling the fool

After a while, you may wish to begin describing to yourself some of the more prominent aspects of your experience. For example, if there is some feeling of hunger, you might say to yourself "hunger is here" or "tummy grumbling". See if you can notice these feelings with a gentle curiosity. If you feel a little tense or bored, you might say "tension is here" or "boredom is here". Or if your mind is wandering into thinking about your experience or something else, try to see if you can notice the type of thoughts they are. If they are judging or fantasy thoughts, you might say to yourself "judging" or "fantasizing". Then return back to the observing mode.

When and if you are ready to start eating the food, become aware of your intention to eat the food, the movements for eating, and the tastes and textures in your mouth as you eat. Observe the movements and feelings as you chew and swallow the food, from moment to moment.

Again, if any thoughts or emotions arise while you are eating, you may wish to give them a descriptive name. If there are thoughts, see the thoughts as just thoughts; notice how they will come and go, and then, as best you can, return your awareness to the process of eating. 
When you have spent some time observing and then describing, you can become aware of fully participating in the task of eating. Expand your awareness to experience all the sensations, smells, and movements together as you eat.

Instructions: In the spaces provided below, describe your practice of each of these skills, immediately after a particular meal, with as much detail as possible. Remember to also record the day, date, time, and the meal that you are practicing being mindful of.

Day/Date:

Time:

Activity:

Observing: (What did I notice? How easy was it to remain focused on sensations? What physical sensations were prominent? Did I notice any distractions or mind wandering and if so, what were they?)

Describing: (What things did I describe? Particular types of thoughts, body sensations, emotions?)

Participating: (Did I participate fully in the task? Or, did I go into automatic pilot, become very self-conscious, or wish I was doing something else?) 


\section{Handout \#2: Group Three}

\section{Feedback on the Group Three Session Date:}

Please do not record your name. This feedback will help us know what worked and what did not worked for you as a result of attending today's group session.

1. Based on today's Group Three session, how helpful was it for you?

No A little Somewhat Yes

2. In one word, please describe how you felt at the end of this Group Three session.

3. I recognize that I have disordered eating habits.

Yes Sometimes Rarely No

4. I felt the group members were / will be accepting of me.

Yes No

Why or why not?

5. I believe that this group program will help me achieve one or more of my goals for change.

Yes Maybe Doubtful No

6. What did you most like about this session?

7. What did you like least about this session?

Thank you for taking the time to complete this feedback form 


\section{References and Resources for Group Leaders: Group Three Session}

Corey, G., Corey, M., \& Haynes, R. (2000). Evolution of a group: Student video and workbook. Belmont, CA: Wadsworth Publishing.

Corey, M., Corey, G., \& Corey, C. (2010). Groups: Process and practice (8th ed.). Belmont: CA: Brooks/Cole.

Delahunt, P. (2008). How to make a therapeutic collage: Eating disorders-healing through collage. Retrieved April 21, 2010, from http://eatingdisorders.suite101.com/article.cfm/collage_for_therapy

Fursland, A., Byrne, S., Nathan, P., Craigie, M., \& Lim, L. (2007). Overcoming disordered eating: Moods and disordered eating. Retrieved June 28, 2009, from Centre for Clinical Interventions: Psychotherapy, Research, Training Web site: http://www.cci.health.wa.gov.au/docs/7\%20Moods\%20\&\%20Disordered\%20Eati ng.pdf 


\section{Adalt Female Anorexia Nervosa Group: Coming Together To Calm the Hangers}

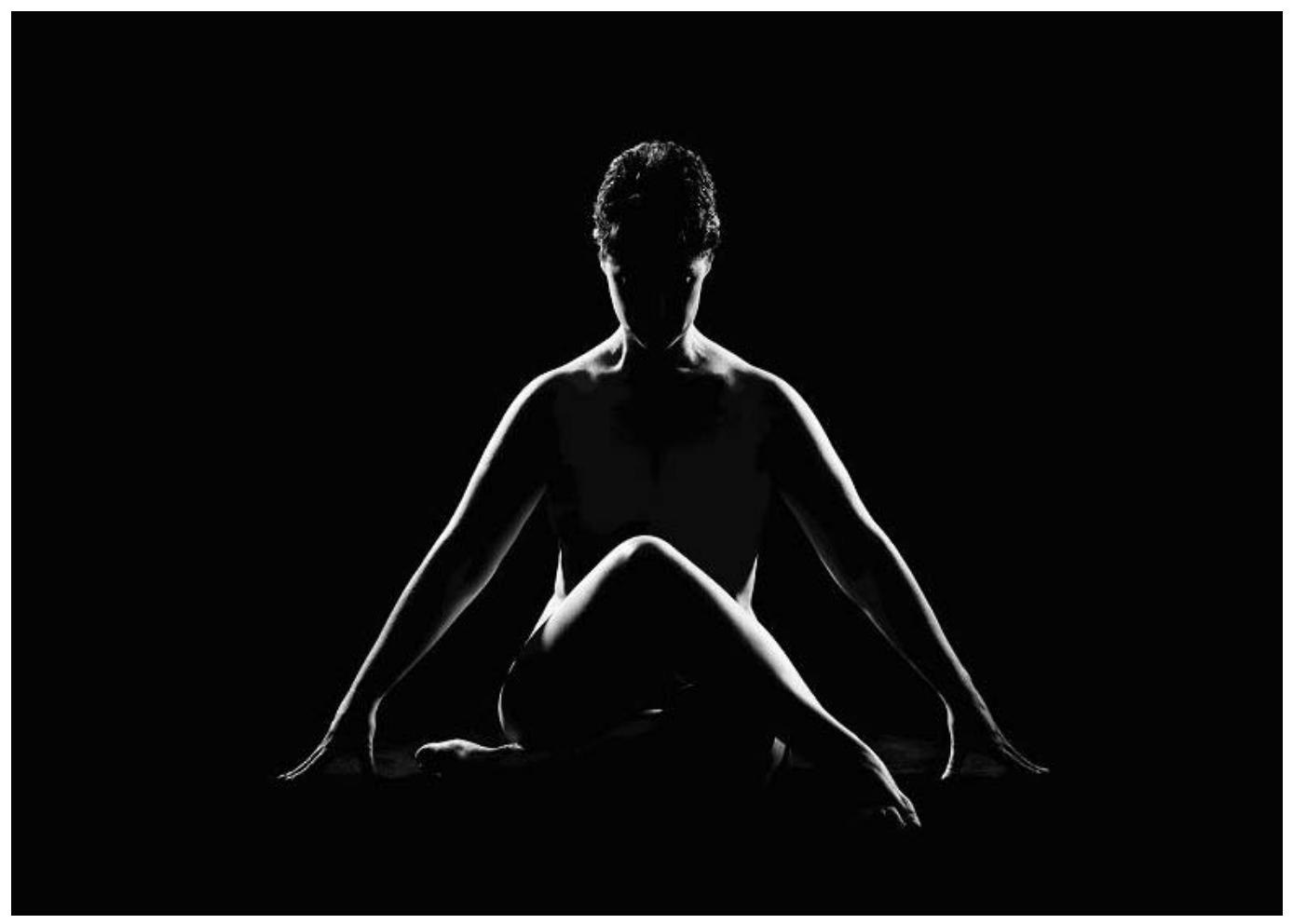

Picture reprinted with the photographer’s permission. Baron PhotoGraphics www.baronphotographics.com

\section{FOURTH GROUP SESSION}


LESSON PLAN \#4

\section{Advance Preparation Required for this Group Session:}

$\begin{array}{ll}4 \text { boxes of Kleenex } & 4 \text { pairs of scissors } \\ \text { Felts } & \text { Full length mirror } \\ \text { Construction paper } & \end{array}$

\section{Important:}

Transition Stage of the

Group

Provide modeling by dealing directly and tactfully with any challenges.

Foster interdependence and independence.

\section{Session Length: 2 hours}

Objectives for today's session:

1. Identify useful components to the mindfulness homework.

2. Investigate member's self-defeating statements.

3. Explore body dissatisfaction through magnifying the dislikes and devaluing the positives.

4. Integrate a disliked body feature into the whole of the body image.

5. Develop a deepening connection to emotions through exploration and inviting the verbalizations of these emotions.

6. Explain the homework of a thought record with the focus on what a hot thought is.

\begin{tabular}{|c|l|l|l|}
$\begin{array}{c}\text { Time } \\
\text { (Minutes) }\end{array}$ & Theme / Goal & \multicolumn{1}{|c|}{ Activity } & \multicolumn{1}{|c|}{$\begin{array}{l}\text { Brief Instructions I } \\
\text { Notes of Interest I } \\
\text { Handout Material }\end{array}$} \\
\hline $\mathbf{5}$ & Check-in activity & $\begin{array}{l}\text { Invite members to use } \\
\text { one word to answer } \\
\text { "This past week was....." }\end{array}$ & $\begin{array}{l}\text { Link similar/different } \\
\text { descriptors of the members. }\end{array}$ \\
\hline $\mathbf{1 0}$ & Warm-up exercise & $\begin{array}{l}\text { Have members stand in } \\
\text { a circle holding hands } \\
\text { and looking at another } \\
\text { group member for three } \\
\text { minutes. }\end{array}$ & $\begin{array}{l}\text { Trust building. } \\
\text { Discuss/process what it was } \\
\text { like participating in this } \\
\text { exercise. } \\
\text { Option to modify participation } \\
\text { given touch is required. }\end{array}$ \\
\hline
\end{tabular}




\begin{tabular}{|c|c|c|c|}
\hline $\begin{array}{c}\text { Time } \\
\text { (Minutes) }\end{array}$ & Theme / Goal & Activity & $\begin{array}{l}\text { Brief Instructions I } \\
\text { Notes of Interest I } \\
\text { Handout Material }\end{array}$ \\
\hline 15 & $\begin{array}{l}\text { Review/process of } \\
\text { content from last } \\
\text { group and the } \\
\text { journaling and } \\
\text { mindfulness } \\
\text { homework }\end{array}$ & $\begin{array}{l}\text { Invite members to } \\
\text { discuss thoughts about } \\
\text { last week and how it was } \\
\text { to complete the } \\
\text { homework. (Objective } \\
\# 1 \text { ). }\end{array}$ & $\begin{array}{l}\text { Link concerns of members as } \\
\text { well as encourage members } \\
\text { to be responsible for what } \\
\text { they want to bring up. } \\
\text { Normalizing the thoughts that } \\
\text { arose from the homework } \\
\text { assignment. }\end{array}$ \\
\hline $\begin{array}{l}40 \\
\text { minutes } \\
\text { and an } \\
\text { additional } \\
10 \text { min } \\
\text { break } \\
\text { needs to } \\
\text { occur at an } \\
\text { appropriat } \\
\text { e point in } \\
\text { this activity }\end{array}$ & $\begin{array}{l}\text { Self-defeating } \\
\text { statements } \\
\text { (Objective \#2) and } \\
\text { confronting the } \\
\text { cognitive distortion } \\
\text { of magnifying the } \\
\text { dislikes while } \\
\text { under- } \\
\text { emphasizing the } \\
\text { likes (Matto, } \\
1997) \text { (Objectives } \\
\# 3 \text { and \#4). }\end{array}$ & $\begin{array}{l}\text { Mirror image and self- } \\
\text { portrait. Members will } \\
\text { look at their bodies in } \\
\text { the mirror and draw a } \\
\text { self-portrait. Have } \\
\text { members write down the } \\
\text { parts of their } \\
\text { appearance that they } \\
\text { are unhappy with and to } \\
\text { put that list in one corner } \\
\text { and then make a list of } \\
\text { at least three things that } \\
\text { they like about their } \\
\text { appearance and put that } \\
\text { list in another corner of } \\
\text { their self-portrait (Matto, } \\
\text { 1997). }\end{array}$ & $\begin{array}{l}\text { Facilitators may need to use } \\
\text { the word 'tolerable' rather } \\
\text { than 'likeable' (Matto, 1997). }\end{array}$ \\
\hline 20 & $\begin{array}{l}\text { Process } \\
\text { (Objective \#5) }\end{array}$ & $\begin{array}{l}\text { Process the activity by } \\
\text { asking questions such } \\
\text { as "What does it feel like } \\
\text { to like a part of your } \\
\text { body?" "What surprised } \\
\text { you about your } \\
\text { likes/dislikes?" "What } \\
\text { stood out to you through } \\
\text { this activity?" "What } \\
\text { does your body need?" }\end{array}$ & $\begin{array}{l}\text { Link common themes and } \\
\text { ideas. } \\
\text { Discussion of } \\
\text { similarities/differences in the } \\
\text { recognition of emotions. What } \\
\text { stood out for the members in } \\
\text { doing this? Developing a } \\
\text { deepening connection to } \\
\text { emotions. }\end{array}$ \\
\hline 5 & $\begin{array}{l}\text { Homework review: } \\
\text { Thought record }\end{array}$ & $\begin{array}{l}\text { Explain thought record } \\
\text { (Greenberger \& } \\
\text { Padesky, 1995) with a } \\
\text { focus on what a hot } \\
\text { thought is (Objective } \\
\# 6) .\end{array}$ & $\begin{array}{l}\text { Thought Record attached: } \\
\text { Handout \#1. }\end{array}$ \\
\hline 10 & $\begin{array}{l}\text { Check-out } \\
\text { question }\end{array}$ & $\begin{array}{l}\text { "What stood out most for } \\
\text { you from tonight's } \\
\text { session" OR } \\
\text { "Was there something }\end{array}$ & $\begin{array}{l}\text { Proceed clockwise for the first } \\
\text { question and then popcorn } \\
\text { session for the second }\end{array}$ \\
\hline
\end{tabular}




\begin{tabular}{|c|c|c|c|}
\hline $\begin{array}{c}\text { Time } \\
\text { (Minutes) }\end{array}$ & Theme / Goal & Activity & $\begin{array}{l}\text { Brief Instructions I } \\
\text { Notes of Interest I } \\
\text { Handout Material }\end{array}$ \\
\hline & & $\begin{array}{l}\text { you wish someone } \\
\text { would have asked you } \\
\text { tonight?" }\end{array}$ & question. \\
\hline 5 & Session feedback & $\begin{array}{l}\text { Distribute session } \\
\text { feedback form. }\end{array}$ & $\begin{array}{l}\text { Evaluation of tonight's } \\
\text { session. Feedback form } \\
\text { attached: Handout \#2. }\end{array}$ \\
\hline
\end{tabular}


Sample Debriefing Questions for Facilitators:

1. How did the group members respond completing the self-portrait?

2. Are there certain members the facilitators want to work with more than others?

3. What were the facilitator's reactions to the self-portrait exercise?

\section{Facilitators' Reflections on the Lesson Delivery:}

1. Have we been able to address individual learning needs? How or how not?

2. Was there enough time allocated to process the self-portrait?

3. Was dividing the thought record into two homework assignments effective and manageable for the members? Why or why not? 
Handout \#1: Lesson 4

Thought Record-Homework Assignment

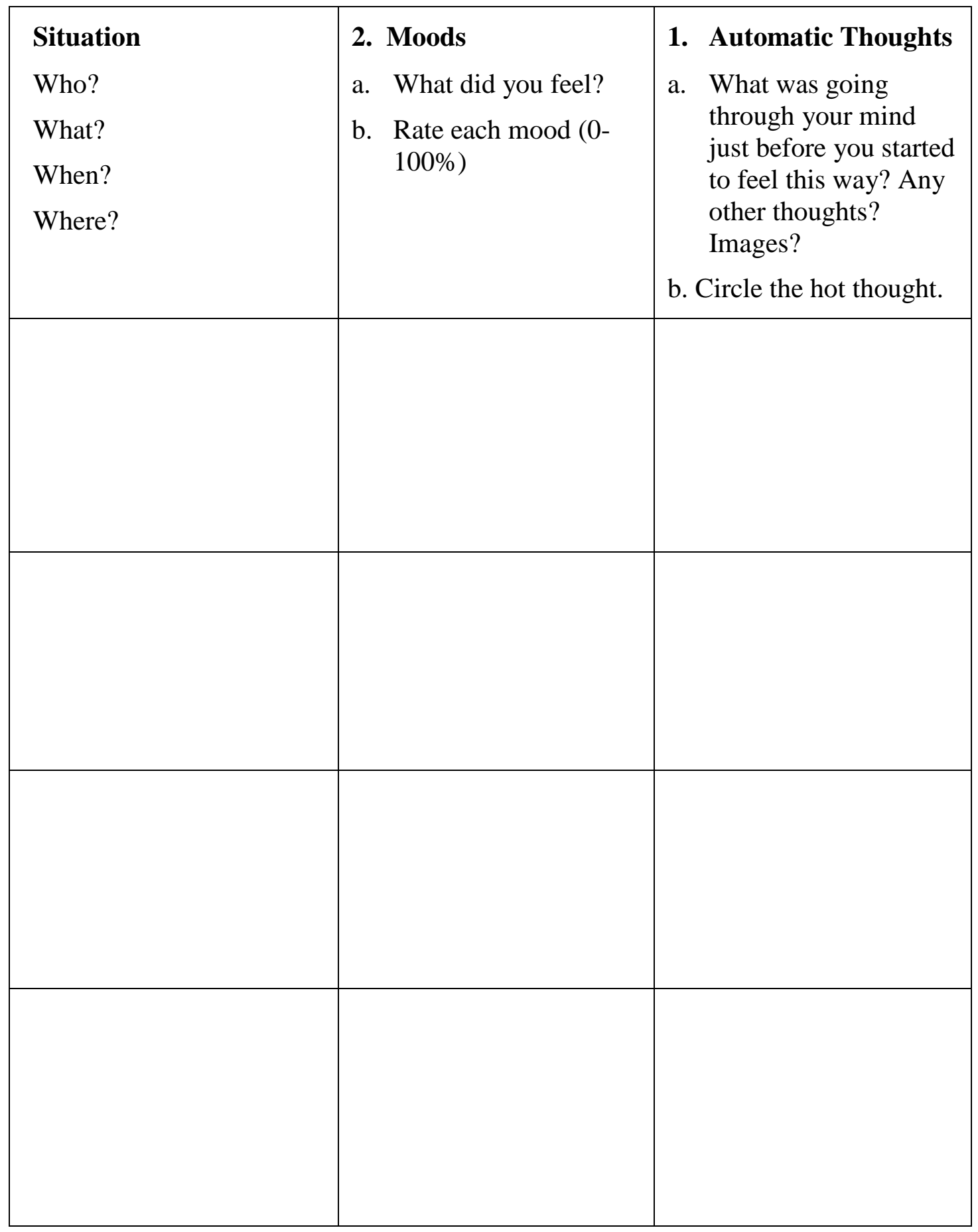




\section{Handout \#2: Group Four}

Feedback on the Group Four Session Date:

Please do not record your name. This feedback will help us know what worked and what did not worked for you as a result of attending today's group session.

1. Based on today’s Group Four session, how helpful was it for you?

No A little Somewhat Yes

2. In one word, please describe how you felt at the end of this Group Four session.

3. I recognize that I have disordered eating habits.

Yes Sometimes Rarely No

4. I felt the group members were / will be accepting of me.

Yes No

Why or why not?

5. I believe that this group program will help me achieve one or more of my goals for change.

Yes Maybe Doubtful No

6. What did you most like about this session?

7. What did you like least about this session?

Thank you for taking the time to complete this feedback form 


\section{References and Resources for Group Leaders: Group Four Session}

Greenberger, D., \& Padesky, C. A. (1995). Mind over mood: Change how you feel by changing the way you think. New York: The Guilford Press.

Matto, H. C. (1997). An integrative approach to the treatment of women with eating disorders. The Arts in Psychotherapy, 24, 347-354. doi:10.1016/S01974556(97)00035-X 


\section{Adalt Female Anorexia Nervosa Group: Coming Together To Calm the Hangers}

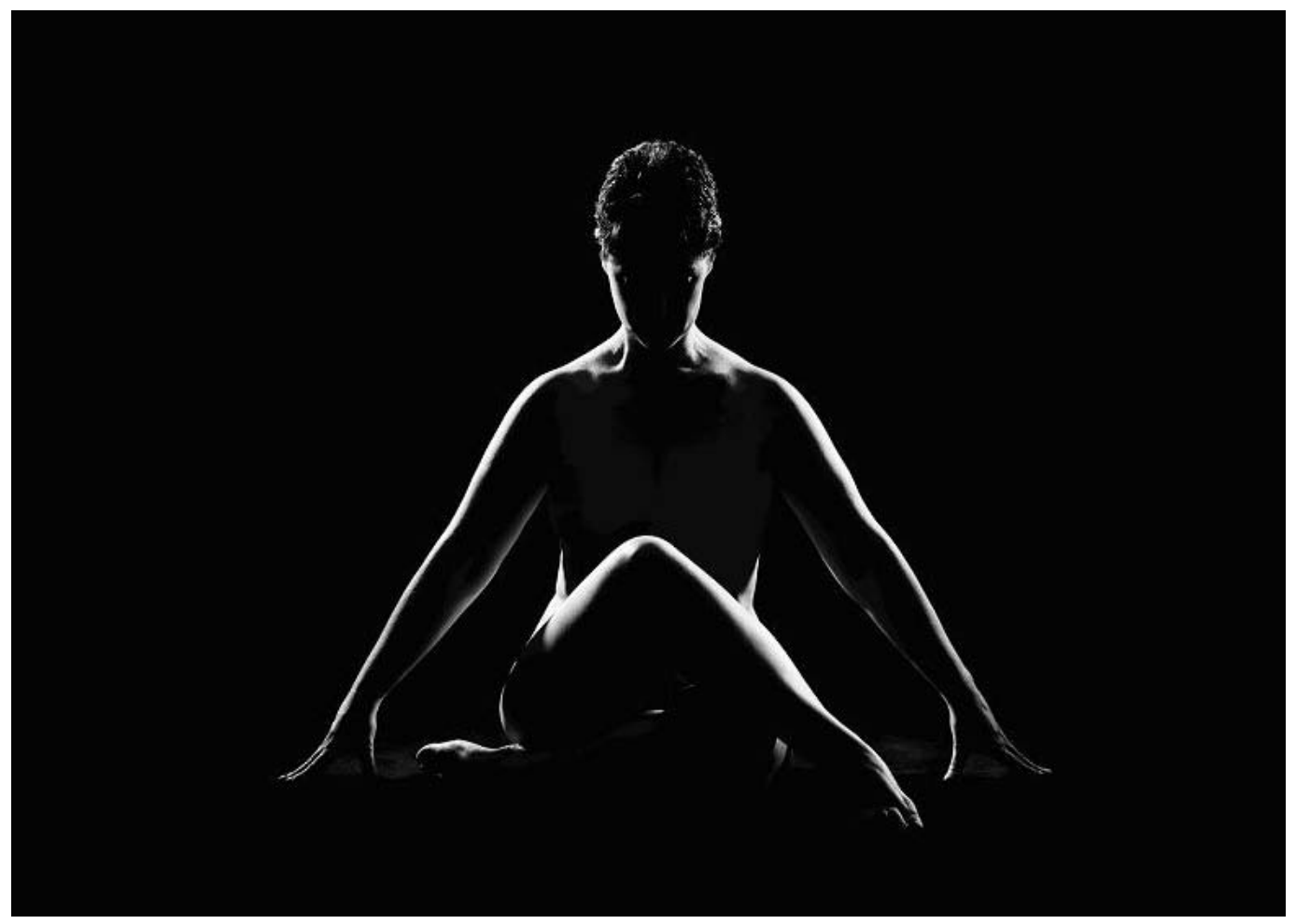

Picture reprinted with the photographer’s permission. Baron PhotoGraphics www.baronphotographics.com

\section{FIFTH GROUP SESSION}


LESSON PLAN \#5

Advance Preparation Required for this Group Session:

4 boxes of Kleenex

Quotes

Drums

\section{Reminder:}

Transition Stage of the Group:

Anxiety will likely be reduced; however defensiveness and reluctant behaviour may develop.

\section{Session Length: 2 hours}

Objectives for today's session:

1. Explore ways to express emotions not using words.

2. Establish interpersonal connections to reduce loneliness.

3. Facilitate emotional regulation activities through experiential activities.

4. Explain the homework of the thought record and the concept of evidence.

\begin{tabular}{|c|c|c|c|}
\hline $\begin{array}{c}\text { Time } \\
\text { (Minutes) }\end{array}$ & Theme / Goal & Activity & $\begin{array}{l}\text { Brief Instructions/ } \\
\text { Notes of Interestl } \\
\text { Handout Material }\end{array}$ \\
\hline 30 & Activity & $\begin{array}{l}\text { Drumming circle } \\
\text { (Objective \#1). }\end{array}$ & $\begin{array}{l}\text { See attached drumming } \\
\text { instructions: Facilitator Notes } \\
\# 1 .\end{array}$ \\
\hline 20 & $\begin{array}{l}\text { Review/process of } \\
\text { content from last } \\
\text { group and the } \\
\text { journaling } \\
\text { homework. }\end{array}$ & $\begin{array}{l}\text { Invite members to } \\
\text { discuss thoughts about } \\
\text { last week and how it } \\
\text { was to complete the } \\
\text { homework. }\end{array}$ & $\begin{array}{l}\text { Link concerns of members as } \\
\text { well as encourage members } \\
\text { to be responsible for what } \\
\text { they want to bring up. } \\
\text { Normalizing of the thoughts } \\
\text { that arose from the homework } \\
\text { assignment. }\end{array}$ \\
\hline 10 & Break & & \\
\hline 20 & $\begin{array}{l}\text { Building emotional } \\
\text { connections } \\
\text { (Objective \#2) }\end{array}$ & $\begin{array}{l}\text { Table will have each } \\
\text { Bone Sigh quote cut, } \\
\text { and each member will } \\
\text { choose which quote } \\
\text { resonated most with } \\
\text { them. }\end{array}$ & $\begin{array}{l}\text { If two or more people choose } \\
\text { one quote, have them sit } \\
\text { beside each other and share } \\
\text { the slip of paper: Facilitator } \\
\text { Notes \#2. Retrieved from } \\
\text { http://www.bonesigharts.com/ }\end{array}$ \\
\hline
\end{tabular}




\begin{tabular}{|c|c|c|c|}
\hline $\begin{array}{c}\text { Time } \\
\text { (Minutes) }\end{array}$ & Theme / Goal & Activity & $\begin{array}{l}\text { Brief Instructions/ } \\
\text { Notes of Interest } \\
\text { Handout Material }\end{array}$ \\
\hline 25 & $\begin{array}{l}\text { Process } \\
\text { (Objective \#3) }\end{array}$ & $\begin{array}{l}\text { Process the activity } \\
\text { using questions such } \\
\text { as: } \\
\text { "What drew you to the } \\
\text { quote?" } \\
\text { "What emotion did you } \\
\text { identify with?" } \\
\text { "What surprised you } \\
\text { about this activity?" } \\
\text { "What did the emotion } \\
\text { say?" }\end{array}$ & $\begin{array}{l}\text { Link common themes and } \\
\text { ideas. } \\
\text { Discussion of similarities/ } \\
\text { differences in the recognition } \\
\text { of emotions. What stood out } \\
\text { for the members in doing this? }\end{array}$ \\
\hline 5 & $\begin{array}{l}\text { Check-out } \\
\text { question }\end{array}$ & $\begin{array}{l}\text { Ask for one word that } \\
\text { describes how the } \\
\text { member is feeling after } \\
\text { tonight's group; popcorn } \\
\text { round. }\end{array}$ & \\
\hline 5 & $\begin{array}{l}\text { Homework: } \\
\text { Continuing the } \\
\text { thought record }\end{array}$ & $\begin{array}{l}\text { Explain the concept of } \\
\text { evidence in the thought } \\
\text { record (Greenberger \& } \\
\text { Padesky, 1995). }\end{array}$ & $\begin{array}{l}\text { Thought Record Homework } \\
\text { sheet attached: Handout } \# 1 .\end{array}$ \\
\hline 5 & Session feedback & $\begin{array}{l}\text { Distribute session } \\
\text { feedback form. }\end{array}$ & $\begin{array}{l}\text { Evaluation of tonight's } \\
\text { session. Feedback form } \\
\text { attached: Handout } \# 2 \text {. }\end{array}$ \\
\hline
\end{tabular}

\section{Sample Debriefing Questions for Facilitators:}

1. Are there any members who are reluctant to participate?

2. What was the level of engagement in choosing a quote that resonated with each member?

3. What emotions surfaced during the drumming circle?

\section{Facilitators' Reflections on the Lesson Delivery:}

1. Based on the feedback we have received, could the facilitators be incorporating the group needs with the lesson plans? How?

2. Was there enough time in the lesson plan to debrief the experience of drumming? What would be a more suitable time frame? 
3. Were there enough quotes and did members find it easy or difficult to choose one? 


\section{Facilitator Notes \#1: Lesson 5}

Title: $\quad$ World Drumming Team-Building Activity (Schmid, 1998).

Rationale: An activity designed to increase a sense of belonging among group members by understanding and demonstrating the value and techniques of cooperative musical teamwork.

General Goal(s): communication, active listening, respect, improvising, and creating.

\begin{tabular}{|c|c|}
\hline $\begin{array}{l}\text { Specific } \\
\text { Goals }\end{array}$ & $\begin{array}{l}\text { - Start developing respect for the instruments and for each } \\
\text { other. } \\
\text { - Listen and respond through echo and question and answer. } \\
\text { - Develop musical teamwork through independent and } \\
\text { interdependent musical performance. } \\
\text { - Develop an understanding of the importance of leaving } \\
\text { - } \quad \text { Democes (silence) for others to drum (speak). } \\
\text { - } \begin{array}{l}\text { and other percussion equipment. } \\
\text { - }\end{array} \text { Iradition. } \\
\text { Improvise drumming patterns which are complementary to } \\
\text { those played by other students. }\end{array}$ \\
\hline
\end{tabular}

Required Materials: Various drums and percussion. CD player and music. Ear plugs for those students who may have sensitive hearing. For students in a wheelchair, a small drum positioned between their legs with the bottom of the drum propped on the footrest of the wheelchair is required. Also a bright piece of cloth placed in the center of the drumhead will aide individuals who have a visual impairment.

Anticipatory Set (Lead-In): Introduce the concept of the drumming circle. A circle is a symbol of equality and respect among cultures such as American Indians, West Coast African Tribes, Australian Aboriginals, and others. 


\begin{tabular}{|c|c|}
\hline $\begin{array}{l}\text { Step-By-Step } \\
\text { Procedures }\end{array}$ & 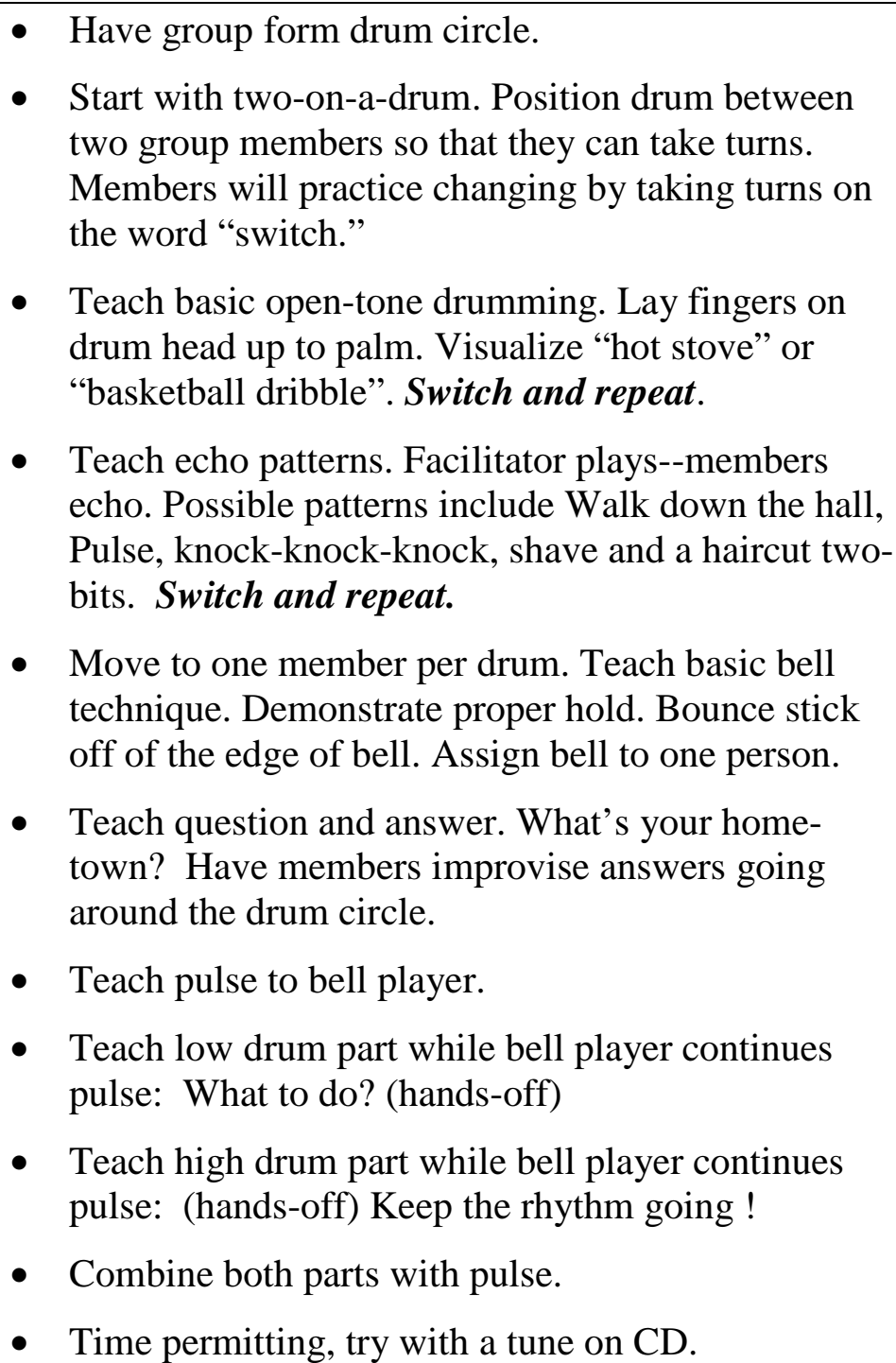 \\
\hline
\end{tabular}

\section{Closure:}

Questions from the Facilitator:

1. What were some thoughts and feelings you had about participating in this drumming circle?

2. Did you learn anything about yourself?

3. What did you like most about it?

4. What did you like least about it? 
Facilitator Notes \#2: Lesson 5

\title{
BONE SIGH QUOTES
}

From http://www.bonesigharts.com/

\section{blame}

\begin{abstract}
"who will take the blame?" she asked. "nobody," he answered "it is too much to carry. leave it behind, and let the wind take it. we have places to go."
\end{abstract}

\section{best parts}

"she let go of the shame and the guilt. seeing that she couldn't have become who she was without those past mistakes. it was time to honor them and thank them, and know that they were some of the best parts of her."

\section{continuing on}

"almost crumbling to the ground, she stopped. looking at how far she had traveled and all it had taken to get there, she recognized her strength. the strengths she had inside of her, the strength she had gained along the way $\sim$ her inner power. and so, she stood up. standing tall, she faced forward and continued on."

\section{discoveries}

"there was no leader. they explored together. asking nothing from each other but honesty, they discovered themselves... they discovered friendship... they discovered real."

\section{dust}

"you are made up of the fabric of the universe. threaded with the very dust of the stars. know it. accept it. and allow it to shine forth." 


\section{enough}

"enough already time to make it what she wanted."

\section{for amy}

"alone and shaking, she wondered how she'd get thru. the doubts surrounded her, keeping her awake. and then she remembered. it's all a ride, a journey, a dream. the twists and turns of which she couldn't even fathom. She closed her eyes and rested. She'd travel where she must. Never knowing where she was going...but knowing it was a ride worth taking."

\section{forever changed}

"maybe some things need to be seen before you know that they're there. but once seen, they are easily felt. and once felt, you are forever changed."

\section{for laura}

"there were no words to take the sorrow away- but there were words to allow the sorrow to be present. and these $i$ offer you, my friend. $i$ will listen as long as you need me to. and hold you longer than you ask. who you are is who i love. we don't need to pretend that it's all okay. all we need to do is be."

\section{for keely}

"there's something inside of you, she said. a flame. a gorgeous flame of light. every action you take affects the flame. some actions make it shine brighter. some make it flicker and dim. and some grow it and make it bigger inside. every moment counts to this flame. every action matters.' she held her face to the girl's and whispered, 'dance with honesty and trust thru your journey, and you will grow your flame. grow your flame, and you will ignite the world." 


\section{forgiveness}

"she reached as deep as she could inside her pain. somewhere in there was a piece of herself she needed to forgive. and only then could her healing be complete."

$$
\text { giving }
$$

"maybe when you really love yourself you can see beyond that self - and then maybe you never give yourself away. maybe you just give."

\section{her beauty}

"i look at her and see beauty, and yet, she's been told she's not beautiful. I watch her and see love, and yet, she's been told she's not lovely. i want to shout to her "you are precious beyond words!" yet i know she can't hear me. and so i won't shout. $i$ will just keep believing in her and reminding her. and wait for her to see it, to hear it, and to know it as deeply as i do."

\section{her angels}

"this was a new twist of the road. such a dark and complicated twist. she could think of only one kind of guide to lead her thru - she called on her angels and leaned heavily on their wings." 


\section{Handout \#1: Lesson 5}

\section{Thought Record-Homework Assignment (continued)}

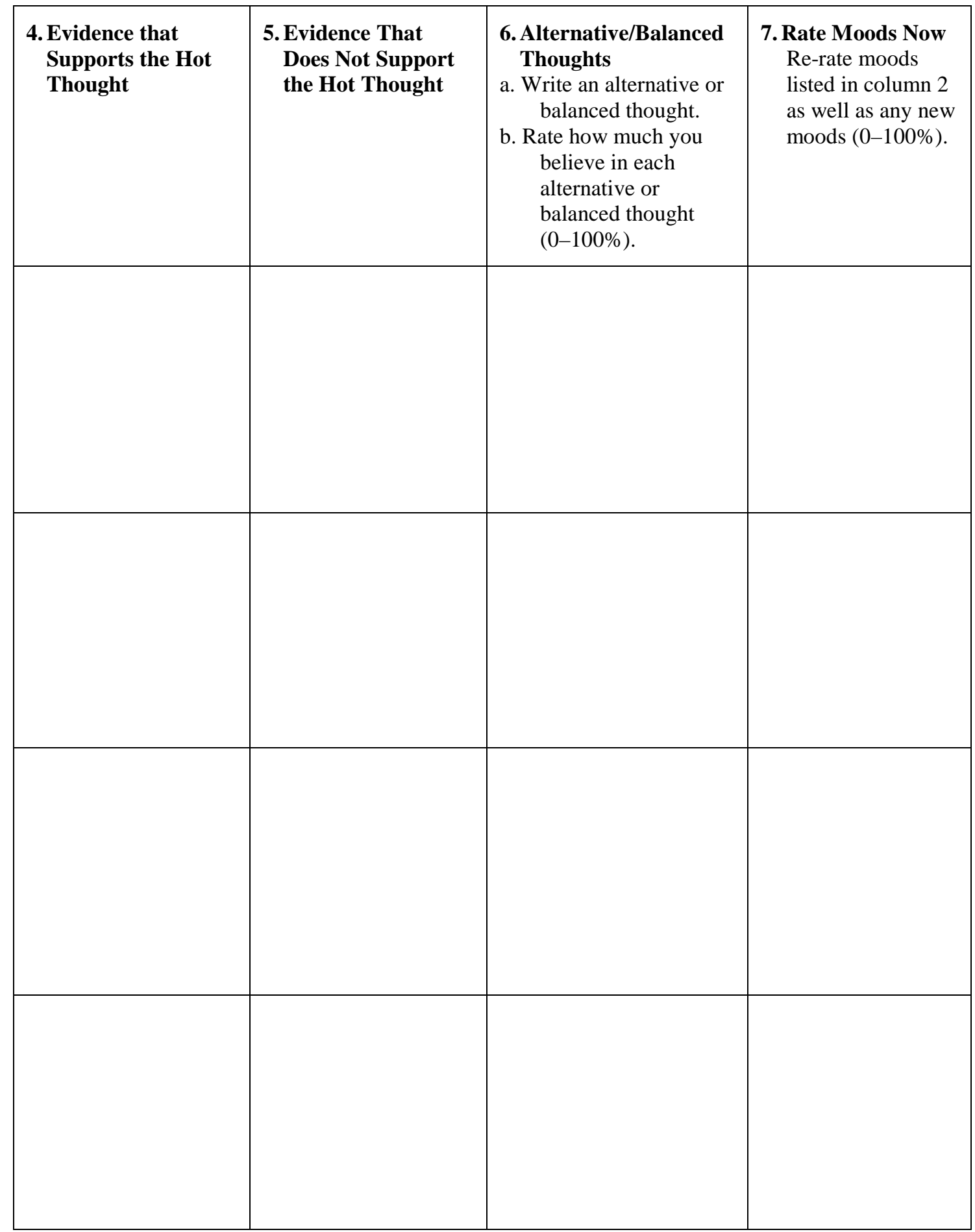




\section{Handout \#2: Group Five Session}

Feedback on the Group Five Session Date:

Please do not record your name. This feedback will help us know what worked and what did not worked for you as a result of attending today's group session.

1. Based on today's Group Five session, how helpful was it for you?

No A little Somewhat Yes

2. In one word, please describe how you felt at the end of this Group Five session.

3. I recognize that I have disordered eating habits.

Yes Sometimes Rarely No

4. I felt the group members were / will be accepting of me.

Yes No

Why or why not?

5. I believe that this group program will help me achieve one or more of my goals for change.

Yes Maybe Doubtful No

6. What did you most like about this session?

7. What did you like least about this session?

Thank you for taking the time to complete this feedback form 


\section{References and Resources for Group Leaders: Group Five Session}

Greenberger, D., \& Padesky, C. A. (1995). Mind over mood: Change how you feel by changing the way you think. New York: The Guilford Press.

Matto, H. C. (1997). An integrative approach to the treatment of women with eating disorders. The Arts in Psychotherapy. 24, 347-354. doi:10.1016/S01974556(97)00035-X

Schmid, W. (1998). World music drumming: A cross-cultural curriculum. Milwaukee, WI: Hal Leonard Corporation.

St. Cloud, T. (2009). Bone sigh arts: Watercolor empowerment. Retrieved October 1, 2009, from http://www.bonesigharts.com/ 


\section{Adalt Female Anorexia Nervosa Group: Coming Together To Calm the Hanger}

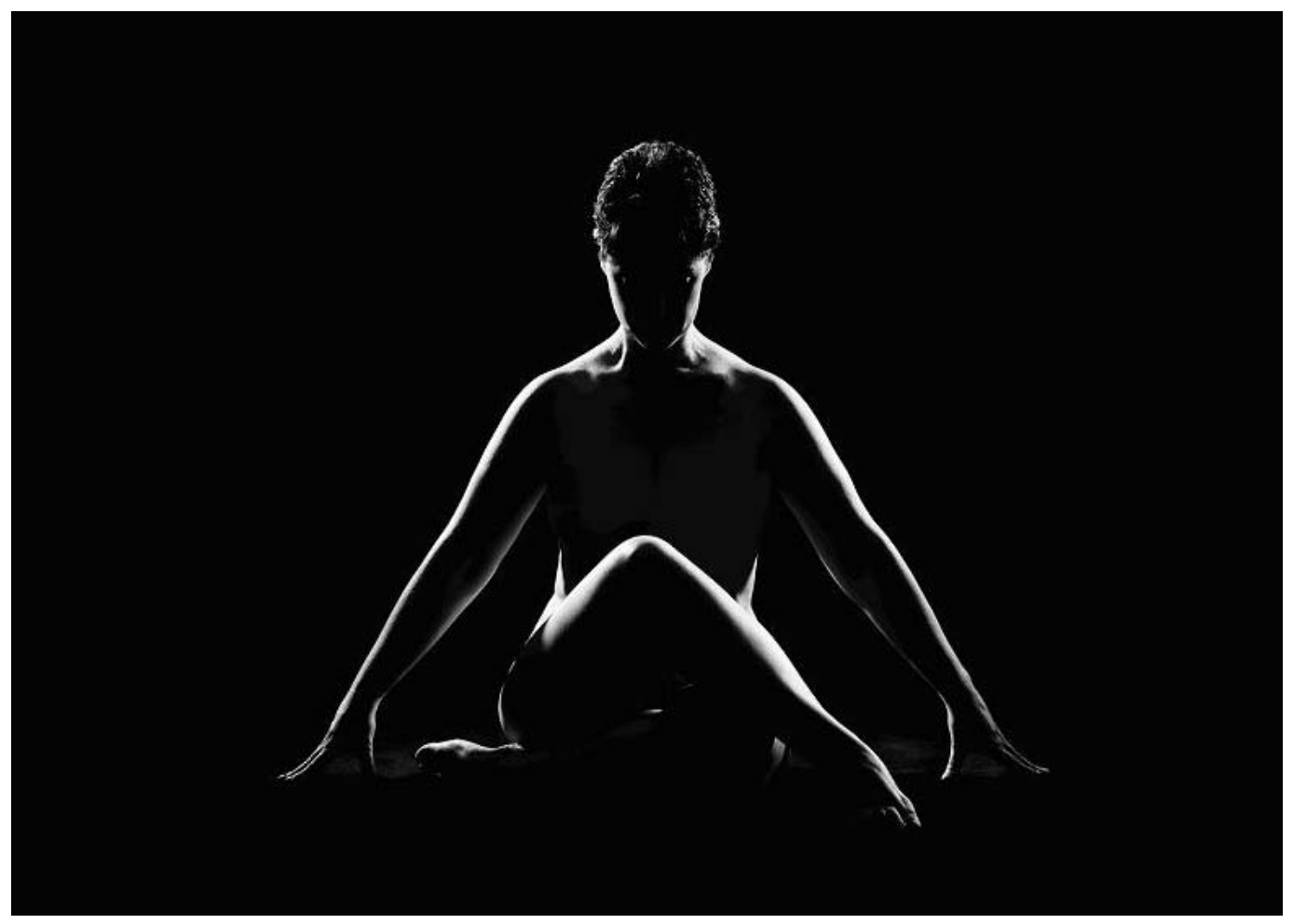

Picture reprinted with the photographer’s permission. Baron PhotoGraphics www.baronphotographics.com

\section{SIXTH GROUP SESSION}




\section{LESSON PLAN \#6}

\section{Advance Preparation Required for this Group Session:}

Cut up plaster gauze

Bowls of water

4 boxes of Kleenex

Paint and brushes

Beads/sequence

10 cameras
Vaseline

Paper

Stickers

Feathers

Felts

\section{Important:}

Reminder that the group is half over.

Working Stage--direct interaction between members. Risk taking, open communication, trust, and cohesion are high.

\section{Session Length: 2 hours}

Objectives for today's session:

1. Explore member's feelings of control and if control may be a factor in their AN behaviours.

2. Identify useful components to the thought record homework.

3. Inquire what the impact of the drumming exercise from Lesson 5 was.

4. Externalize members self and opening a dialogue with the inner self.

\begin{tabular}{|c|c|c|c|}
\hline $\begin{array}{c}\text { Time } \\
\text { (Minutes) }\end{array}$ & Theme / Goal & Activity & $\begin{array}{l}\text { Brief Instructions I } \\
\text { Notes of Interest / } \\
\text { Handout Material }\end{array}$ \\
\hline 10 & Check-in activity & Two-handed drawing & $\begin{array}{l}\text { Divide the group into dyads and } \\
\text { have each pair place their hand } \\
\text { on the same felt and draw } \\
\text { something together without } \\
\text { speaking. }\end{array}$ \\
\hline 15 & $\begin{array}{l}\text { Process check-in } \\
\text { activity (Objective } \\
\# 1) \text {. }\end{array}$ & $\begin{array}{l}\text { Discussion of what it } \\
\text { was like to share control } \\
\text { of something with } \\
\text { someone else and how } \\
\text { this parallels situations } \\
\text { in their own lives. }\end{array}$ & $\begin{array}{l}\text { Link common themes and } \\
\text { ideas. } \\
\text { Discussion of similarities/ } \\
\text { differences in the experience. }\end{array}$ \\
\hline 20 & $\begin{array}{l}\text { Discuss last } \\
\text { week's session } \\
\text { and homework } \\
\text { assignment. }\end{array}$ & $\begin{array}{l}\text { Discussion on the } \\
\text { thought record } \\
\text { homework assignment } \\
\text { (Objective \#2) and last } \\
\text { week's session, } \\
\text { particularly on the use of } \\
\text { drumming to identity } \\
\text { and release feelings } \\
\text { (Objective \#3). }\end{array}$ & $\begin{array}{l}\text { Members will be invited to } \\
\text { share their homework, discuss } \\
\text { what it was like to complete it, } \\
\text { or what they learned about } \\
\text { themselves by completing it. } \\
\text { Remind members to share } \\
\text { what they are comfortable } \\
\text { sharing. }\end{array}$ \\
\hline
\end{tabular}




\begin{tabular}{|c|c|c|c|}
\hline $\begin{array}{c}\text { Time } \\
\text { (Minutes) }\end{array}$ & Theme / Goal & Activity & $\begin{array}{l}\text { Brief Instructions I } \\
\text { Notes of Interest / } \\
\text { Handout Material }\end{array}$ \\
\hline 10 & Break & & \\
\hline 45 & $\begin{array}{l}\text { Externalizing } \\
\text { one's false self } \\
\text { and confronting } \\
\text { dysfunctional } \\
\text { beliefs and } \\
\text { thoughts. Through } \\
\text { confronting one's } \\
\text { false self, one } \\
\text { may inevitable } \\
\text { uncover one's } \\
\text { true self (Matto, } \\
\text { 1997). (Objective } \\
\text { \#4). }\end{array}$ & $\begin{array}{l}\text { Mask-making. In dyads, } \\
\text { members soften plaster } \\
\text { gauze with water and } \\
\text { place on the face. This } \\
\text { is molded to conform to } \\
\text { the facial structures } \\
\text { (Matto, 1997). This } \\
\text { mask will harden in } \\
\text { approximately } 15 \\
\text { minutes. }\end{array}$ & $\begin{array}{l}\text { Important: Allow members to } \\
\text { choose which partner they will } \\
\text { work with. The process of this } \\
\text { technique may be just as } \\
\text { significant as the product itself } \\
\text { (Matto, 1997). Facilitators are } \\
\text { to move around the room } \\
\text { ensuring that safety is } \\
\text { maintained. }\end{array}$ \\
\hline 20 & Process & $\begin{array}{l}\text { Invite members to } \\
\text { discuss their thoughts } \\
\text { and feelings of the } \\
\text { mask-making using } \\
\text { certain questions. } \\
\text { "What is the mask } \\
\text { disguising?" } \\
\text { What is the mask } \\
\text { protecting?" } \\
\text { What feelings are } \\
\text { present?" } \\
\text { "What does the mask } \\
\text { need?" } \\
\text { "What is the mask } \\
\text { asking for?" (Matto, } \\
\text { 1997). }\end{array}$ & $\begin{array}{l}\text { Link common themes and } \\
\text { ideas. } \\
\text { Discussion of similarities/ } \\
\text { differences in the masks. What } \\
\text { stood out for the members in } \\
\text { doing this? }\end{array}$ \\
\hline 10 & $\begin{array}{l}\text { Check-out } \\
\text { question }\end{array}$ & $\begin{array}{l}\text { Invite members to } \\
\text { report, in one sentence } \\
\text { what today was like for } \\
\text { them. }\end{array}$ & Popcorn participation. \\
\hline 5 & $\begin{array}{l}\text { Session feedback } \\
\text { and instructions } \\
\text { for disposable } \\
\text { camera } \\
\text { homework }\end{array}$ & $\begin{array}{l}\text { Distribute session } \\
\text { feedback form } \\
\text { Instruct members to } \\
\text { take pictures with their } \\
\text { camera that they would } \\
\text { describe as 'peaceful' }\end{array}$ & $\begin{array}{l}\text { Evaluation of tonight's session. } \\
\text { Feedback form attached: } \\
\text { Handout \#1. }\end{array}$ \\
\hline
\end{tabular}


Sample Debriefing Questions for Facilitators:

1. What emotions surfaced realizing the group is half completed?

2. Were the facilitators open and honest in regard to their feelings about the half-way point of the group's life?

3. What members stood out for each facilitator during the mask-making? Why?

Facilitators' Reflections on the Lesson Delivery:

1. Was the group stage appropriate for the mask-making? Why or why not?

2. Could the group have used more time to complete the activity or process the activity?

3. What happened during the making of the mask--were group members silent or talkative?

4. How did the group respond to the verbal reminder that the group is half over? 


\section{Handout \#1: Group Six Session}

Feedback on the Group Six Session

Please do not record your name. This feedback will help us know what worked and what did not worked for you as a result of attending today's group session.

1. Based on today's Group Six session, how helpful was it for you?
No
A little
Somewhat
Yes

2. In one word, please describe how you felt at the end of this Group Six session.

3. I recognize that I have disordered eating habits.

Yes Sometimes Rarely No

4. I felt the group members were / will be accepting of me.

Yes No

Why or why not?

5. I believe that this group program will help me achieve one or more of my goals for change.

Yes Maybe Doubtful No

6. What did you most like about this session?

7. What did you like least about this session?

Thank you for taking the time to complete this feedback form 


\section{Adalt Female Anorexia Nervosa Group: Coming Together To Calm the Hanger}

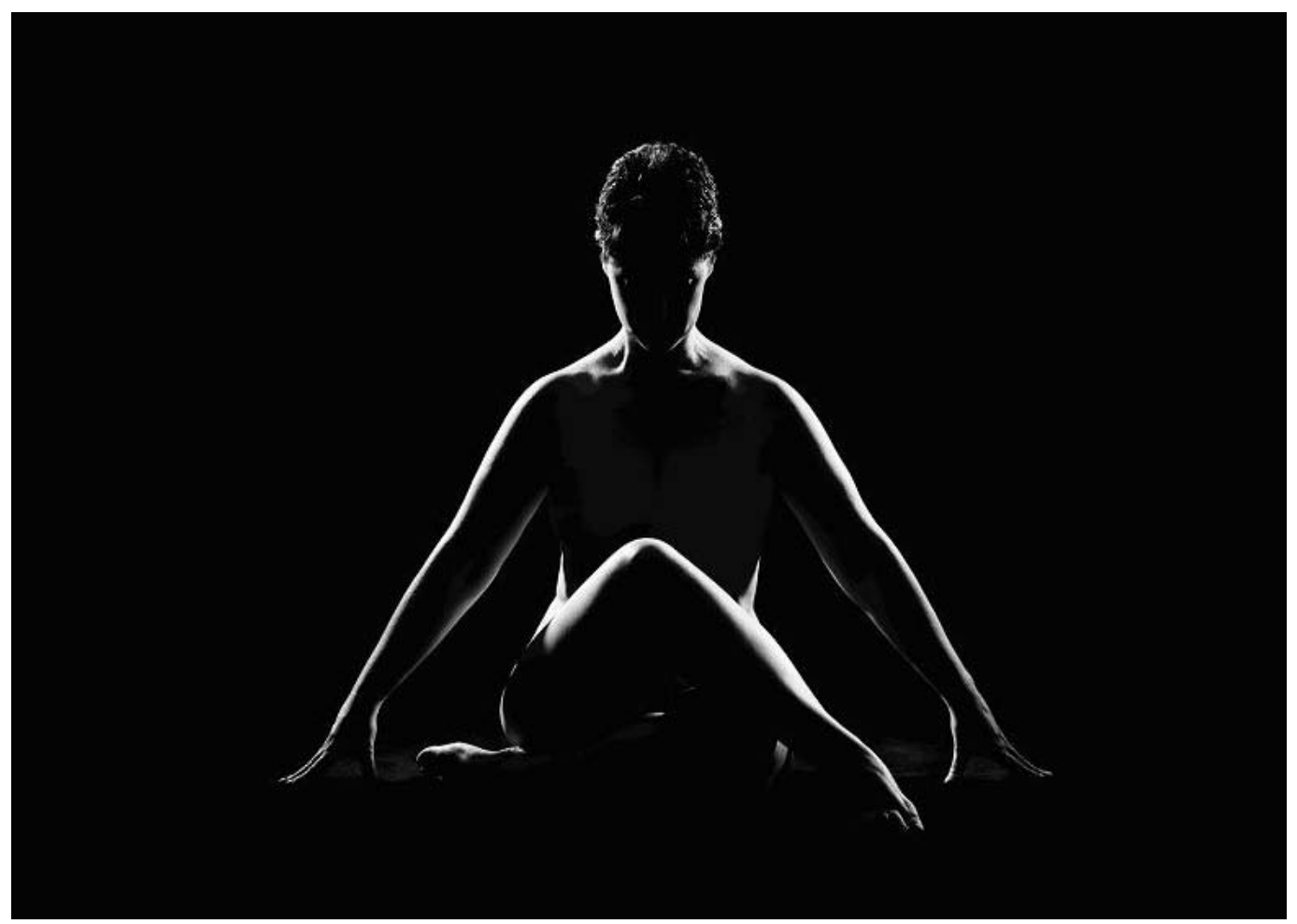

Picture reprinted with the photographer’s permission. Baron PhotoGraphics www.baronphotographics.com SEVENTH GROUP SESSION 


\section{LESSON PLAN \#7}

\section{Advance Preparation Required for this Group Session:}

10 Paint brushes

10 Smocks

10 Pencils

10 cups with water

Package of white paper

\section{Important:}

Collect the disposable cameras from group members.

Working Stage: Communication is clear and direct; feelings of a sense of power with one another; willing to practice new skills and behaviour; and able to assess their level of satisfaction.

\section{Session Length: 2 hours}

Objectives for today's session:

1. Process the emotions and thoughts associated with closure (i.e., group has 6 sessions left).

2. Identify useful components of the picture taking homework.

3. Encourage group members, through processing, to explore and identify their emotions.

\begin{tabular}{|c|c|c|c|}
\hline $\begin{array}{c}\text { Time } \\
\text { (Minutes) }\end{array}$ & Theme / Goal & Activity & $\begin{array}{l}\text { Brief Instructions I } \\
\text { Notes of Interest I } \\
\text { Handout Material }\end{array}$ \\
\hline 10 & $\begin{array}{l}\text { Check-in activity } \\
\text { completed in } \\
\text { pairs }\end{array}$ & $\begin{array}{l}\text { The group is half over-- } \\
\text { invite members to report } \\
\text { on whether their goals } \\
\text { from the beginning of the } \\
\text { group are still the same or } \\
\text { have there been any } \\
\text { changes? }\end{array}$ & $\begin{array}{l}\text { Provide each group member } \\
\text { with pencil and paper to } \\
\text { update their goals. }\end{array}$ \\
\hline 20 & $\begin{array}{l}\text { Process/discuss } \\
\text { the group being } \\
\text { half over } \\
\text { (Objective \#1) } \\
\text { and homework } \\
\text { assignment } \\
\text { (Objective \#2). }\end{array}$ & $\begin{array}{l}\text { Concerns, thoughts, } \\
\text { questions in regards to the } \\
\text { half way point. Also, ask } \\
\text { group members about the } \\
\text { picture-taking homework } \\
\text { assignment, as well as } \\
\text { what other insights have } \\
\text { they gained about their } \\
\text { mask. }\end{array}$ & $\begin{array}{l}\text { Members will be invited to } \\
\text { share their homework } \\
\text { assignment, discuss what it } \\
\text { was like to complete it, or what } \\
\text { they learned about themselves } \\
\text { by completing it. Remind } \\
\text { members to share what they } \\
\text { are comfortable sharing. }\end{array}$ \\
\hline 10 & Break & & \\
\hline
\end{tabular}




\begin{tabular}{|c|c|c|c|}
\hline $\begin{array}{l}\text { Time } \\
\text { (Minutes) }\end{array}$ & Theme / Goal & Activity & $\begin{array}{l}\text { Brief Instructions I } \\
\text { Notes of Interest I } \\
\text { Handout Material }\end{array}$ \\
\hline 35 & Mood/mind states & $\begin{array}{l}\text { Abstractly draw } 12 \text { mood } \\
\text { states. }\end{array}$ & $\begin{array}{l}\text { See facilitator notes for } \\
\text { instructions: Facilitator Notes } \\
\# 1 \text {. }\end{array}$ \\
\hline 30 & $\begin{array}{l}\text { Process in } \\
\text { facilitator chosen } \\
\text { dyads (Objective } \\
\# 3 \text { ). }\end{array}$ & $\begin{array}{l}\text { Dyads place their paintings } \\
\text { together and then separate } \\
\text { them based on what } \\
\text { visually appears to match } \\
\text { each mood/mind state. } \\
\text { Members should end up } \\
\text { with } 12 \mathrm{mood} / \text { mind state } \\
\text { pairs, with two paintings } \\
\text { from each member (Hinz, } \\
2006 \text { ). }\end{array}$ & $\begin{array}{l}\text { Link common themes and } \\
\text { ideas. } \\
\text { Discussion of similarities/ } \\
\text { differences in the paintings. } \\
\text { Processing questions may } \\
\text { include "What emotions were } \\
\text { linked together?" "What did } \\
\text { they learn about themselves?" } \\
\text { "What mood affected them?" } \\
\text { "What mood caused anxiety?" } \\
\text { "What mood were they most } \\
\text { uncomfortable/comfortable } \\
\text { with?" "What does } \\
\text { uncomfortable/comfortable } \\
\text { feel like within their body?" } \\
\text { Discussion of how mind/ mood } \\
\text { states can be confused. } \\
\text { What stood out for the } \\
\text { members in doing this? }\end{array}$ \\
\hline 10 & $\begin{array}{l}\text { Check-Out } \\
\text { question }\end{array}$ & $\begin{array}{l}\text { Ask the group members, } \\
\text { "What would you like to } \\
\text { learn more about and } \\
\text { focus on changing about } \\
\text { yourself in the next six } \\
\text { sessions?" }\end{array}$ & Popcorn participation. \\
\hline 5 & $\begin{array}{l}\text { Session feedback } \\
\text { and instructions } \\
\text { on recognizing } \\
\text { emotions } \\
\text { homework }\end{array}$ & $\begin{array}{l}\text { Distribute session } \\
\text { feedback form. } \\
\text { Homework: Draw/paint } \\
\text { emotions throughout the } \\
\text { week when identified. }\end{array}$ & $\begin{array}{l}\text { Evaluation of tonight's } \\
\text { session. Feedback form } \\
\text { attached: Handout \#1. } \\
\text { Encourage members to } \\
\text { participate in the homework } \\
\text { assignment. }\end{array}$ \\
\hline
\end{tabular}


Sample Debriefing Questions for Facilitators:

1. How did the group respond recognizing the group is half completed?

2. Were the group members able to articulate their goals more effectively than at the beginning of the group?

3. Based on the check out question, how can facilitators aide in this process?

Facilitators' Reflections on the Lesson Delivery:

1. Was there enough time to process the group being half completed?

2. How did the group respond to the art activity?

3. Are the learning styles of the group members reflected in the group thus far? How? 


\section{Facilitator Notes \#1: Lesson 7}

\section{Abstractly Drawing 12 Mood States}

\section{Materials Required}

Three sheets of $12 \times 18$ inch white paper, water-colour paints, paintbrush, water, and pencil. Write out the following words for reference: Angry, Anxious, Calm, Curious, Depressed, Excited, Fearful, Guilty, Happy, Helpless, Innocent, and Sad (Hinz, 2006).

\section{Instructions}

Members sharply crease and gently tear four pieces of paper in to four rectangle sections. When finished, there should be 12 small sheets of paper. Members write the mood or mind state from the list above on one side. These labels will be on the back and, therefore, not seen, and the images will be on the front. Members use colors, shapes, and patterns to abstractly demonstrate each mood or mind state. They state one mind or mood state on each paper, referring to the label not visible on the back. Once finished, there will be 12 separate, small paintings (Hinz, 2006). 


\section{References and Resources for Group Leaders: Group Seven Session}

Hinz, L. D. (2006). Drawing from within: Using art to treat eating disorders. London, UK: Jessica Kingsley. 


\section{Handout \#1: Group Seven Session}

\section{Feedback on the Group Seven Session Date:}

Please do not record your name. This feedback will help us know what worked and what did not worked for you as a result of attending today's group session.

1. Based on today's Group Seven session, how helpful was it for you?

No A little Somewhat $\quad$ Yes

2. In one word, please describe how you felt at the end of this Group Seven session.

3. I recognize that I have disordered eating habits.

Yes Sometimes Rarely No

4. I felt the group members were / will be accepting of me.

Yes No

Why or why not?

5. I believe that this group program will help me achieve one or more of my goals for change.

Yes Maybe Doubtful No

6. What did you most like about this session?

7. What did you like least about this session?

Thank you for taking the time to complete this feedback form 


\section{Adalt Female Anorexia Nervosa Group: Coming Together To Calm the Hanger}

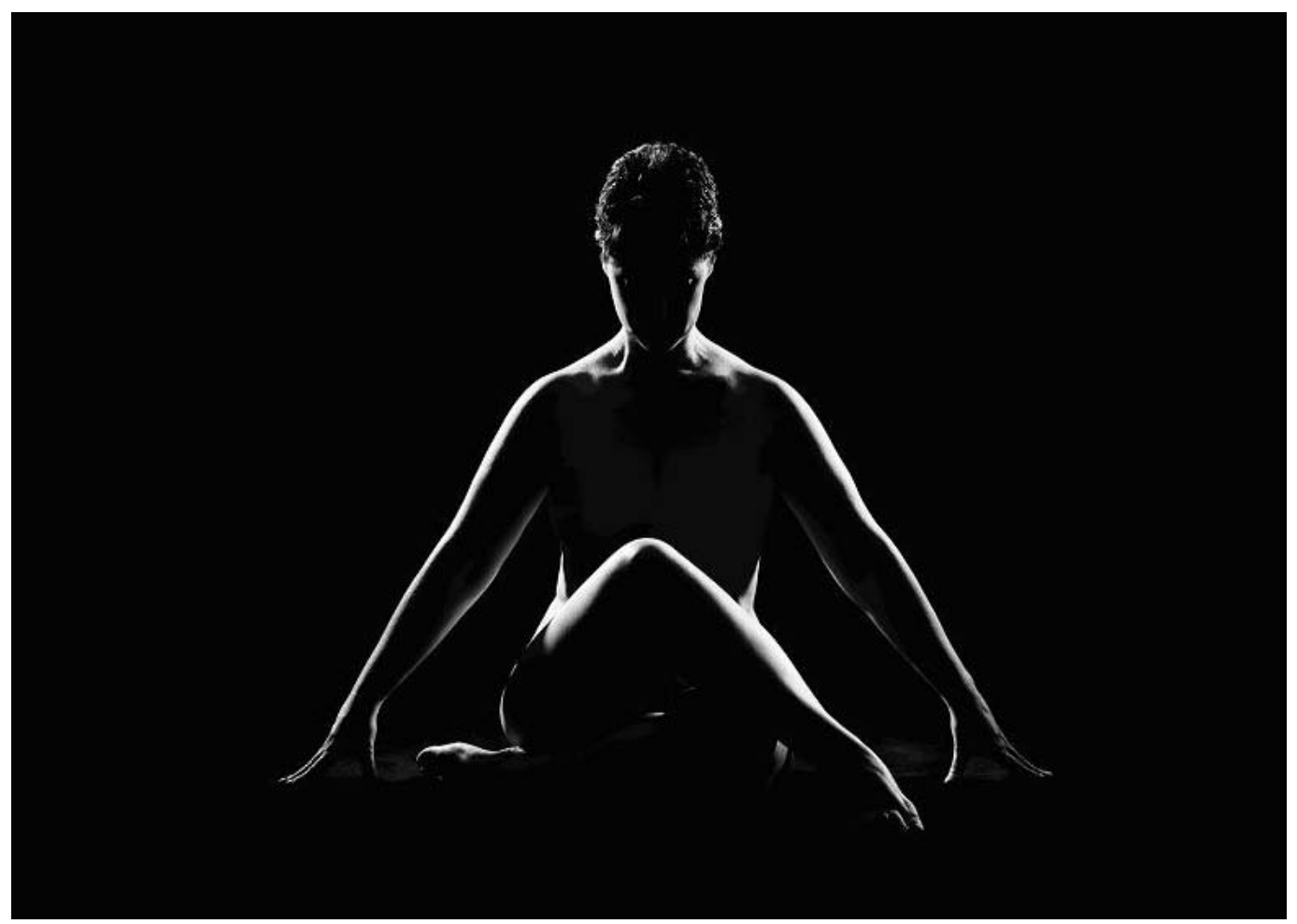

Picture reprinted with the photographer’s permission. Baron PhotoGraphics www.baronphotographics.com

\section{EIGTH GROUP SESSION}




\section{LESSON PLAN \#8}

\section{Advance Preparation Required for this Group Session:}

4 boxes of Kleenex

Pictures developed

\section{Important:}

Working Stage Continued: Interpret the meaning of behaviour patterns at appropriate times so that members will be able to engage in a deeper level of self-exploration and consider alternative behaviours. Support members' willingness to take risks.

\section{Session Length: 2 hours}

Objectives for today's session:

1. Identify the useful components in the homework assignment.

2. Encourage members to explore their experiences of a variety of emotions.

3. Facilitate emotional recognition through experiential activity.

4. Explore, through processing, member's interpretation and feelings of peace.

\begin{tabular}{|c|l|l|l|}
\hline $\begin{array}{c}\text { Time } \\
\text { (Minutes) }\end{array}$ & Theme / Goal & \multicolumn{1}{|c|}{ Activity } & $\begin{array}{l}\text { Brief Instructions I } \\
\text { Notes of Interest I } \\
\text { Handout Material }\end{array}$ \\
\hline $\mathbf{1 0}$ & Check-in activity & Strike a pose. & $\begin{array}{l}\text { Have each member choose an } \\
\text { emotion and display that } \\
\text { emotion through striking a pose } \\
\text { of it. Have the group guess } \\
\text { which emotion they are } \\
\text { showing. }\end{array}$ \\
\hline $\begin{array}{l}\text { 25 } \\
\text { last week's } \\
\text { session and } \\
\text { assignment } \\
\text { (Objective \#1 } \\
\text { and \#2). }\end{array}$ & $\begin{array}{l}\text { Presentation of the } \\
\text { drawing/painting of } \\
\text { emotions identified } \\
\text { throughout the week. }\end{array}$ & $\begin{array}{l}\text { Invite members to show their } \\
\text { homework. Discuss how } \\
\text { emotions may be identified } \\
\text { differently for each member. } \\
\text { Process questions may include } \\
\text { "Are members able to identify a } \\
\text { theme in the drawing/paintings } \\
\text { and the emotions they choose } \\
\text { to draw, and if so, how?" } \\
\text { "How the emotions were } \\
\text { familiar/not familiar?" } \\
\text { "What does the } \\
\text { drawing/painting let them } \\
\text { know?" } \\
\text { "What behaviour/ thoughts/ }\end{array}$ \\
\hline
\end{tabular}




\begin{tabular}{|c|c|c|c|}
\hline $\begin{array}{c}\text { Time } \\
\text { (Minutes) }\end{array}$ & Theme / Goal & Activity & $\begin{array}{l}\text { Brief Instructions I } \\
\text { Notes of Interest / } \\
\text { Handout Material }\end{array}$ \\
\hline & & & $\begin{array}{l}\text { feelings occur when these } \\
\text { emotions surface in their day to } \\
\text { day lives?" }\end{array}$ \\
\hline 10 & Break & & \\
\hline 30 & $\begin{array}{l}\text { Pictures } \\
\text { developed from } \\
\text { each member } \\
\text { (Objective \#3) }\end{array}$ & $\begin{array}{l}\text { Work in dyads; members } \\
\text { discuss each picture } \\
\text { taken. }\end{array}$ & $\begin{array}{l}\text { Facilitators pair group } \\
\text { members. } \\
\text { Instruct members to discuss } \\
\text { similarities and differences in } \\
\text { their pictures of "peace". }\end{array}$ \\
\hline 30 & $\begin{array}{l}\text { Process } \\
\text { (Objective \#4) }\end{array}$ & $\begin{array}{l}\text { Work in groups of four or } \\
\text { five with one facilitator. }\end{array}$ & $\begin{array}{l}\text { Link common themes and } \\
\text { ideas. } \\
\text { Processing questions may } \\
\text { include "What stood out to the } \\
\text { member's from the } \\
\text { assignment?" "What did peace } \\
\text { say?" "How did peace feel } \\
\text { within their bodies?" } \\
\text { "What did they learn about their } \\
\text { visual concept of peace?" "How } \\
\text { can peace be incorporated into } \\
\text { their lives?" "Is peace a familiar } \\
\text { place?" "Would they like it to be } \\
\text { familiar?" }\end{array}$ \\
\hline 10 & $\begin{array}{l}\text { Check-out } \\
\text { question }\end{array}$ & Simon says emotions. & $\begin{array}{l}\text { Have each member state an } \\
\text { emotion for the group to show } \\
\text { by saying Simon says. If the } \\
\text { member does not say Simon } \\
\text { says, instruct the members to } \\
\text { hide the emotion by showing } \\
\text { another one. }\end{array}$ \\
\hline 5 & $\begin{array}{l}\text { Homework } \\
\text { assignment and } \\
\text { session } \\
\text { feedback }\end{array}$ & $\begin{array}{l}\text { Distribute positive } \\
\text { checklist homework. } \\
\text { Distribute session } \\
\text { feedback form. }\end{array}$ & $\begin{array}{l}\text { Positive checklist homework } \\
\text { attached: Handout \#1. } \\
\text { Evaluation of tonight's session. } \\
\text { Feedback form attached: } \\
\text { Handout \#2. }\end{array}$ \\
\hline
\end{tabular}


Sample Debriefing Questions for Facilitators:

1. What was the non-verbal behaviour of the group members during the session on emotions?

2. How did the group respond to taking pictures of peace? Would more choices of what to take a picture of be valuable?

3. Was there a group member the facilitators felt more connected to in this session?

Facilitators' Reflections on the Lesson Delivery:

1. How fitting was the opening and closing activity for the session?

2. Was it effective to work in dyads for discussing the pictures or might this be more beneficial to discuss it as a group? Why or why not?

3. Does the closing activity successfully close the session or is containment an issue? How did facilitators recognize this? 
Handout \#1: Lesson 8

Progress Checklist: Homework Assignment

\begin{tabular}{|c|c|c|c|c|c|}
\hline & No Problem & A Little & Moderate & A Lot & Extreme \\
\hline \multicolumn{6}{|l|}{ Physical Health } \\
\hline $\begin{array}{l}\text { Being underweight } \\
\text { (BMI under 19) }\end{array}$ & O & O & $\mathrm{O}$ & 0 & 0 \\
\hline $\begin{array}{l}\text { Menstruation } \\
\text { (irregular/absent) }\end{array}$ & $\bigcirc$ & $\bigcirc$ & 0 & 0 & $\bigcirc$ \\
\hline $\begin{array}{l}\text { Other Physical } \\
\text { complications }\end{array}$ & $\mathrm{O}$ & O & 0 & $\mathrm{O}$ & O \\
\hline $\begin{array}{l}\text { Disturbed eating } \\
\text { habits and weight } \\
\text { control behaviours }\end{array}$ & $\mathrm{O}$ & O & $\mathrm{O}$ & $\mathrm{O}$ & $\mathrm{O}$ \\
\hline $\begin{array}{l}\text { Misuse of } \\
\text { laxatives/diuretics }\end{array}$ & 0 & O & O & O & O \\
\hline Over-exercising & $\mathrm{O}$ & O & $\mathrm{O}$ & 0 & $\mathrm{O}$ \\
\hline Irregular eating & 0 & 0 & 0 & 0 & 0 \\
\hline $\begin{array}{l}\text { Low variety of } \\
\text { foods }\end{array}$ & $\mathrm{O}$ & O & O & ○ & O \\
\hline Undereating & O & O & $\mathrm{O}$ & 0 & $\mathrm{O}$ \\
\hline $\begin{array}{l}\text { Preoccupation with } \\
\text { food/eating }\end{array}$ & $\mathrm{O}$ & $\mathrm{O}$ & O & $\mathrm{O}$ & $\mathrm{O}$ \\
\hline $\begin{array}{l}\text { Preoccupation with } \\
\text { shape/weight and its } \\
\text { control }\end{array}$ & $\mathrm{O}$ & O & $\mathrm{O}$ & O & $\mathrm{O}$ \\
\hline Feeling fat & $\mathrm{O}$ & $\mathrm{O}$ & O & $\mathrm{O}$ & $\mathrm{O}$ \\
\hline $\begin{array}{l}\text { Fear of gaining } \\
\text { weight or getting fat }\end{array}$ & $\mathrm{O}$ & $\mathrm{O}$ & O & O & $\mathrm{O}$ \\
\hline $\begin{array}{l}\text { Frequent weighing } \\
\text { or avoidance }\end{array}$ & 0 & 0 & $\mathrm{O}$ & 0 & O \\
\hline $\begin{array}{l}\text { Body shape } \\
\text { checking or } \\
\text { avoidance }\end{array}$ & $\mathrm{O}$ & O & $\mathrm{O}$ & O & O \\
\hline
\end{tabular}

Homework assignment from Overcoming Disordered Eating: Maintaining Change and Relapse

Prevention, by from A. Fursland, S. Byrne, P. Nathan, and A. Lampard, 2007, retrieved June 28, 2009, from http://www.cci.health.wa.gov.au/docs/7\%20Apr3rd.pdf 


\section{Positive Changes}

Look over your Progress Checklist and consider your progress. What changes have you already made? Do you eat regularly? Have you changed your eating habits? Are you following guidelines instead of strict dietary rules? What are the behaviours or thoughts that cause you little or no problem? Identify the positive changes that you have made and list them.

\section{Remaining Challenges}

Identify concerning behaviours. Changing ingrained habits is a difficult process and takes time. Identifying your problem behaviours will help you direct attention to areas that you feel need more work. What behaviours are still challenging? What areas did you identify as "a lot" or "extreme" problems and need more work? Identify your problem areas and list them. 


\section{References and Resources for Group Leaders: Group Eight Session}

Fursland, A., Byrne, S., Nathan, P., \& Lampard, A. (2007). Overcoming disordered eating: Maintaining change and relapse prevention. Retrieved June 28, 2009, from Centre for Clinical Interventions: Psychotherapy, Research, Training Web site: http://www.cci.health.wa.gov.au/docs/7\%20Apr3rd.pdf 


\section{Handout \#2: Group Eight Session}

\section{Feedback on the Group Eight Session Date:}

Please do not record your name. This feedback will help us know what worked and what did not worked for you as a result of attending today's group session.

1. Based on today's Group Eight session, how helpful was it for you?

No A little Somewhat Yes

2. In one word, please describe how you felt at the end of this Group Eight session.

3. I recognize that I have disordered eating habits.

Yes Sometimes Rarely No

4. I felt the group members were / will be accepting of me.

Yes No

Why or why not?

5. I believe that this group program will help me achieve one or more of my goals for change.

Yes Maybe Doubtful No

6. What did you most like about this session?

7. What did you like least about this session?

Thank you for taking the time to complete this feedback form 


\section{Adalt Female Anorexia Nervosa Group: Coming Together To Calm the Hanger}

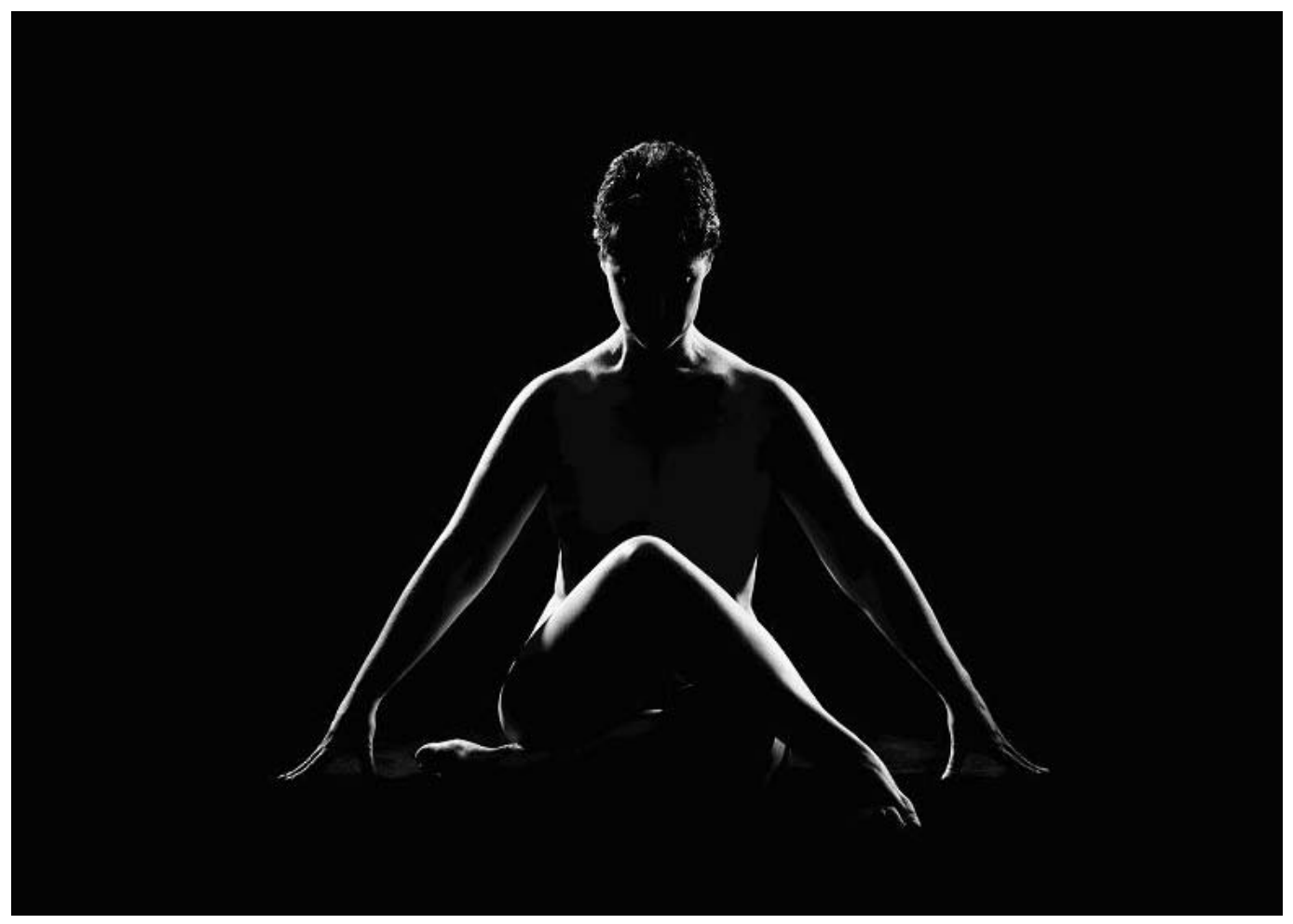

Picture reprinted with the photographer’s permission. Baron PhotoGraphics www.baronphotographics.com

\section{NINTH GROUP SESSION}




\section{LESSON PLAN \#9}

\section{Advance Preparation Required for this Group Session:}

\begin{abstract}
4 boxes of Kleenex
Felts

Watercolour paint

10 cups with water
\end{abstract}

10 cut-out Mandalas

Oil-based markers

10 paintbrushes

3 flip charts

\section{Important:}

Working Stage Continued:

Explore common themes that provide for some universality, and link one or more members' work with that of others in the group. Focus on the importance of translating insight into action; encourage members to practice new skills.

\section{Session Length: 2 hours}

\section{Objectives for today's session:}

1. Identify useful components to the homework assignment.

2. Explore opposing forces of recovery within AN through an experiential activity.

3. Invite members to recognize ambivalence of recovery and if their ambivalence has changed throughout the group.

\begin{tabular}{|c|l|l|l|}
\hline $\begin{array}{c}\text { Time } \\
\text { (Minutes) }\end{array}$ & \multicolumn{1}{|c|}{$\begin{array}{c}\text { Theme I } \\
\text { Goal }\end{array}$} & \multicolumn{1}{|c|}{ Activity } & $\begin{array}{l}\text { Brief Instructions I } \\
\text { Notes of Interest I } \\
\text { Handout Material }\end{array}$ \\
\hline $\mathbf{1 0}$ & Check-in activity & Phobias & $\begin{array}{l}\text { Facilitators ask the group if they } \\
\text { have heard of phobias, and if so, } \\
\text { which ones. Divide the members } \\
\text { into three groups with a flip chart } \\
\text { and marker. Ask them to develop } \\
\text { phobias of feeling that have not } \\
\text { yet been named. After five } \\
\text { minutes, have the group state the } \\
\text { feeling phobia and give their } \\
\text { definition of it. }\end{array}$ \\
\hline 25 & $\begin{array}{l}\text { Process/discuss } \\
\text { last week's } \\
\text { session and } \\
\text { homework } \\
\text { assignment } \\
\text { (Objective \#1). }\end{array}$ & $\begin{array}{l}\text { Progress checklist, } \\
\text { positive changes, and } \\
\text { remaining challenges. }\end{array}$ & $\begin{array}{l}\text { Invite members to share their } \\
\text { homework. What was it like to } \\
\text { identify positive qualities? What did } \\
\text { you learn about yourself? Were you } \\
\text { surprised by your answers, if so } \\
\text { why? Encourage members to link } \\
\text { common themes and experiences. }\end{array}$ \\
\hline
\end{tabular}




\begin{tabular}{|c|c|c|c|}
\hline $\begin{array}{c}\text { Time } \\
\text { (Minutes) }\end{array}$ & $\begin{array}{c}\text { Theme I } \\
\text { Goal }\end{array}$ & Activity & $\begin{array}{l}\text { Brief Instructions I } \\
\text { Notes of Interest I } \\
\text { Handout Material }\end{array}$ \\
\hline 10 & Break & & \\
\hline 30 & $\begin{array}{l}\text { Opposing forces } \\
\text { of recovery } \\
\text { (Objective \#2) }\end{array}$ & $\begin{array}{l}\text { Recovery Mandala } \\
\text { (Hinz, 2006). }\end{array}$ & $\begin{array}{l}\text { Instructions for facilitators. } \\
\text { Facilitator notes } \# 1\end{array}$ \\
\hline 30 & $\begin{array}{l}\text { Process } \\
\text { (Objective \#3) }\end{array}$ & $\begin{array}{l}\text { Discussion of the } \\
\text { ambivalence of } \\
\text { change. }{ }^{2} \\
\text { Discussion of the fear } \\
\text { that may be present } \\
\text { without anorexia } \\
\text { nervosa. }\end{array}$ & $\begin{array}{l}\text { Link common themes and ideas. } \\
\text { Discussion of mixed emotions } \\
\text { about change. Facilitators } \\
\text { recognize and empathize with the } \\
\text { fear of change and the unknown. } \\
\text { What stood out for the members } \\
\text { in doing this? }\end{array}$ \\
\hline 10 & $\begin{array}{l}\text { Check-out } \\
\text { question }\end{array}$ & Star moment & $\begin{array}{l}\text { Invite group members to state a } \\
\text { 'star moment' they saw in } \\
\text { someone else. Facilitators } \\
\text { participate as well ensuring that } \\
\text { everyone has a star moment. }\end{array}$ \\
\hline 5 & $\begin{array}{l}\text { Session } \\
\text { feedback and } \\
\text { homework } \\
\text { assignment }\end{array}$ & $\begin{array}{l}\text { Distribute session } \\
\text { feedback form } \\
\text { Encourage members } \\
\text { to draw a Mandala } \\
\text { when anorexia } \\
\text { symptoms are } \\
\text { present. }\end{array}$ & $\begin{array}{l}\text { Reminder: Ask the group } \\
\text { members to bring something } \\
\text { meaningful to them from home } \\
\text { they would be willing to share with } \\
\text { the group for next week's session. } \\
\text { Evaluation of tonight's session. } \\
\text { Feedback form attached: } \\
\text { Handout } \# 1 \text {. }\end{array}$ \\
\hline
\end{tabular}

${ }^{2}$ Ambivalence of change explored in Session 9 to ensure group members feel safe within the group and has had time to recognize and identify emotions. Discussion of change earlier may hinder participation and openness. 
Sample Debriefing Questions for Facilitators:

1. What stood out to the facilitators during or after this session?

2. Who stood out to the facilitators during or after this session?

3. Were members able to articulate the mixed emotions about change?

Facilitators' Reflections on the Lesson Delivery:

1. Was enough time provided to process the emotions associated with change?

2. Would the processing of the emotions be better suited in dyads? Why or why not?

3. How was the allotted time from for completing the Mandala? 


\section{Facilitator Notes \#1: Lesson 9}

Recovery Mandala (Hinz, 2006)

\section{Materials}

10 circles cut from white paper, using a dinner plate.

Felts, pastels, watercolour paints, paintbrushes, and water.

Instructions

Facilitators use Hinz's (2006) statement:

Think about your recovery and the contradicting forces pulling you in opposite directions. This could be an instance of black-and-white thinking in which you would like to find some grey. It may involve ambivalence about wanting to give up your eating disorder. You may want to try integrating your opposing parts of your personality. Start your painting in the centre, adding symbols, colors, and patterns to represent the problem and possible courses of action. Keep working around the centre filling more of the circle until it feels whole. (p. 86) 


\section{References and Resources for Group Leaders: Group Nine Session}

Hinz, L. D. (2006). Drawing from within: Using art to treat eating disorders. London, UK: Jessica Kingsley. 


\section{Handout \#1: Group Nine Session}

Feedback on the Group Nine Session Date:

Please do not record your name. This feedback will help us know what worked and what did not worked for you as a result of attending today's group session.

1. Based on today’s Group Nine session, how helpful was it for you?

No A little Somewhat Yes

2. In one word, please describe how you felt at the end of this Group Nine session.

3. I recognize that I have disordered eating habits.

Yes Sometimes Rarely No

4. I felt the group members were / will be accepting of me.

Yes No

Why or why not?

5. I believe that this group program will help me achieve one or more of my goals for change.

Yes Maybe Doubtful No

6. What did you most like about this session?

7. What did you like least about this session?

Thank you for taking the time to complete this feedback form 


\section{Adabt Female Anorexia Neruosa Group: Coming Together To Calm the Harger}

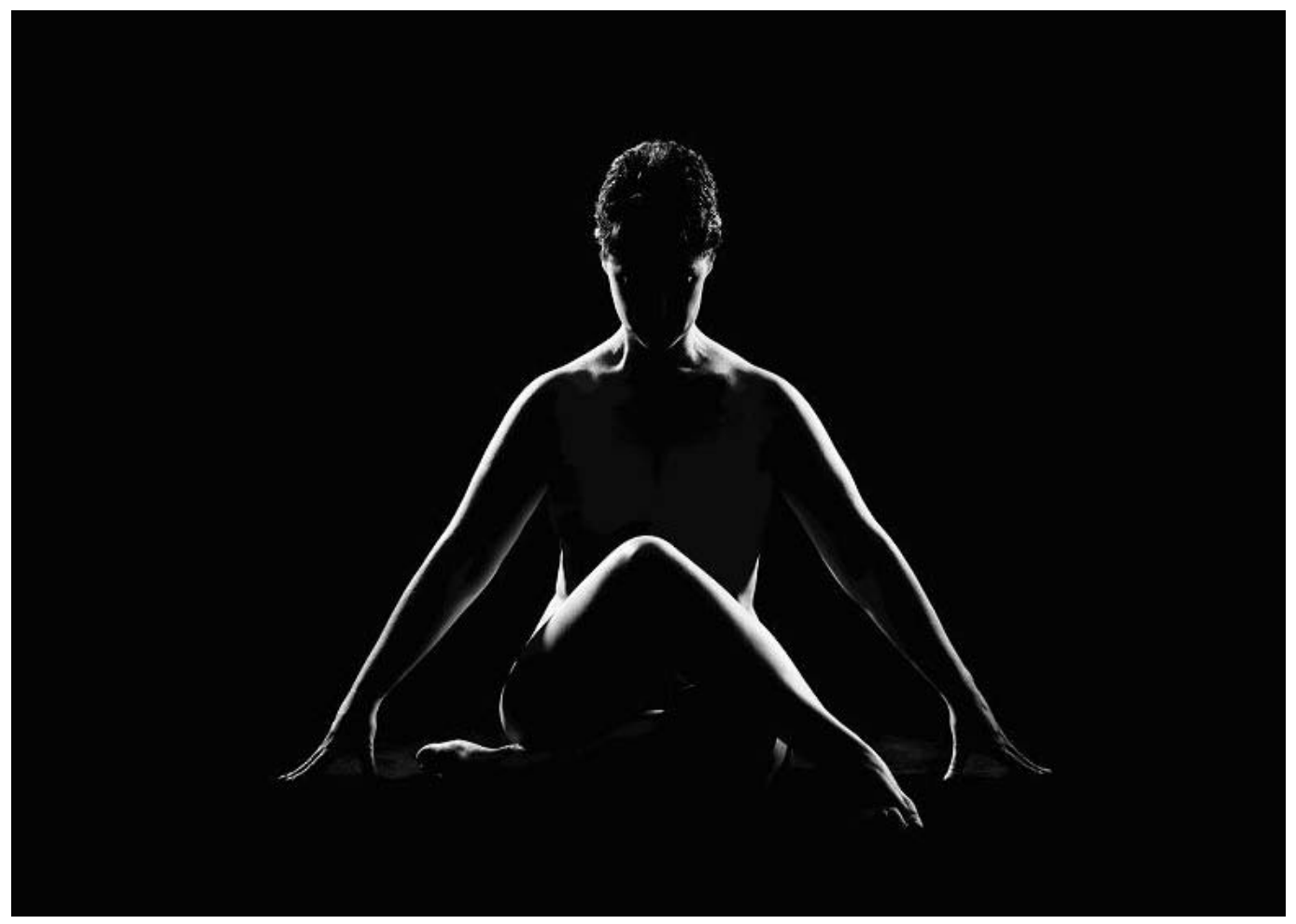

Picture reprinted with the photographer’s permission. Baron PhotoGraphics www.baronphotographics.com

\section{TENTH GROUP SESSION}




\section{LESSON PLAN \#10}

\section{Advance Preparation Required for this Group Session:}

4 boxes of Kleenex

\section{Important:}

Termination Stage: Group

members may experience sadness and anxiety. May also pull back and participate in less intense ways. Evaluation of the impact of the group and assist members in dealing with any feelings they may have about termination.

\section{Session Length: 2 hours}

\section{Objectives for today's session:}

1. Recognize shame through sculpting.

2. Encourage members to identify how shame may sabotage their lives.

3. Invite members to explore their internal/external shame.

\begin{tabular}{|c|c|c|c|}
\hline $\begin{array}{c}\text { Time } \\
\text { (Minutes) }\end{array}$ & Theme / Goal & Activity & $\begin{array}{l}\text { Brief Instructions I } \\
\text { Notes of Interest I } \\
\text { Handout Material }\end{array}$ \\
\hline 10 & Check-in activity & $\begin{array}{l}\text { Show and tell a } \\
\text { favourite thing. }\end{array}$ & $\begin{array}{l}\text { Each group member brings an } \\
\text { item from home that is important } \\
\text { to them and explains the } \\
\text { significance to the group. }\end{array}$ \\
\hline 15 & $\begin{array}{l}\text { Process/discuss } \\
\text { last week's session } \\
\text { and homework } \\
\text { assignment. }\end{array}$ & Mandala & $\begin{array}{l}\text { Link concerns of members as well } \\
\text { as encourage members to be } \\
\text { responsible for what they want to } \\
\text { bring up. } \\
\text { Normalizing the thoughts that } \\
\text { arose from the homework } \\
\text { assignment. }\end{array}$ \\
\hline 10 & Break & & \\
\hline $\begin{array}{c}1 \mathrm{hr} \\
\& \\
10 \mathrm{~min}\end{array}$ & $\begin{array}{l}\text { Recognizing shame } \\
\text { (Objective \#1) and } \\
\text { how it sabotages } \\
\text { our lives (Objective } \\
\text { \#2). Process } \\
\text { shame (Objective } \\
\# 3 \text { ). }\end{array}$ & Shame sculpting & $\begin{array}{l}\text { Each member sculpts how their } \\
\text { shame sabotages them using the } \\
\text { other group members. It is } \\
\text { suggested that one facilitator } \\
\text { completes this activity before the } \\
\text { group members as an example } \\
\text { and to normalize shame. The }\end{array}$ \\
\hline
\end{tabular}




\begin{tabular}{|c|c|c|c|}
\hline $\begin{array}{c}\text { Time } \\
\text { (Minutes) }\end{array}$ & Theme / Goal & Activity & $\begin{array}{l}\text { Brief Instructions I } \\
\text { Notes of Interest I } \\
\text { Handout Material }\end{array}$ \\
\hline & & & $\begin{array}{l}\text { facilitators choose the first } \\
\text { member to participate and then } \\
\text { allow that participant, once } \\
\text { finished, choose the next member } \\
\text { to participate. } \\
\text { After sculpting their shame, they } \\
\text { are invited to step away from their } \\
\text { design and process it. Questions } \\
\text { such as "What do they notice } \\
\text { about their sculpting?" "What was } \\
\text { the experience like?" "What did } \\
\text { they notice in their body while } \\
\text { sculpting?" Link common themes } \\
\text { and ideas. }\end{array}$ \\
\hline 10 & Check-out question & $\begin{array}{l}\text { One-word statement } \\
\text { about how it feels to } \\
\text { realize the group is } \\
\text { coming to an end. }\end{array}$ & Popcorn participation. \\
\hline 5 & $\begin{array}{l}\text { Homework } \\
\text { assignment and } \\
\text { session feedback. }\end{array}$ & $\begin{array}{l}\text { Distribute positive } \\
\text { qualities homework } \\
\text { sheet and session } \\
\text { feedback form. }\end{array}$ & $\begin{array}{l}\text { Positive qualities homework sheet } \\
\text { attached: Handout } \# 1 \text {. } \\
\text { Evaluation of tonight's session. } \\
\text { Feedback form attached: Handout } \\
\# 2 \text {. }\end{array}$ \\
\hline
\end{tabular}

Sample Debriefing Questions for Facilitators:

1. What emotions surfaced during the shame activity?

2. Is there a member(s) who is participating less?

3. Was there any member that stood out for the facilitators with their one word checkout?

Facilitators' Reflections on the Lesson Delivery:

1. Was enough time allotted for processing the shame activity? Why or why not?

2. Is the check out question suitable for this session or would a sentence be more effective?

3. How is the group responding to the amount of homework provided? 


\section{Handout \#1: Lesson 10}

\section{Positive Qualities Record: Homework Assignment}

\section{My Positive Qualities Record}

To help you make a list of your positive qualities, ask yourself the following questions:

- What do I like about who I am?

- What characteristics do I have that are positive?

- What are some of my achievements?

- What are some challenges I have overcome?

- What are some skills or talents that I have?

- What do others say they like about me?

- What are some attributes I like in others that I also have in common with them?

- If someone shared my identical characteristics, what would I admire in them?

- How might someone who cared about me describe me?

- What do I think are negative qualities that I do not have?

*Remember to include everything no matter how small, insignificant, modest, or unimportant you think they are.

1.

2.

3.

4.

5.

6.

7.

8.

9.

10. 


\section{References and Resources for Group Leaders: Group Ten Session}

Fursland, A., Byrne, S., Nathan, P., \& Lim, L. (2007). Overcoming disordered eating: Low self-esteem. Retrieved November 27, 2009, from Centre for Clinical Interventions: Psychotherapy, Research, Training Web site:

http://www.cci.health.wa.gov.au/docs/5\%20Low\%20self-esteem.pdf 


\section{Handout \#2: Group Ten Session}

\section{Feedback on the Group Ten Session Date:}

Please do not record your name. This feedback will help us know what worked and what did not worked for you as a result of attending today's group session.

1. Based on today’s Group Ten session, how helpful was it for you?

No A little Somewhat Yes

2. In one word, please describe how you felt at the end of this session.

3. I recognize that I have disordered eating habits.

Yes Sometimes Rarely No

4. What did you most like about this session?

5. What did you like least about this session?

6. Did the Group Ten session include discussions of the group ending?

No A little Somewhat Yes

7. Using one feeling word, please describe how you feel about the group coming to a close: 


\section{Adabt Female Anorexia Neruosa Group: Coming Together To Calm the Harger}

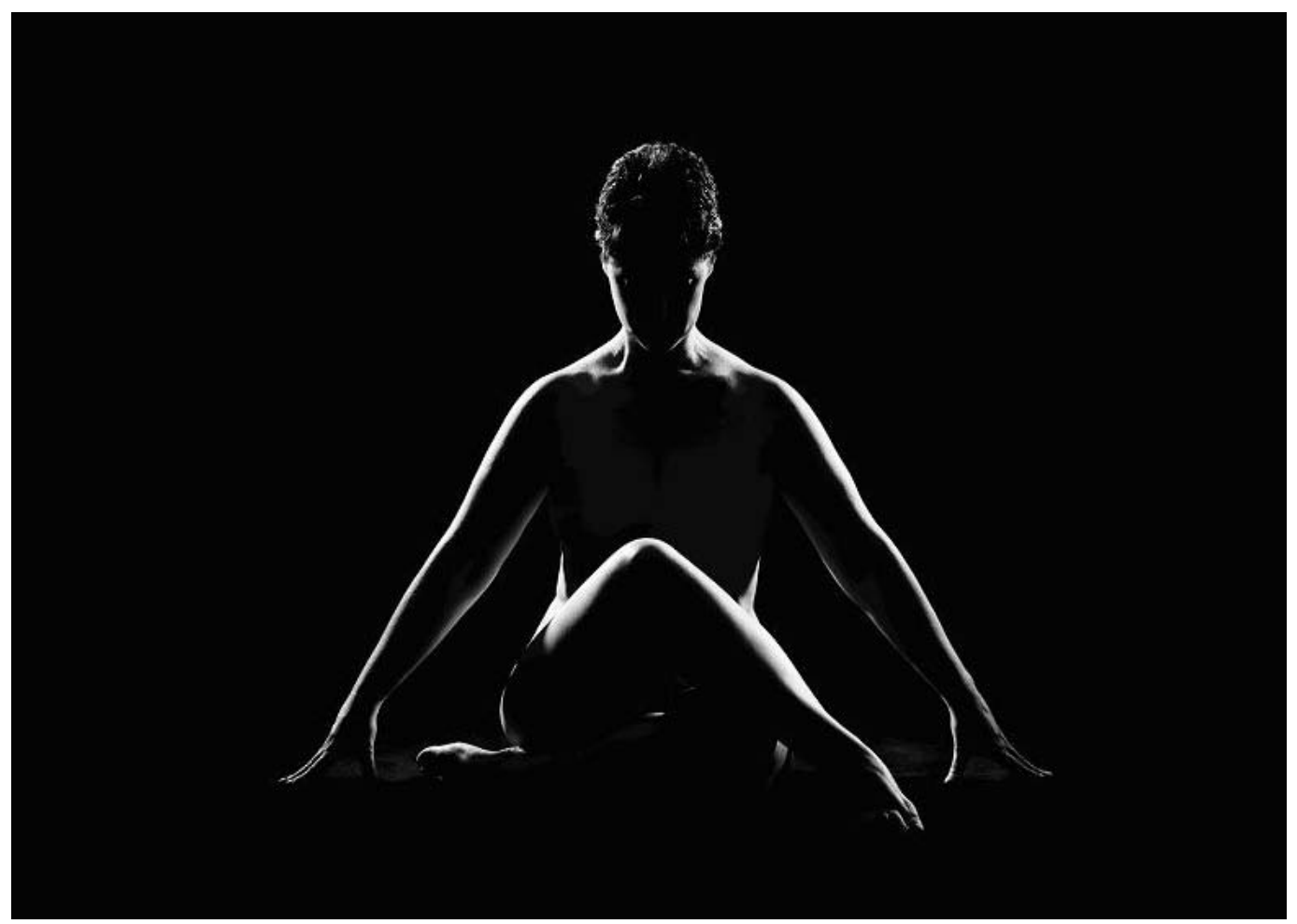

Picture reprinted with the photographer’s permission. Baron PhotoGraphics www.baronphotographics.com ELEVENTH GROUP SESSION 


\section{LESSON PLAN \#11}

\section{Advance Preparation Required for this Group Session:}

4 boxes of Kleenex Roll of yarn Felts $8.5 \times 11$ colored paper attached to string

\section{Important:}

Termination Stage: Provide specific referral resources; encourage members to find continued support and challenge.

Ensure enough time to process goodbyes; model healthy goodbyes.

Discussion of the effectiveness of the group, noting areas for change and what went well.

Reminder: Last session is 2 hours and 10 minutes.

\section{Session Length: 2 hours}

Objectives for today's session:

1. Identify the useful components in the homework assignment and recognize some of their positive qualities.

2. Address goodbyes through processing a visualization of walking away.

3. Identify and provide specific referral resources for aftercare.

4. Invite processing of the effectiveness of the group and what they felt went well and areas for change.

\begin{tabular}{|c|l|l|l|}
\hline $\begin{array}{c}\text { Time } \\
\text { (Minutes) }\end{array}$ & \multicolumn{1}{|c|}{$\begin{array}{c}\text { Theme I } \\
\text { Goal }\end{array}$} & \multicolumn{1}{|c|}{ Activity } & $\begin{array}{r}\text { Brief Instructions I } \\
\text { Notes of Interest I } \\
\text { Handout Material }\end{array}$ \\
\hline $\mathbf{1 0}$ & Check-in activity & String toss & $\begin{array}{l}\text { Have a roll of yarn. Invite } \\
\text { members to throw the yarn to } \\
\text { other members while hanging on } \\
\text { to the piece that was thrown to } \\
\text { them. }\end{array}$ \\
\hline $\mathbf{2 5}$ & $\begin{array}{l}\text { Process/discuss } \\
\text { last week's } \\
\text { session and } \\
\text { homework } \\
\text { assignment. } \\
\text { (Objective } \# 1) .\end{array}$ & $\begin{array}{l}\text { Positive qualities } \\
\text { checklist. }\end{array}$ & $\begin{array}{l}\text { Link concerns of members as well } \\
\text { as encourage members to be } \\
\text { responsible for what they want to } \\
\text { bring up. } \\
\text { Normalize the thoughts that arose } \\
\text { from the homework assignment. }\end{array}$ \\
\hline $\mathbf{1 0}$ & \begin{tabular}{l} 
Break \\
\hline
\end{tabular} & & \\
\hline
\end{tabular}




\begin{tabular}{|c|c|c|c|}
\hline $\begin{array}{c}\text { Time } \\
\text { (Minutes) }\end{array}$ & $\begin{array}{c}\text { Theme I } \\
\text { Goal }\end{array}$ & Activity & $\begin{array}{l}\text { Brief Instructions I } \\
\text { Notes of Interest I } \\
\text { Handout Material }\end{array}$ \\
\hline 30 & $\begin{array}{l}\text { Group ending } \\
\text { and visualization } \\
\text { (Objective \#2) }\end{array}$ & Walking away. & See Facilitator Notes \#1. \\
\hline 40 & $\begin{array}{l}\text { Process and } \\
\text { discussion of } \\
\text { resources } \\
\text { (Objective \#3) } \\
\text { and the } \\
\text { effectiveness of } \\
\text { the group. } \\
\text { (Objective \#4). }\end{array}$ & Open forum. & $\begin{array}{l}\text { Facilitators to ask, "What stood } \\
\text { out for the group member's in the } \\
\text { visualization?" Facilitators to } \\
\text { invite members to identify } \\
\text { community or personal resources } \\
\text { available. Discussion of the } \\
\text { effectiveness of the group, noting } \\
\text { areas for change and what went } \\
\text { well. }\end{array}$ \\
\hline 10 & $\begin{array}{l}\text { Check-out } \\
\text { activity }\end{array}$ & Impact exercise. & $\begin{array}{l}\text { Members to wear their sheet on } \\
\text { their back while tied to the string. } \\
\text { Each member, including the } \\
\text { facilitators, write something on the } \\
\text { paper about what they will } \\
\text { remember about the individual or } \\
\text { what stood out to them about the } \\
\text { individual. }\end{array}$ \\
\hline 5 & $\begin{array}{l}\text { Homework } \\
\text { assignment and } \\
\text { session } \\
\text { feedback. }\end{array}$ & $\begin{array}{l}\text { Distribute resources } \\
\text { homework sheet and } \\
\text { feedback form. }\end{array}$ & $\begin{array}{l}\text { Homework sheet attached: } \\
\text { Handout \#1. } \\
\text { Feedback form attached: Handout } \\
\# 2 \text {. }\end{array}$ \\
\hline
\end{tabular}


Sample Debriefing Questions for Facilitators:

1. How did the group members respond to identifying their positive qualities?

2. Were there any group members who stood out to the facilitators in the visualization?

3. How is each facilitator feeling about the group ending?

\section{Facilitators' Reflections on the Lesson Delivery:}

1. Is providing community and personal resources suited for this lesson?

2. Was enough time given for the check-out activity? Why or why not?

3. Were group members able to articulate what went well within the group and were there areas for change? What was the feedback? 


\section{Facilitator Notes \#1: Lesson 11}

\section{Group Ending and Visualization: Walking Away}

\section{Exercise - Walking Away}

*Invite group members to either close their eyes or keep them open.

\section{Instructions:}

Imagine the group is just about over. You just finished sharing your check'out and now it is time to leave. You get up and walk away. This is the last time you will see all your group members. Pay attention to what you are feeling, thinking, and sensing as you see your group members for the last time. Imagine yourself walking out of this room for the last time. Notice what is occurring in your body, what you are thinking and feeling.

Hold discussion in dyads and invite members to ask:

- How are you feeling?

- What are you feeling?

- What is the most valuable thing you have gained from this group?

- What is the least valuable thing you have gained from this group?

- One thing you wish you had asked for or gotten from this group?

- When you first started this group, what did you think and feel about the group? And now?

- How can you ask for it now?

Move into the large group and process activity and questions. 


\section{Handout \#1: Lesson 11}

\section{Resources}

1. Five individuals I can contact when I find myself struggling or having a difficult day:

1.

2.

3.

4.

5.

2. Three community resources that I believe can offer help if I feel I require it:

1.

2.

3.

3. Three specific things I learned in group that will help ground me:

1.

2.

3. 


\section{Handout \#2: Group Eleven Session}

\section{Feedback on the Group Eleven Session Date:}

Please do not record your name. This feedback will help us know what worked and what did not worked for you as a result of attending today's group session.

1. Based on today's Group Eleven session, how helpful was it for you?

No A little Somewhat Yes

2. In one word, please describe how you felt at the end of this Group Eleven session.

3. I recognize that I have disordered eating habits.

Yes Sometimes Rarely No

4. What did you most like about this session?

5. What did you like least about this session?

6. Did the Group Eleven session include discussions of the group ending?
No
A little
Somewhat
Yes

7. Using one feeling word, please describe how you feel about the group coming to a close:

Thank you for taking the time to complete this feedback form 


\section{Adalt Female Anorexia Nervosa Group: Coming Together To Calm the Hangers}

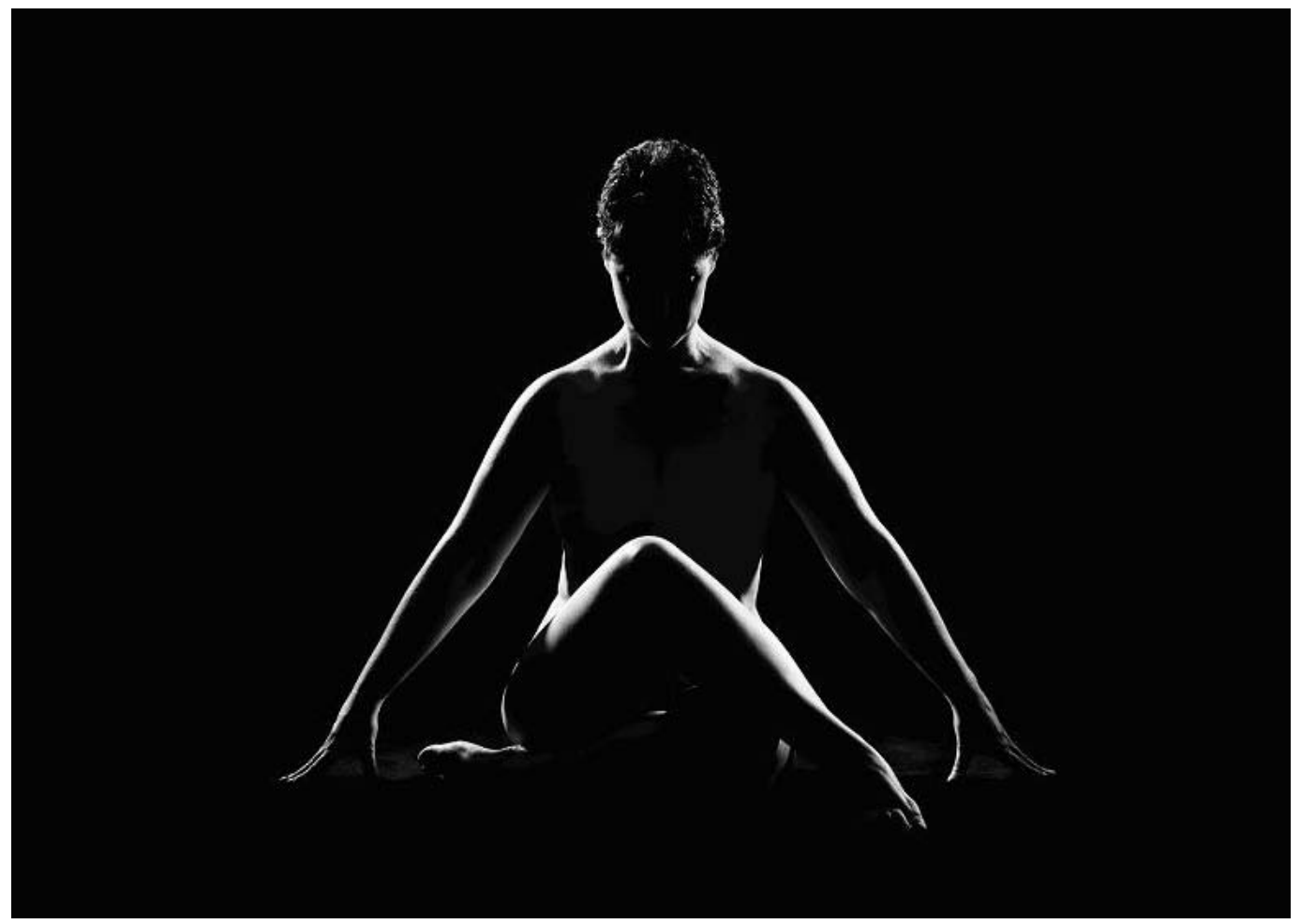

Picture reprinted with the photographer’s permission. Baron PhotoGraphics www.baronphotographics.com

\section{TWELFTH GROUP SESSION}




\section{LESSON PLAN \#12}

\section{Advance Preparation Required for this Group Session:}

$\begin{array}{ll}\text { Kleenex } & \text { Beads } \\ \text { Felts } & \text { Oil-based markers } \\ \text { 10 Scissors } & \text { Glue } \\ \text { Watercolor paint } & 10 \text { paintbrushes } \\ 10 \text { cups with water } & \text { Paper } \\ \text { Shells } & \text { Stickers } \\ \text { Magazines } & \text { String } \\ \text { Feathers } & \text { Tape } \\ \text { Stapler } & \end{array}$

\section{Important: \\ Final Group:}

Provide members with an opportunity to express and deal with any unfinished business within the group. Identify ways to reinforce themselves without the support of the group.

\section{Remember:}

Ask each group member to bring all of their art work completed in this group to the post-group session.

\section{Session Length: 2 hours and 10 minutes.}

Objectives for today's session:

1. Invite members to explore their lives with or without AN.

2. Identify and process the feelings of giving and receiving gifts, feedback, and comments from other group members.

3. Explore saying goodbye in an emotionally regulated way.

\begin{tabular}{|c|l|l|l|}
\hline $\begin{array}{c}\text { Time } \\
\text { (Minutes) }\end{array}$ & Theme / Goal & \multicolumn{1}{|c|}{ Activity } & $\begin{array}{l}\text { Brief Instructions / } \\
\text { Notes of Interest / } \\
\text { Handout Material }\end{array}$ \\
\hline 10 & Check-in activity & Goal writing. & $\begin{array}{l}\text { Facilitators hand out a postcard to } \\
\text { each group member. Have them } \\
\text { write their name and address (or } \\
\text { email address) and have them } \\
\text { state one goal they plan to } \\
\text { achieve in the next three months. } \\
\text { If members choose to, they can } \\
\text { read their goal to the group. } \\
\text { Facilitators send out the } \\
\text { postcards three months later. }\end{array}$ \\
\hline
\end{tabular}




\begin{tabular}{|c|c|c|c|}
\hline $\begin{array}{l}\text { Time } \\
\text { (Minutes) }\end{array}$ & Theme / Goal & Activity & $\begin{array}{l}\text { Brief Instructions I } \\
\text { Notes of Interest I } \\
\text { Handout Material }\end{array}$ \\
\hline 25 & $\begin{array}{l}\text { Process each } \\
\text { member's life } \\
\text { with/without } \\
\text { anorexia } \\
\text { nervosa. } \\
\text { (Objective \#1) }\end{array}$ & $\begin{array}{l}\text { Painting anorexia } \\
\text { nervosa and painting } \\
\text { their healing. }\end{array}$ & $\begin{array}{l}\text { Five minutes allotted for each } \\
\text { painting. Each member to do one } \\
\text { painting reflecting anorexia } \\
\text { nervosa and then the other } \\
\text { painting reflecting their healing. } \\
\text { During the second painting, hang } \\
\text { to dry the first painting behind } \\
\text { each member. Process paintings } \\
\text { by asking questions such as: } \\
\text { "What would you like to do with } \\
\text { the paintings?" "What stood out } \\
\text { for you looking at the paintings?" } \\
\text { Link common themes of the } \\
\text { members. }\end{array}$ \\
\hline 10 & Break & & \\
\hline 30 & Gifts & Gift making. & $\begin{array}{l}\text { See facilitator notes \#1 for } \\
\text { instructions. }\end{array}$ \\
\hline 30 & $\begin{array}{l}\text { Process } \\
\text { (Objective \#2) }\end{array}$ & $\begin{array}{l}\text { Each member shares } \\
\text { their gift and the } \\
\text { feelings associated } \\
\text { with the giving and } \\
\text { receiving of the gift. }\end{array}$ & $\begin{array}{l}\text { Link common themes and } \\
\text { feelings. "What did it feel like to } \\
\text { give the gifts, and what was it like } \\
\text { to receive a gift?" "What was the } \\
\text { experience of being part of a } \\
\text { group like?" }\end{array}$ \\
\hline 35 & $\begin{array}{l}\text { Process the } \\
\text { ending of group } \\
\text { (Objective \#3). } \\
\text { Distribute } \\
\text { session } \\
\text { feedback form } \\
\text { and group } \\
\text { feedback form. }\end{array}$ & $\begin{array}{l}\text { Sharing past group } \\
\text { experience. }\end{array}$ & $\begin{array}{l}\text { Open forum for exciting, } \\
\text { meaningful, important past group } \\
\text { events to be remembered. } \\
\text { Facilitators to emphasize the } \\
\text { importance of maintaining } \\
\text { confidentiality after the group is } \\
\text { over. } \\
\text { Feedback forms attached: } \\
\text { Handout } \# 1 \text { and } \# 2 \text {. }\end{array}$ \\
\hline
\end{tabular}


Sample Debriefing Questions for Facilitators:

1. Were there any members who stood out to the facilitators in the painting exercise?

2. What is the initial impact of the group ending on the facilitators?

3. Were there any themes or surprises in what the group discussed about the group's events?

Facilitators' Reflections on the Lesson Delivery:

1. How was the processing of the group's ending?

2. Is the gift-giving exercise suitable for the last group? Why or why not?

3. Would the processing of the ending be more effective with more structure? Why? 


\section{Facilitator Notes \#1: Lesson 12}

\section{Gift Making}

1. Facilitators allow group members to choose a partner.

2. Invite group members to make a gift they would like to give their partner.

3. Invite group members to make a gift they would like to receive from someone in the group or the group as a whole.

4. Exchange gifts and discuss the giving and receiving feelings as a large group. 


\section{Handout \#1: Group Twelve Session}

\section{Feedback on the Group Twelve Session Date:}

Please do not record your name. This feedback will help us know what worked and what did not worked for you as a result of attending today's group session.

1. Based on today's Group Twelve session, how helpful was it for you?

No A little Somewhat Yes

2. In one word, please describe how you felt at the end of this Group Twelve session.

3. I recognize that I have disordered eating habits.

Yes Sometimes Rarely No

4. What did you most like about this session?

5. What did you like least about this session?

6. Did the Group Twelve session include discussions of the group ending?
No
A little
Somewhat
Yes

7. Using one feeling word, please describe how you feel about the group coming to a close: 


\section{Handout \#2: Lesson 12 \\ Group Feedback Form}

Please provide your experience in this group by completing the following questionnaire.

I believe I shared my personal experiences within the group:

Not at all Some Average Often Always

I believe the group respected confidentiality:

Not at all Some Average Often Always

I felt valued by the facilitators.

Not at all Some Average Often Always

Feelings of shame regarding my eating disorder have decreased by:

Why I found it valuable to discuss my eating disorder is:

My self-awareness has increased by:

My anxiety in regards to food and food choices has changed in these ways:

I believe my personal relationships have been impacted by:

I believe this eating disorder group was beneficial because:

What I liked most about this group:

What I liked least about this group:

The facilitators could improve this group by:

Thank you for taking the time to complete this questionnaire 


\section{Adabt Female Anorexia Nervosa Group: Coming Together To Calm the Harger}

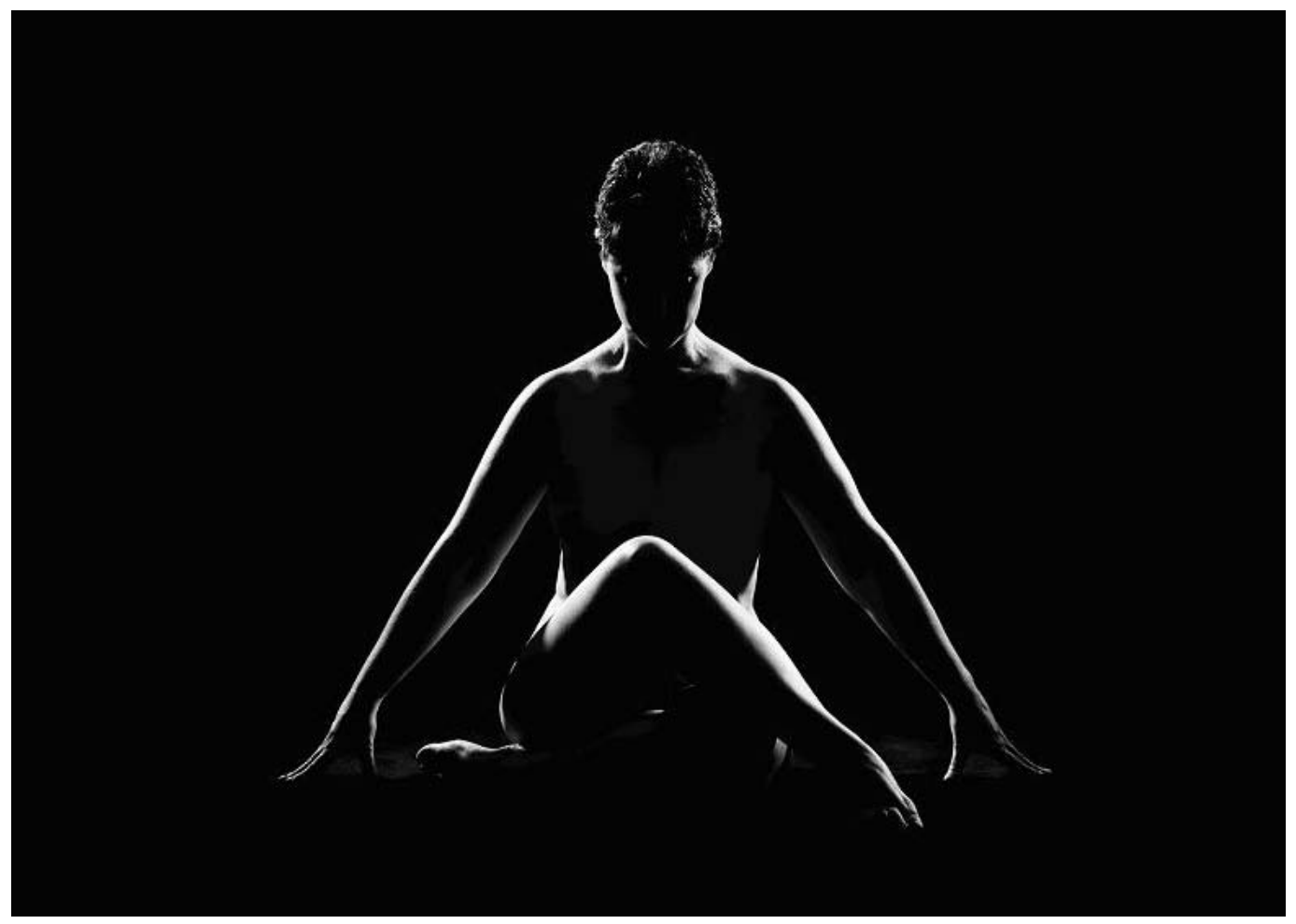

Picture reprinted with the photographer’s permission. Baron PhotoGraphics www.baronphotographics.com

\section{POST-GROUP SESSION}




\section{POST-GROUP LESSON PLAN}

\section{Advance Preparation Required for this Group Session:}

Eating Disorder Inventories

Pencils Felts

Glue Tape

Scissors

Large construction paper

\section{Important:}

Solution-Focused Theme:

Encourage members to find some avenues of continued support.

Provide specific referral resources adding to their personal list. Document a summary report of the group including the strengths and weaknesses of the group.

\section{Session Length: 2 hours}

Objectives for today's session:

1. Administer the EDI-3 (Garner, 2004).

2. Identifying and processing experiences with AN after the group ending.

\begin{tabular}{|c|c|c|c|}
\hline $\begin{array}{c}\text { Time } \\
\text { (Minutes) }\end{array}$ & Theme / Goal & Activity & $\begin{array}{l}\text { Brief Instructions I } \\
\text { Notes of Interest I } \\
\text { Handout Material }\end{array}$ \\
\hline 10 & Check-in activity & $\begin{array}{l}\text { Invite group members } \\
\text { to share a metaphor as } \\
\text { to how things are going } \\
\text { since the group ended. }\end{array}$ & Popcorn participation. \\
\hline 25 & $\begin{array}{l}\text { Administer the } \\
\text { EDI-3 (Garner, } \\
\text { 2004). (Objective } \\
\# 1) .\end{array}$ & $\begin{array}{l}\text { Each member will be } \\
\text { given the self-report } \\
\text { questionnaire to be } \\
\text { completed at their own } \\
\text { pace. }\end{array}$ & $\begin{array}{l}\text { The members will be contacted } \\
\text { to meet with a facilitator to } \\
\text { discuss the results as well as } \\
\text { complete the EDE (Fairburn \& } \\
\text { Cooper, 1993). }\end{array}$ \\
\hline 10 & Break & & \\
\hline 30 & Collage & $\begin{array}{l}\text { Each member to create } \\
\text { a collage of their art } \\
\text { work completed } \\
\text { throughout the group. }\end{array}$ & $\begin{array}{l}\text { Facilitators to encourage } \\
\text { member's to complete this } \\
\text { activity in whichever way feels } \\
\text { right. Some may want to use } \\
\text { only certain artwork, some may } \\
\text { want to share their artwork with } \\
\text { another member, or some may } \\
\text { want to make one for } \\
\text { themselves and another as a } \\
\text { reflection of the group as a } \\
\text { whole. }\end{array}$ \\
\hline
\end{tabular}




\begin{tabular}{|c|c|c|c|}
\hline $\begin{array}{c}\text { Time } \\
\text { (Minutes) }\end{array}$ & Theme / Goal & Activity & $\begin{array}{l}\text { Brief Instructions I } \\
\text { Notes of Interest I } \\
\text { Handout Material }\end{array}$ \\
\hline 30 & $\begin{array}{l}\text { Process and } \\
\text { discussion of } \\
\text { what is going } \\
\text { well or not so } \\
\text { well since the } \\
\text { group ended. } \\
\text { (Objective \#2). }\end{array}$ & Open forum. & $\begin{array}{l}\text { "What stood out for each } \\
\text { member in completing the } \\
\text { collage?" } \\
\text { Link common themes of } \\
\text { member's feelings since the } \\
\text { ending of the group. Facilitator } \\
\text { process questions attached: } \\
\text { Facilitator Notes \#1. } \\
\text { Discussion of goals for the } \\
\text { future. }\end{array}$ \\
\hline 10 & $\begin{array}{l}\text { Check-Out } \\
\text { Question }\end{array}$ & $\begin{array}{l}\text { "What would you most } \\
\text { like to remember from } \\
\text { this group experience?" }\end{array}$ & $\begin{array}{l}\text { Facilitator to go first, then the } \\
\text { member on the right, and } \\
\text { continuing around the circle. }\end{array}$ \\
\hline 5 & $\begin{array}{l}\text { Session } \\
\text { feedback and } \\
\text { group feedback } \\
\text { form }\end{array}$ & $\begin{array}{l}\text { Distribute session } \\
\text { feedback form and } \\
\text { group feedback form. }\end{array}$ & $\begin{array}{l}\text { Evaluation of tonight's session } \\
\text { and group feedback form. } \\
\text { Feedback forms attached: } \\
\text { Handout \# } 1 \text { and } \# 2 \text {. }\end{array}$ \\
\hline
\end{tabular}

Sample Debriefing Questions for Facilitators:

1. Was there a member(s) who stood out to the facilitators who needs follow up?

2. What was the experience for the facilitators during this post-group lesson?

3. Was there a theme in the last artwork activity? Did this activity suit the needs of the members?

\section{Facilitators' Reflections on the Lesson Delivery:}

1. What resources were identified as lacking within the community?

2. Was completing the EDI-3 (Garner, 2004) suited for the beginning of this lesson? Why?

3. How was the discussion on what has gone well or not so well within the group? 


\section{Facilitator Notes \#1: Post-Group Lesson}

\section{Facilitator Process Questions for Post Group Session}

1. What general effect has your group experience had on your life?

2. What were some specific things you became aware of about your lifestyle, attitudes, and relationship with others? What are some changes you have made in your life that you can attribute, at least partially, to your group experience?

3. What problems did you encounter on leaving the group and following up on your decision to change?

4. What effects do you think your participation in the group had on the significant people in your life?

5. Have there been any crises in your life since the termination of the group? How did you handle them?

6. How might your life be different now if you had not experienced the group?

7. Do you have anything to add about yourself and your experience either during or since the group? 


\section{References and Resources for Group Leaders: Post-Group Session}

Corey, M., Corey, G., \& Corey, C. (2010). Groups: Process and practice (8th ed.). Belmont: CA: Brooks/Cole. 


\section{Handout \#1: Post-Group Lesson}

Feedback on the Post Group Session Date:

Please do not record your name. This feedback will help us know what worked and what did not worked for you as a result of attending today's group session.

1. Based on today's Post Group session, how helpful was it for you?

No A little Somewhat Yes

2. In one word, please describe how you felt at the end of this Post Group session.

3. I recognize that I have disordered eating habits.

Yes Sometimes Rarely No

4. I felt the group members were accepting of me.

Yes No

Why or why not?

5. I believe that this group program helped me achieve one or more of my goals for change.

Yes A little Somewhat No

6. What did you most like about this session?

7. What did you like least about this session?

Thank you for taking the time to complete this feedback form 


\section{Handout \#2: Post Group Lesson}

\section{Group Feedback Form}

Please provide your experience in this group by completing the following questionnaire.

I believe I shared my personal experiences within the group:

Not at all Some Average Often Always

I believe the group respected confidentiality:

Not at all Some Average Often Always

I felt valued by the facilitators.

Not at all Some Average Often Always

Feelings of shame regarding my eating disorder have decreased by:

Why I found it valuable to discuss my eating disorder is:

My self-awareness has increased by:

My anxiety in regards to food and food choices has changed in these ways:

I believe my personal relationships have been impacted by:

I believe this eating disorder group was beneficial because:

What I liked most about this group:

What I liked least about this group:

The facilitators could improve this group by: 